Universidad de Lima

Escuela de Posgrado

Maestría en Administración y Dirección de Negocios

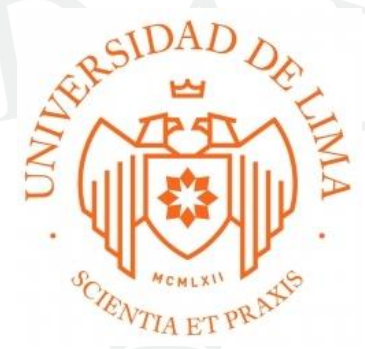

\title{
PROYECTO DE NEGOCIO 3D LAB \& CAFÉ
}

Trabajo de investigación para optar el Grado Académico de Maestro en Administración

y Dirección de Negocios

Percy Enrique Hurtado de Mendoza Barra

Código 19902343

Segundo Enrique Vásquez Rojas

Código 20152644

Lima - Perú

Noviembre 2019 


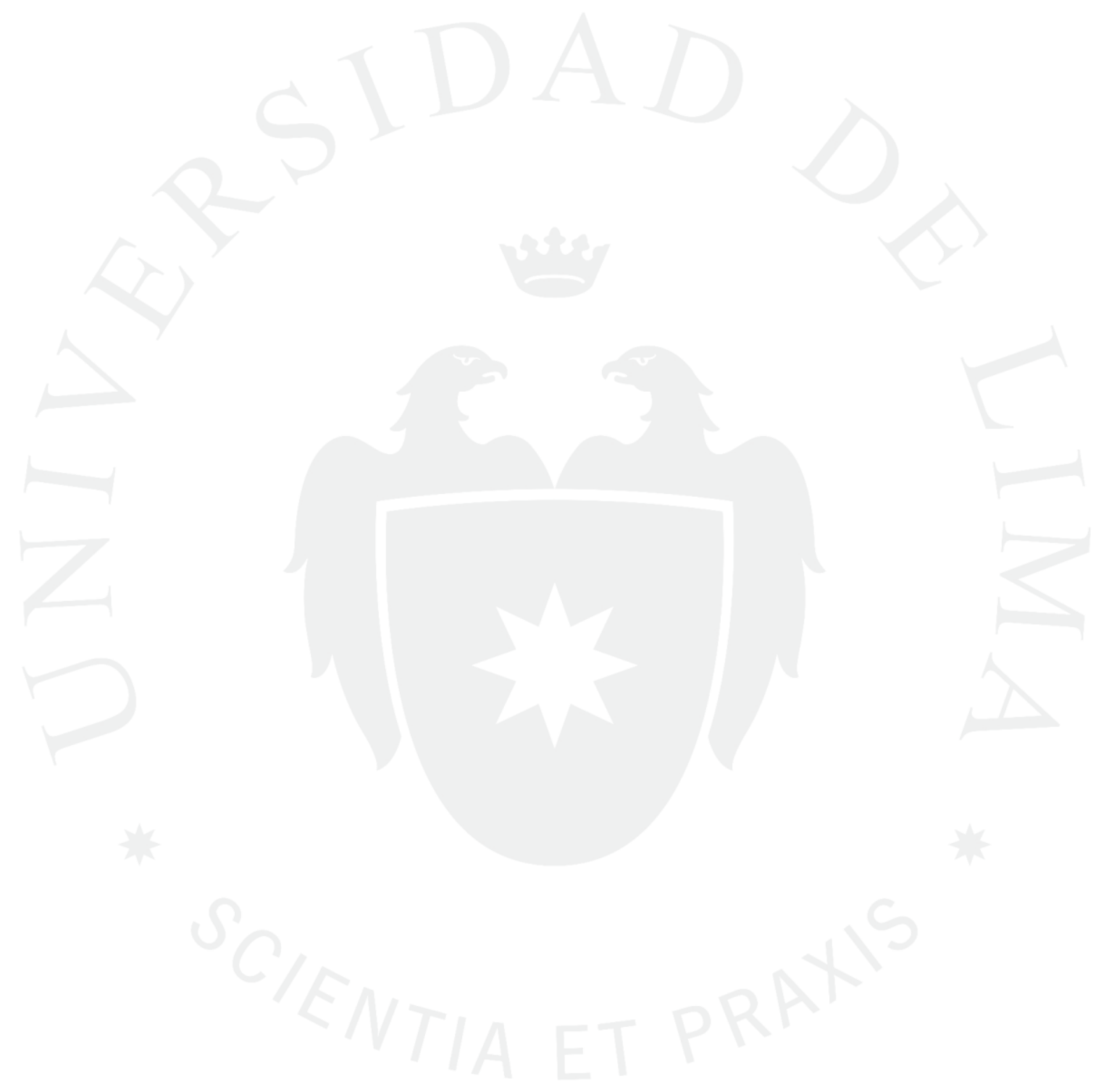




\section{D LAB \& CAFE BUSINESS PROJECT}




\section{TABLA DE CONTENIDO}

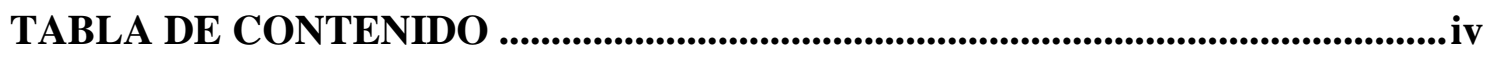

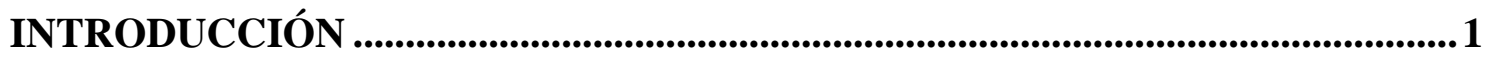

CAPITULO I: ASPECTOS GENERALES DEL NEGOCIO ................................. 12

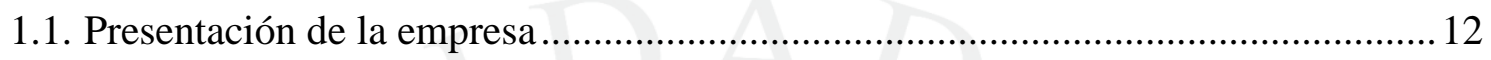

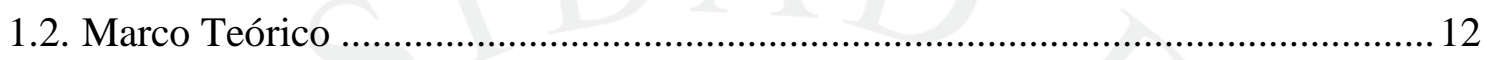

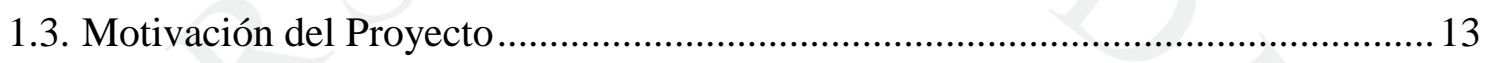

1.4. Percepción de la necesidad: análisis problema-solución ....................................... 13

1.5. Descripción de la idea y la oportunidad ........................................................... 14

1.6. Justificación del atractivo de la propuesta ........................................................... 14

1.7. Estrategia inicial y objetivos de alcance …................................................... 14

1.8. Impacto comercial y responsabilidad social................................................... 15

CAPITULO II: IDEA, INVESTIGACIÓN Y VALIDACIÓN DE LA SOLUCIÓN 16

2.1. Diseño y metodología de la investigación ........................................................ 16

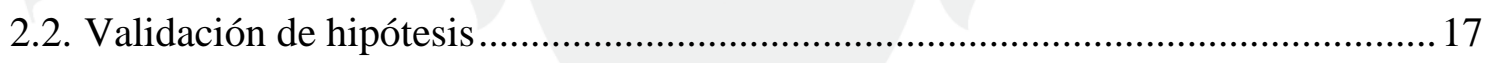

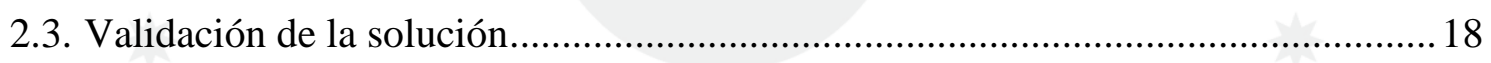

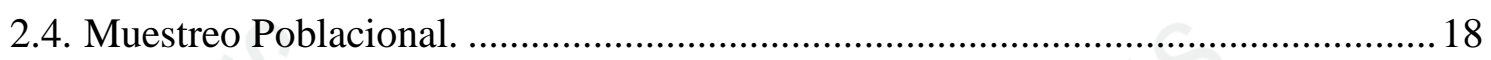

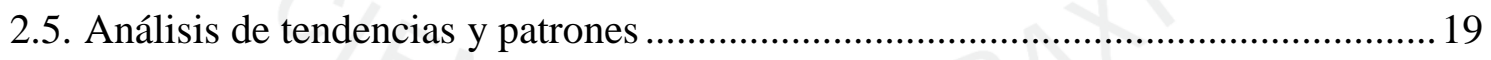

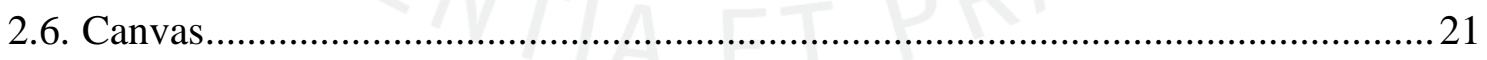

CAPÍTULO III: PLANEAMIENTO ESTRATÉGICO ................................................22

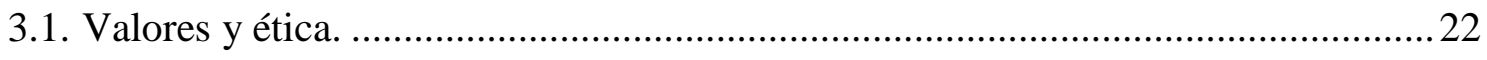

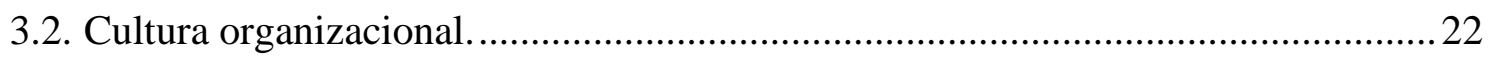

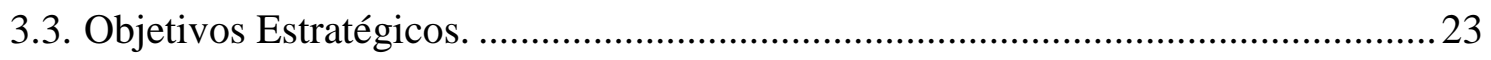

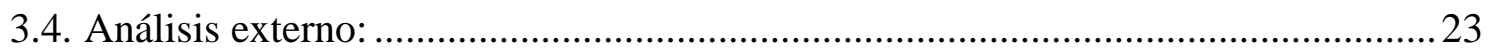


3.4.1. Político

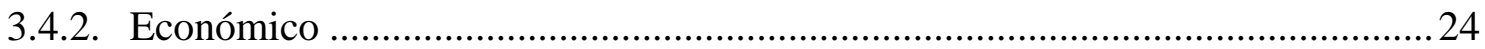

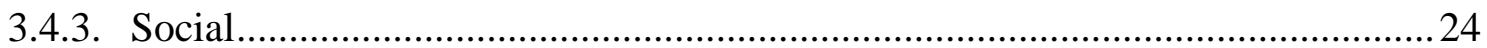

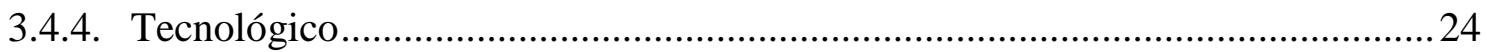

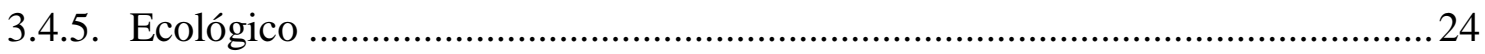

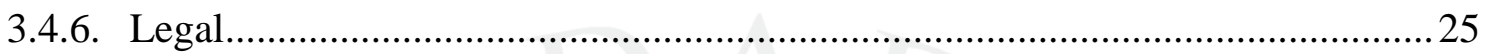

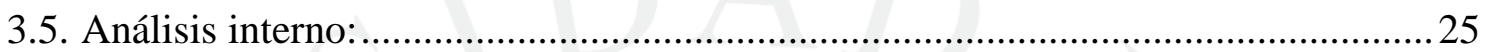

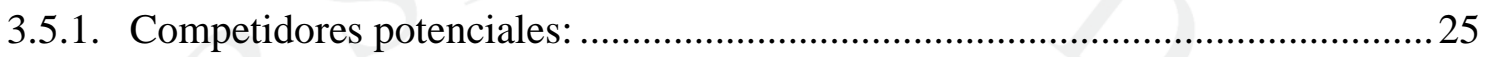

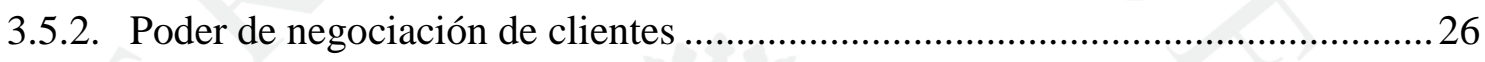

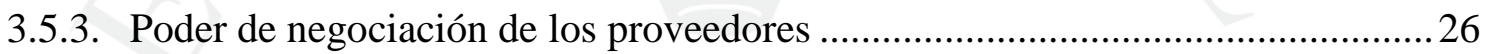

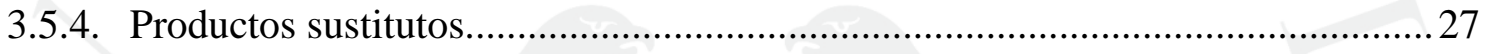

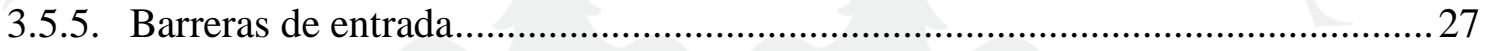

3.6. Matriz FODA (Fortalezas, oportunidades, debilidades y amenazas) ......................28

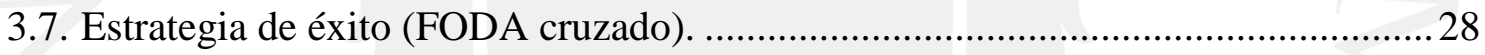

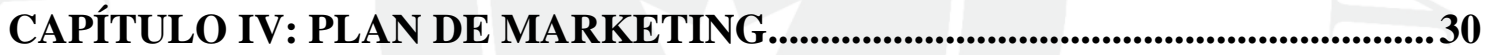

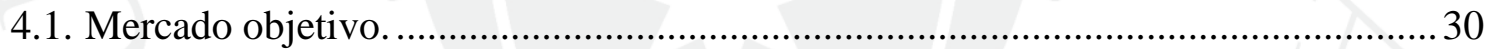

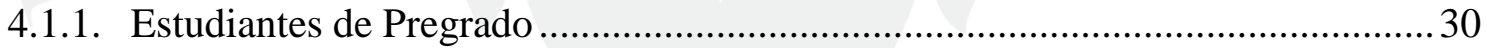

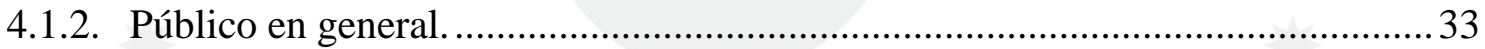

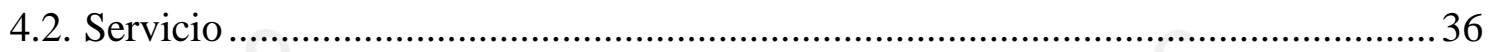

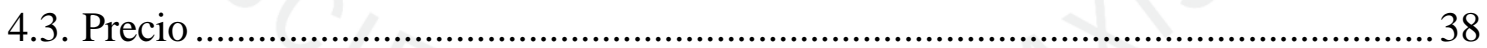

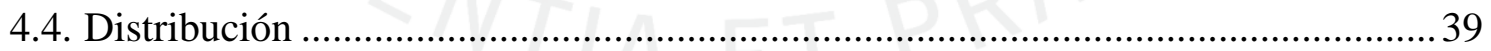

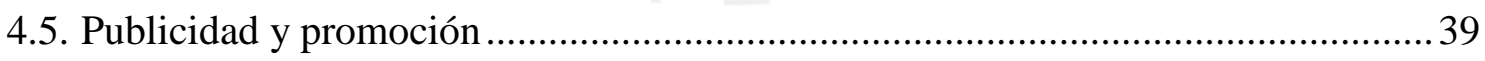

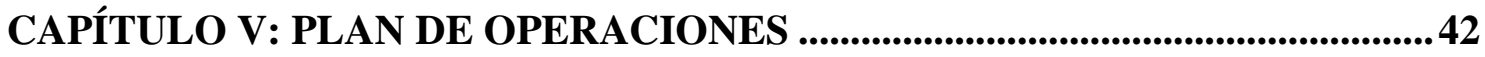

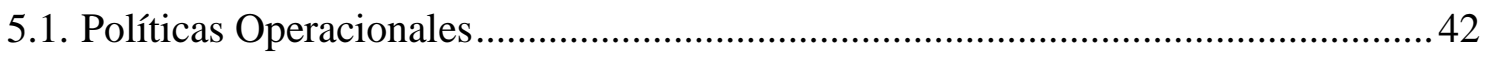

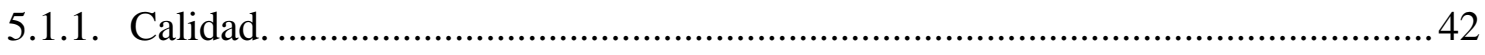

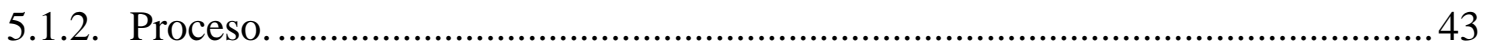


5.1.3. Planificación

5.1.4. Inventarios 44

5.2. Equipos, actividades y procesos. .45

5.2.1. Equipo .45

5.2.2. Diseño y capacidad de Instalaciones .46

5.2.3. Macro Localización 47

5.2.4. Micro Localización (ubicación del local) 47

5.2.5. Equipos de trabajo y apoyo. .52

5.2.6. Gestión de proveedores, compras y stock. .52

5.2.7. Implementación de las actividades por fases. Cadena de valor. .53

5.2.8. Proceso de elaboración de bienes y/o prestación de servicio .53

5.2.9. Flujograma de la actividad. .55

5.2.10. Diagrama de Gantt. .56

5.2.11. Balance Scorecard: 56

\section{CAPÍTULO VI: ESTRUCTURA ORGANIZACIONAL Y RECURSOS}

HUMANOS. 58

6.1. Naturaleza y Objetivos organizacionales 58

6.2. Diseño de Puestos y .59

6.2.1. Barista y cajero: .59

6.3. Gestión del talento . .59

6.4. Estructura de gastos de RRHH .60

CAPÍTULO VII: PLAN ECONÓMICO FINANCIERO ......................................61

7.1. Inversiones. 62

7.2. Estimación de la Demanda. .63

7.3. Capacidad Instalada de Impresión y Diseño. .66

7.4. Estado de Resultados. 67 
7.5. Financiamiento.

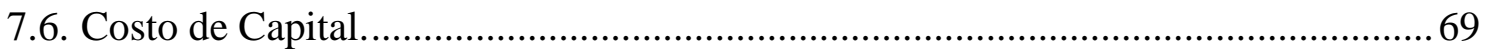

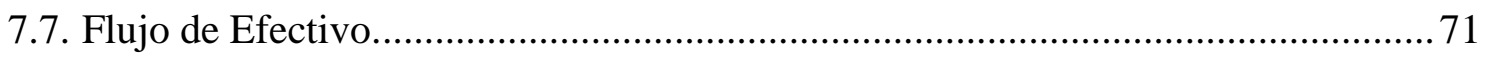

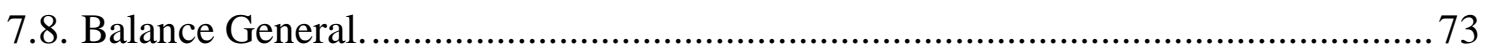

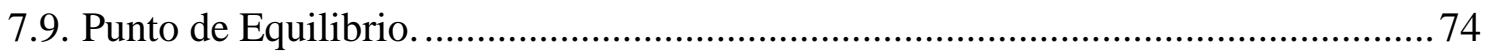

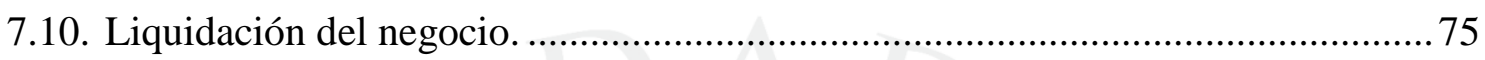

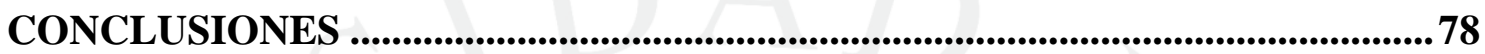

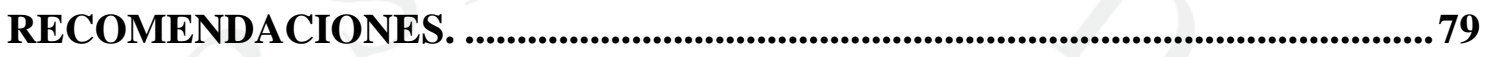

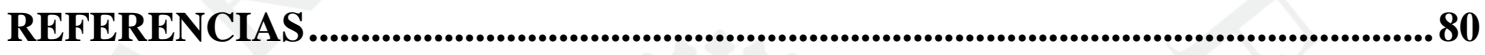

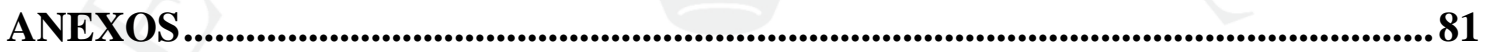




\section{ÍNDICE DE TABLAS}

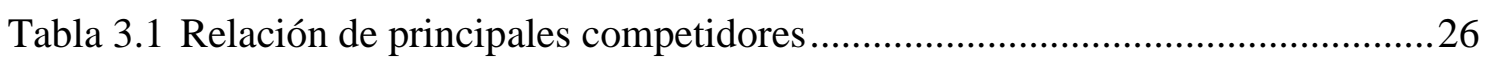

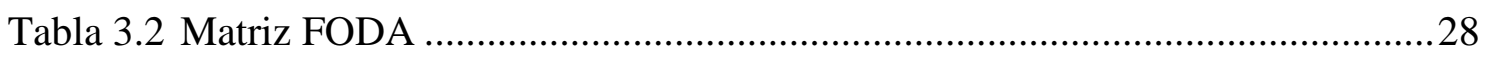

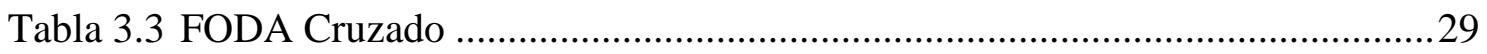

Tabla 4.1 Población de Lima Metropolitana entre 18 y 55 años ...................................33

Tabla 4.2 Análisis por zonas geográficas y en \% según el nivel socioeconómico..........33

Tabla 4.3 Población de nivel socioeconómico A.B y C entre 18 y 25 años.................... 34

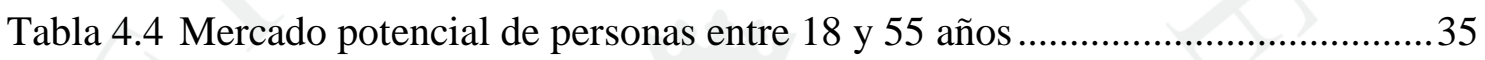

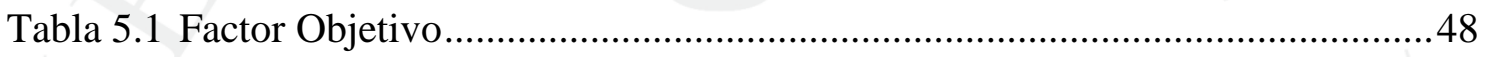

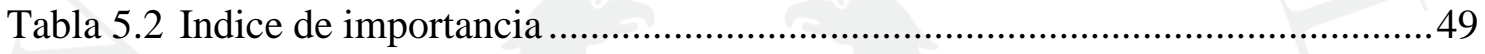

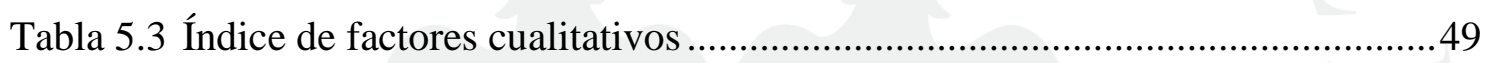

Tabla 5.4 Resultado de la medida de preferencia de localización.................................49

Tabla 5.5 Resultado de Ubicación del negocio según encuesta ....................................50

Tabla 5.6 Resultado de participación de estudiantes universitarios ..............................51

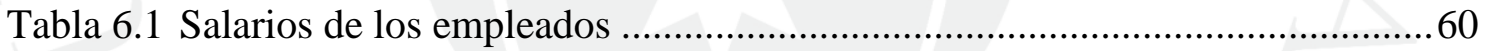

Tabla 7.1 Participación de industrias que utilizan la impresión 3D ...............................61

Tabla 7.2 Participación para el mercado de estudiantes y público general ....................62

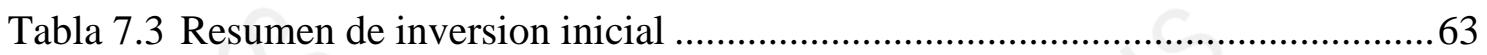

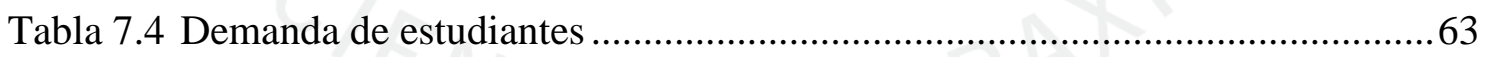

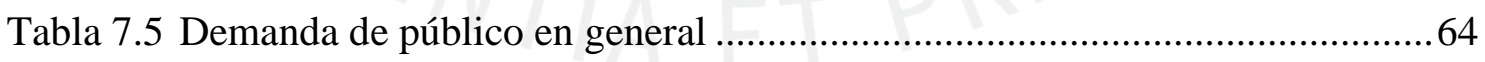

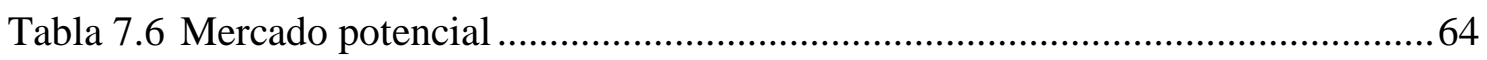

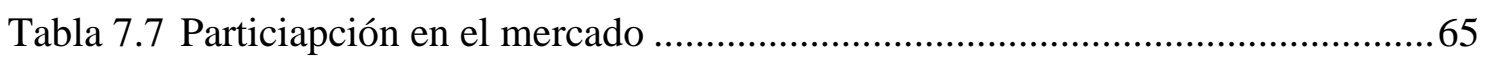

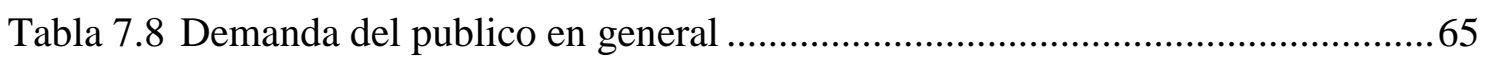

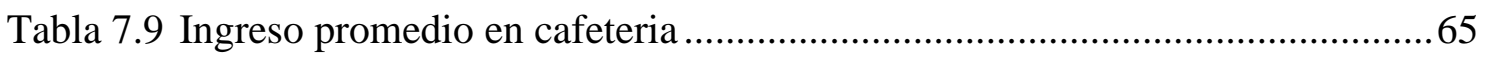

Tabla 7.10 Proyeccion de porcentaje de ganancias del negocio.................................66 
Tabla 7.11Participacion de estudiantes en los resultados .66

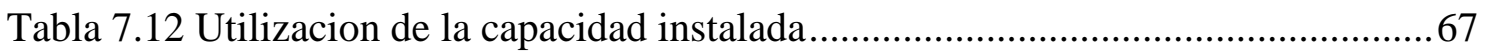

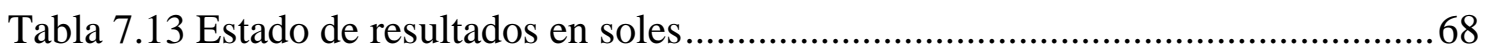

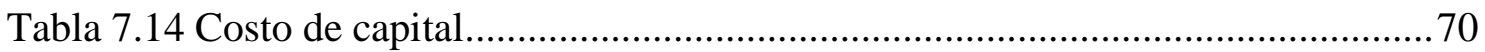

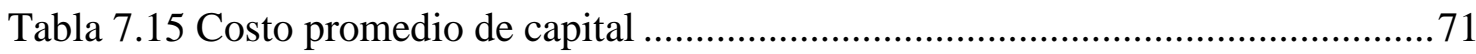

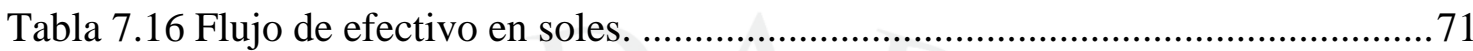

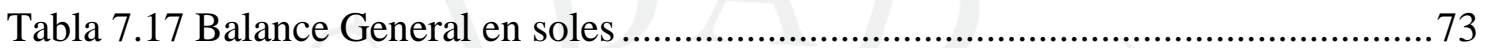

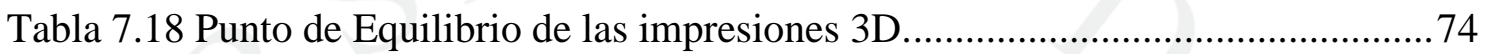




\section{ÍNDICE DE FIGURAS}

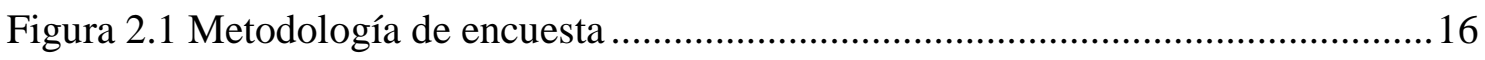

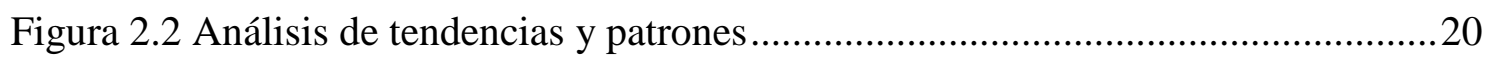

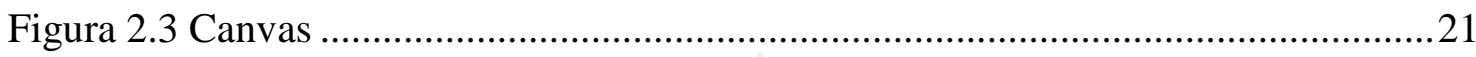

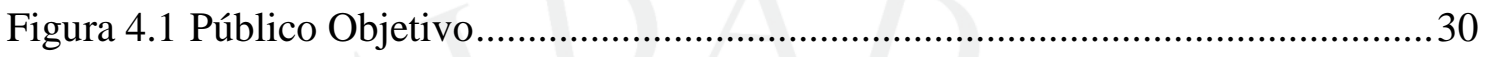

Figura. 4.2 Alumnos en universidades de Lima de programas afines a la impresión

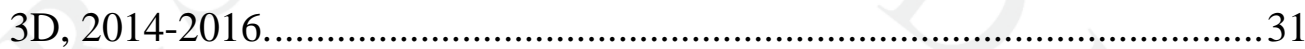

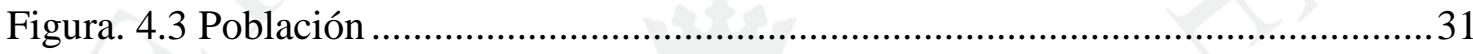

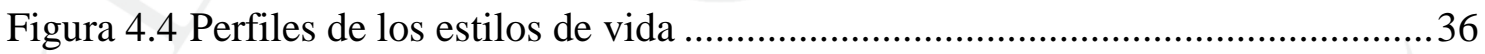

Figura 4.5 Customer Journey Map de nuestro local ................................................. 37

Figura 4.6 Tendencia de la demanda de impresión 3D .................................................. 37

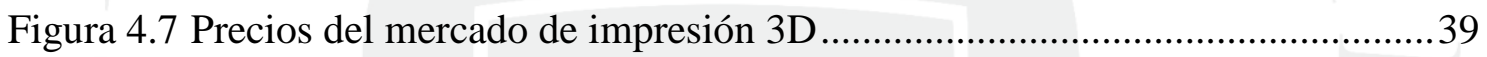

Figura 5.1 Mapa referencial de la ubicación del negocio .........................................52

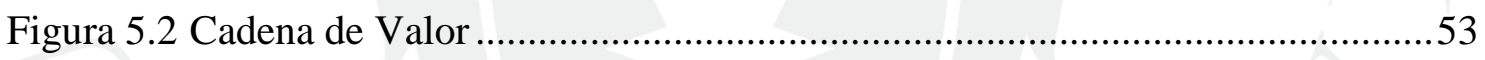

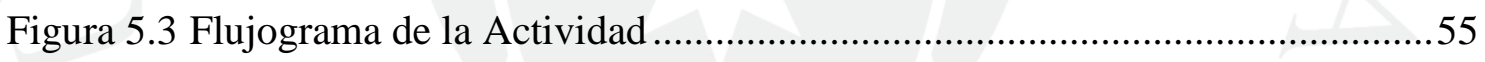

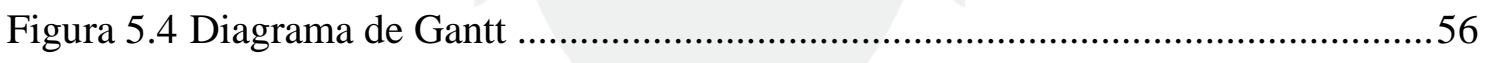

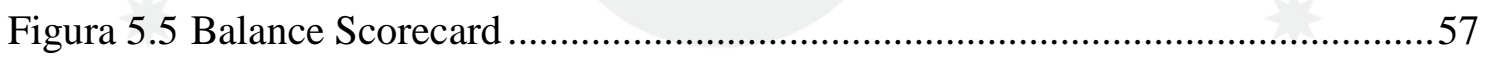

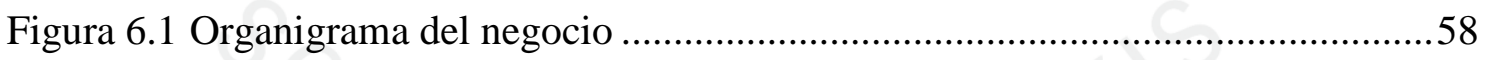

Figura 7.1 Proyección de flujos de ingresos ............................................................. 75

Figura 7.2 Flujos proyectados del negocio a 10 años ............................................... 77 


\section{ÍNDICE DE ANEXOS}

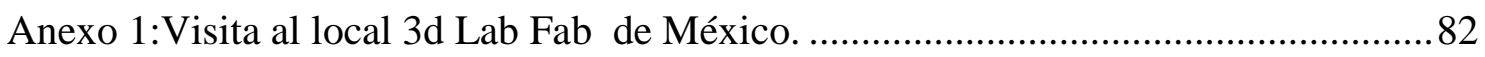

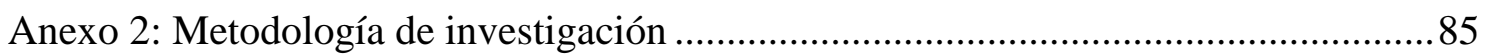

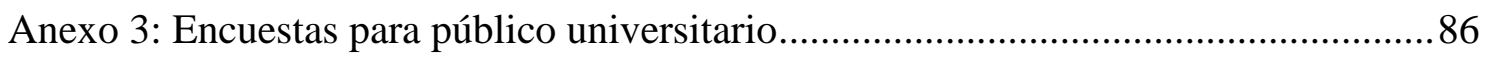

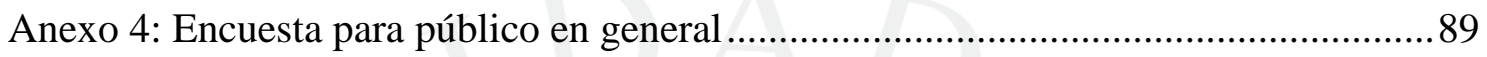

Anexo 5: Resultado de encuesta de público universitario ...........................................92

Anexo 6: Resultado de encuesta de público en general ............................................97

Anexo 7: Estudiantes de prepago matriculados en el 2014 ....................................... 101

Anexo 8: Estudiantes de prepago matriculados en el 2015 ....................................... 103

Anexo 9: Estudiantes de prepago matriculados en el 2016 ....................................... 105

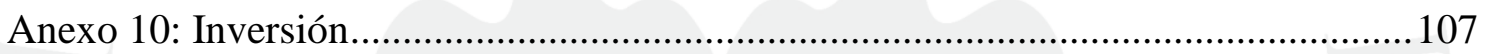

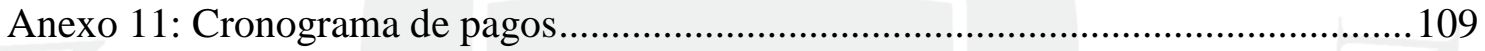

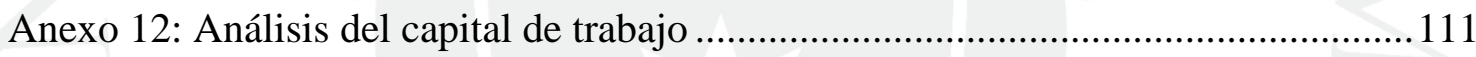

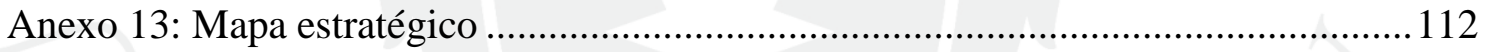

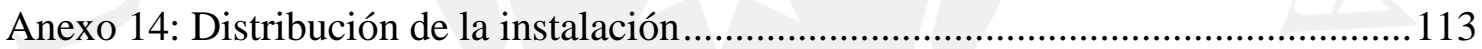

Anexo 15:. Proceso general de impresión ................................................................ 115

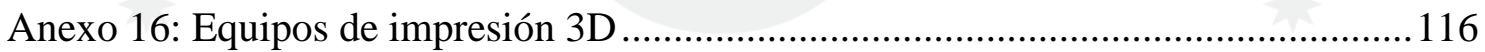




\section{RESUMEN}

El presente proyecto de negocios muestra la viabilidad para instalar en la ciudad de Lima una nueva experiencia que fusione el concepto de cafetería con las oportunidades que nos ofrece la tecnología de la impresión 3D de manera que permita acercar esta tecnología a la vida cotidiana dentro de un ambiente innovador que permita estimular la creatividad.

La investigación de campo mostró que existe una demanda insatisfecha y un gran interés en estudiantes universitarios que necesitan un espacio donde realizar sus trabajos de impresión 3D. Igualmente se evidenció que para el público no conocedor de esta tecnología se tendrá que trabajar en difundir las oportunidades que esta nueva herramienta ofrece. La finalidad es dejar de ser consumidores para convertirnos en creadores.

Los centros de fabricación digital de Universidades así como de empresas están comenzando a invertir en esta tecnología ocasionando en el mercado interno un desarrollo positivo. Igualmente este modelo de negocio ya es rentable en otros países.

Finalmente el análisis financiero desarrollado evidencia un muy buen retorno de la inversión por lo que se concluye que nuestro proyecto de negocio 3D Lab \& Café es viable.

Impresión 3D, Experiencia, Creatividad, Tecnología, 3D Lab \& Café 


\begin{abstract}
The present business project shows the feasibility to install a new experience in the city of Lima that merges the concept of cafeteria with the opportunities offered by 3D printing. We are bringing this technology closer to the everyday life within an innovative environment which stimulates creativity.

Our research has showed that there is an unsatisfied demand and a great interest in university students who need a space to carry out their 3D printing work. It was also evidenced that for the general public there is not much knowledge about this technology. We will have to work in order to spread the opportunities that this new tool could bring to them. The purpose is to stop being consumers and to become creators.

The digital manufacturing centers of universities as well as companies are beginning to invest in this technology causing a positive development in the domestic market. Also this business model is already profitable in other countries.

Finally, the financial analysis shows a very good return on investment, so it is concluded that our 3D Lab \& Cafe business project is viable.
\end{abstract}

3D printing, Experience, Creativity, Technology, 3D Lab \& Coffee 


\section{INTRODUCCIÓN}

Actualmente en la ciudad de Lima hemos identificado que el concepto de Café \& Impresión 3D no se encuentra desarrollado. Las personas que desean hacer impresiones en 3D tienen que ir a centros de impresión especializados o adquirir este equipo. La venta y uso de estos equipos todavía se encuentra reducido a profesionales que trabajan dentro del mundo del diseño, arquitectura y de la investigación. No existe un lugar que ofrezca la experiencia de crear, diseñar y hacer realidad sus ideas dentro de una atmósfera ideal que inspire la creatividad y las bondades de esta nueva herramienta.

La motivación que nos impulsa a realizar este proyecto es justamente ser el primer lugar en Lima en combinar la experiencia de impresión 3D dentro de una atmosfera agradable de un café que permita al cliente observar como los bits de una imagen digital se transforman en algo real que uno puedo tocar y llevárselo a casa. Además queremos ser el lugar de referencia en donde se incentive la creatividad, el arte, diseño y se difunda el uso de esta tecnología. Un lugar en donde nuestros clientes (estudiantes conocedores de la impresión 3D y público en general) puedan reunirse para intercambiar ideas y avances del mundo de la impresión 3D.

La tecnología de impresión 3D tiene una gran oportunidad de crecimiento y queremos aprovecharlo para fusionarlo con el concepto Café \& Impresión 3D. Cualquier persona, conocedora o no de la impresión 3D, es invitada a pasar un buen momento ya sea trabajando sobre su proyecto de impresión 3D o experimentando y conociendo esta nueva herramienta.

Nuestra propuesta consiste en difundir el concepto Café \& Impresión 3D rápidamente y posicionarnos como los pioneros dentro del público universitario y público en general. Debemos ser capaces igualmente de crear una atmósfera atractiva y adaptarnos a las necesidades de nuestro público objetivo.

Para garantizar la continuidad del negocio debemos estar atentos al avance tecnológico de la impresión 3D e incorporarlas a nuestro negocio, con la finalidad de estar siempre a la vanguardia de esta tecnología. 


\section{Mercado}

El perfil de los clientes serán los estudiantes y público en general entre 18 y 55 años de edad que quieran vivir la experiencia 3D. Debemos acercarnos y hacernos conocidos dentro del ámbito estudiantil ya que este público nos permitirá difundir el concepto rápidamente a través de las redes sociales y de esta manera también llegar a jóvenes curiosos que estén buscando algo novedoso, donde, diseñar sus propios proyectos y disfrutar de una buena experiencia.

Deseamos que nuestro local tenga un diseño interior y exterior único, por lo tanto debemos buscar una buena empresa de diseño de interiores que permita hacer realidad nuestro concepto.

\section{Descripción del Valor}

Nos diferenciamos de otros negocios de impresiones 3D en el sentido que ofrecemos una atmósfera especial en un lugar que incentive la creatividad de las personas materializando sus ideas usando la impresión 3D. Para lograr, esto nuestro local contará con instalaciones cómodas y modernas especialmente diseñadas para el trabajo en solitario y en quipo. De más está mencionar que también ofreceremos internet gratuito, música, monitores especiales, scaner y un buen servicio de cafetería. Todo ello originará una sinergia que permitirá el "co-working” y "networking” de nuestros clientes.

Queremos que nuestro local sea visto como punto de referencia en la ciudad donde uno pueda diseñar libremente e intercambiar ideas y experiencias del mundo de la impresión 3D. En resumen, pretendemos difundir este nuevo concepto dentro de un local que ofrezca una experiencia diferente de impresión 3D, disfrutando, creando, innovando y desarrollando el talento humano.

\section{Viabilidad del Mercado}

Del estudio de mercado realizado se obtuvo como resultado que este modelo de negocio tiene una gran aceptación en los universitarios y público en general por ser innovador y único en su concepto en Lima.

\section{Factor Inversión}


En el Perú se inicia el desarrollo de Impresión 3D a nivel profesional a partir del 2009, comentó Delia Barriga, Ejecutiva del Fab Lab Perú iniciando esta apuesta con 8 Fab Lab en Lima y uno en Arequipa, al 2019 ya se cuenta con un Centro en Huancayo implementado por la Universidad Continental en el año 2017 y otro en la ciudad de Trujillo por parte de la Universidad TECSUP en el 2019 con una inversión de más de S/. 1'000,000 de soles.

Esta tendencia de crecimiento en los centros de innovación de las principales universidades del país nos ha permitido analizar como se viene consolidando el mercado de la Impresión 3D liderado por los centros de Innovación y Fab Lab que promueven las universidades, la inversión que hace cada una de ellas y la proyección a futuro considerando el gran potencial que tiene para las industrias, el arte y el uso doméstico.

La universidad ESAN abre su Fab Lab en enero del 2015 con una inversión inicial de \$1’000,000 y para el 2019 lograron certificarse como centro de Innovación y Desarrollo lo que le genera un retorno de inversión del 175\% de acuerdo a Nancy Matos, Vice rectora académica.

La Pontificia Universidad Católica del Perú, en el 2013 realizó una inversión en la compra de Impresora 3D Fortus 400 mc por el valor de \$100,000 y para el 2020 tienen proyectado invertir $\$ 5^{\prime} 000,000$ en infraestructura para la investigación, dentro de esa inversión está planeado comprar una impresora 3D de menor envergadura para atender las necesidades del mercado.

El Fab Lab TECSUP sede Trujillo, tiene una inversión de más de S/. 1’000,000 y es uno de los primeros de la zona norte del Perú, mientras que la UCAL, también se unió a esta tendencia con la apertura de su centro Fab Lab en el año 2018 integrándose a la red Internacional.

Por lo expuesto podemos coincidir en que el desarrollo de la Impresión 3D en nuestro país viene en constante crecimiento, por la inversión en equipos de última generación, el interés de las universidades de seguir armando redes de conocimientos, la apertura de nuevos centros de experiencia y la aplicación industrial que vienen desarrollando empresas como REY, iFurniture, Citeccal, animan a seguir apostando en el rubro. El crecimiento a futuro es constante.

Siguiendo en este análisis, un primer factor usado para obtener información sobre el mercado de impresión 3D es el factor de inversión, el cual no sólo es a nivel de 
implementación de equipos e infraestructura, sino también de promoción de esta tecnología, los eventos que promueven los Fab Lab, congresos, talleres, capacitaciones, desarrollo de proyectos y prototipos genera una réplica en las otras aristas de la cadena a través de mayores ingresos, para proveedores, profesionales de diseño, mayor demanda, mejor oferta, procesos en corto tiempo. Esta tendencia no solo se centraliza en Lima, sino que se replica en otras ciudades de Perú.

Nuestra participación en el negocio la medimos a nivel de inversión, actualmente estos centros especializados invierten sobre el \$1 000000 como punto inicial como es el caso de la Universidad ESAN, teniendo la cuenta el nivel de expertise y la tecnología. En nuestro caso, tenemos la ventaja de que la tecnología de impresión 3D en nuestro país es una comunidad prácticamente nueva con menos de 10 años en desarrollo.

Actualmente nuestra inversión inicial será de aproximadamente de 550,000 soles, el cual representa $16 \%$ de la inversión total que hacen los Fab Lab, y hemos visto que el retorno de la inversión es alto. Posicionándonos dentro de la cadena en la categoría de entretenimiento como el primer centro de experiencia de Lima.

2. Factor consumo de material

Otro factor para determinar el tamaño del mercado es la cantidad de filamento que se usa para la producción. El determinar el consumo promedio de filamento que usa una persona natural nos da un acercamiento de su demanda en kilos. Para ello realizamos una pequeña encuesta a tres personas naturales independientes (freelancers) que obtienen sus ingresos a partir de trabajos de impresión en 3D. Sus ingresos mensuales promedio son de $\$ 3,000$ ( $\mathrm{S} /$. 119,000 al año) que llevándolo a gramos en bruto de filamento y al precio de venta aproximado de estos tres independientes (1.50 soles $\mathrm{x}$ gramo) nos da un consumo anual de 79 kilos de filamento.

Este cálculo se puede contrastar claramente con un estudio realizado para implementar un centro de impresión de coronas dentales 3D dirigido a odontólogos donde se determinó una demanda anual de 163 kilos de filamento para la producción de las piezas, Canela Fuentes, Herboso Rodríguez. Montoya Rivas y Pérez de los Ríos (2019).

Claramente, el consumo de los filamentos nos da un alcance más preciso del valor promedio del mercado en demanda en kilos de filamento que van desde los 79 kilos en el sector independiente hasta 163 kilos en una micro empresa que atiende un sector 
específico como es el de la odontología. Nuestro proyecto tendrá un consumo de 400 kilos durante el primer año y esperamos llegar a tener consumo de 800 kilos hacia finales del quinto año de vida del proyecto.

Las ganancias del negocio tendrán que venir principalmente de las impresiones 3D complementándose con la venta de café, bebidas, ensaladas, sándwich, postres entre otros de nuestra cafetería. Otros ingresos pueden venir de la venta de "merchandising" como tazas, llaveros del local previamente elaborados y que permitan realizar una rápida personalización a fin de que sean comprados por los clientes impulsando la difusión de nuestra marca y local. En una segunda fase pensamos dar el servicio de venta y reparación de impresoras 3D al igual que otorgar curso prácticos sobre diseño e impresión. También se tiene pensado otorgar servicio de impresión a empresas que deseen desarrollar con nosotros sus trabajos de acuerdo a las características técnicas de nuestros equipos.

El diseño del local, la calidad de la impresión y la experiencia hacia el cliente serán para nosotros los pilares que darán éxito a la idea de negocio. El precio de venta de impresión al público se encuentra en 1.80 soles el gramo de material de impresión utilizado. El tiempo puede variar entre 45 minutos hasta 5 horas o más dependiendo de la complejidad del proyecto. Igualmente se proporcionará un servicio de escaneo y de asesoría en diseño por el cual se cobrará 20 soles por hora.

\section{Fuentes de Inversión}

El capital de inversión está compuesto por una inversión inicial de ciento doce mil doscientos noventa y ocho con 00/100 Soles (S/ 112,298.00) de los socios fundadores y un financiamiento bancario total de cuatrocientos veinte y dos mil con 00/100 soles (S/ 422,000.00), que proviene de la línea de crédito de cada uno de los socios. Como se mostrará en el capítulo del Análisis Financiero, el proyecto devuelve una rentabilidad interesante. 


\section{CAPITULO I: ASPECTOS GENERALES DEL NEGOCIO}

\subsection{Presentación de la empresa}

Nuestra empresa desea difundir en la ciudad de Lima el potencial de la impresión 3D fusionado con un servicio de cafetería dentro de un ambiente que inspire a la creatividad y permita a nuestros clientes pasar un momento agradable, realizando su proyecto de impresión o simplemente experimentando con esta nueva herramienta.

Desde el año 2014 el concepto ha comenzado a implementarse en ciudades importantes como Buenos Aires, Londres, Barcelona y Ciudad de México. Estos nuevos espacios permiten atraer el interés de aquellas personas usuarias de esta tecnología y renovar el concepto de Café Restaurante. Estos Cafés se han convertido en centros de difusión del concepto impresión 3D permitiendo atraer al público conocedor de la materia $\mathrm{y}$ en general a aquellos que simplemente quieran conocer y experimentar este nuevo mundo.

Para crear este ambiente tomaremos como referencia lo logrado por los cafés Starbucks en lo que se refiere a diseño del local, experiencia ofrecida al cliente y calidad del servicio.

\subsection{Marco Teórico}

Actualmente a nivel mundial hay una tendencia en el desarrollo de diseños 3D para aplicaciones en la ingeniería, medicina, industria y arte, destacando por su eficiencia y precisión. En el Perú desde hace varios años ha ido calando en diversos puntos de la cadena productiva desde proveedores, empresas que aplican el modelado 3D y servicios de impresión.

Este desarrollo viene de la mano de organizaciones que se dedican a promover su uso como los FAB LAB que se han ido implementando en las principales universidades del país, que además están incluyendo cursos y talleres dentro de su estructura curricular, donde la tecnología 3D se hace presente a través del diseño de trabajos y prototipos en carreras como ingeniería, arquitectura y diseño. 
Ejemplos como el Centro de Tecnologías de la Información y Comunicaciones de la Universidad de Ingeniería (CTIC-UNI) que viene realizando bioimpresiones en 3D para reproducir prótesis faciales, narices, marcapasos y elementos odontológicos.

Por otro lado, tenemos al público que en su vida cotidiana no está familiarizado con el uso de esta tecnología y que sin embargo le parece interesante, generando aceptación y buenas expectativas para la implementación del negocio.

\subsection{Motivación del Proyecto}

La motivación que nos impulsa a realizar este proyecto es justamente ser el lugar de referencia en la ciudad de Lima que fomente la tecnología 3D dentro una cafetería en una atmósfera agradable y confortable que motive la creatividad.

La impresión 3D es una tecnología que poco a poco está comenzando a desplazarse del uso exclusivo de las grandes industrias al uso doméstico. Muchos expertos opinan que esta creación es parte de la Tercera Revolución Industrial ya que permitirá la democratización de la fabricación. Szilard A. K. y Ruiz de G Garibay. (2015)

Actualmente el filamento de plástico es el principal insumo utilizado en este tipo de impresión. Sin embargo, el futuro es muy prometedor ya que se espera que estas máquinas puedan hacer impresiones en cualquier tipo de material, inclusive podría en un futuro no muy lejano usarse para imprimir tejidos, huesos y órganos humanos a lo que se denomina como bioimpresión.

\subsection{Percepción de la necesidad: análisis problema-solución}

Actualmente en la ciudad de Lima hemos identificado que el concepto de Café e Impresión 3D no se encuentra desarrollado. Las personas que desean hacer impresiones en 3D tienen que ir a centros de impresión especializados o adquirir este equipo. La venta y uso de estos equipos todavía se encuentra reducido a profesionales que trabajan dentro del mundo del diseño industrial, ingeniería, arquitectura y centros de investigación de universidades así como los Fab-Lab.

Producto de la aplicación de la técnica de encuesta, hemos podido notar que existe una demanda del servicio de impresión, principalmente en estudiantes universitarios de arquitectura, ingeniería y diseño gráfico, que se encuentran ávidos por tener un espacio en donde puedan imprimir sus proyectos y pasar un momento agradable. Asimismo, 
existe un potencial mercado para este servicio dentro del público no conocedor de esta tecnología de la ciudad de Lima.

\subsection{Descripción de la idea y la oportunidad}

La tecnología de impresión 3D tiene una gran oportunidad de crecimiento y queremos aprovecharlo para fusionarlo con el concepto Café \& Impresión 3D. Cualquier persona, conocedora o no de la impresión 3D es invitada a pasar un buen momento recibiendo nuestro servicio personalizado de impresión, escaneo y diseño. “Acercando la tecnología de impresión 3D a la vida cotidiana", sería nuestro lema.

\subsection{Justificación del atractivo de la propuesta}

Nos diferenciamos de otros centros de impresión 3D en el sentido que ofrecemos una experiencia al cliente basado en crear una atmósfera atractiva y un lugar con equipos de última tecnología para que las personas puedan imprimir sus proyectos en $3 \mathrm{D}$ y, a su vez, promocionar y difundir esta nueva herramienta en la sociedad limeña. Rápidamente nos posicionaremos como los pioneros dentro del público universitario y jóvenes profesionales, principalmente. El rápido crecimiento de la masa poblacional de universitarios se concentra en la ciudad de Lima por lo cual tendremos una interesante demanda para nuestro servicio diferenciador.

Este nuevo concepto de impresión 3D es empleado en otros países por las empresas siguientes:

- FabCafe (fabcafe.com) en Tokio, Taipe, Hida, Toulouse, Strasbourg, Hong Kong, Kyoto, Barcelona, Bangkok, Singapur, Monterrey.

- Createcafe (createcafe.ca) y Wave of the future (waveofthefuture3d.com) ambos en Canadá

- 3D Lab Fab \& Café en Ciudad de México, detalles de la visita al negocio (Anexo 1).

- Makerscafe (makerscafe.com) en Londres, que tiene interés de expandirse de manera internacional a manera de franquicia.

\subsection{Estrategia inicial y objetivos de alcance}

Debido a que es un negocio fácilmente imitable, estamos en la obligación de brindar una experiencia diferenciadora y ser los primeros en lanzar esta idea al mercado local. 
Debemos participar en cualquier evento, feria de diseño o de innovación relacionada a la impresión 3D e igualmente participar activamente en las redes sociales. Realizaremos convenios con centros de educación para hacernos conocidos dentro del público estudiantil (técnico y universitario) así como en los Fab Lab de los principales centros universitarios.

Nuestros clientes potenciales en una primera fase serán los estudiantes técnicos, universitarios y público en general de los dos estilos de vida (sofisticado y progresista) desarrollado por Rolando Arellano. En una segunda fase alcanzaremos a empresas que estén igualmente buscando un lugar donde poder imprimir sus diseños como por ejemplo estudios de arquitectura y centros odontológicos.

El perfil de los clientes en la primera fase son estudiantes universitarios afines a la impresión 3D y público entre 18 y 55 años de edad que quieran experimentar la impresión 3D. Debemos acercarnos y hacernos conocidos dentro del ámbito estudiantil ya que este público nos permitirá poder difundir el concepto rápidamente a través de las redes sociales.

Deseamos que nuestro local tenga un diseño interior y exterior único, por lo tanto, debemos buscar una empresa de diseño de interiores que permita plasmar nuestro concepto innovador.

Seremos los primeros con este concepto en Lima, por lo que debemos posicionarnos en la mente de nuestro público objetivo rápidamente y ser reconocidos como el lugar por excelencia en el servicio de impresión 3D fusionado con el servicio de cafetería en donde se vive una atmósfera de creatividad.

\subsection{Impacto comercial y responsabilidad social.}

Socialmente pretendemos empoderar muy fácilmente a las personas de manera que se apropien de técnicas de impresión y puedan solucionar problemas de su vida cotidiana o sencillamente materializar una idea en un producto que no existe en el mercado fabricado por el usuario final. Igualmente desarrollaremos campañas para ayudar a personas que necesiten cierto tipo de prótesis básicas principalmente para niños que puedan ser creados desde nuestras instalaciones. 


\section{CAPITULO II: IDEA, INVESTIGACIÓN Y VALIDACIÓN DE LA SOLUCIÓN}

\subsection{Diseño y metodología de la investigación}

Nuestra investigación es descriptiva. La metodología empleada se basa en el uso de encuestas y entrevistas que sustentan la aceptabilidad y viabilidad de este modelo de negocio.

- Muestreo Poblacional (desarrollo del trabajo de campo)

En el desarrollo de nuestra investigación durante la primera etapa se ejecutó la investigación exploratoria, con el fin de recopilar y procesar la información que se obtuvo de fuentes secundarias externas y de visitas de prospección a centros de impresión 3D. Para el levantamiento de información se desarrollaron entrevistas a expertos en el tema de impresión 3D con el objetivo de conocer la opinión de estos respecto al mercado y sus características, obteniendo una retroalimentación positiva.

Durante la segunda etapa se implementó una investigación cuantitativa de tipo descriptiva, mediante la aplicación de encuestas personales como fuente de información primaria. Las encuestas fueron diseñadas de una manera estandarizada y estructurada teniendo en consideración nuestros dos públicos objetivos (estudiantes universitarios y público en general).

El objetivo de la encuesta es determinar la motivación y las expectativas respecto a la impresión 3D, para lo cual aplicaremos la siguiente metodología:

Figura 2.1

Metodología de encuesta

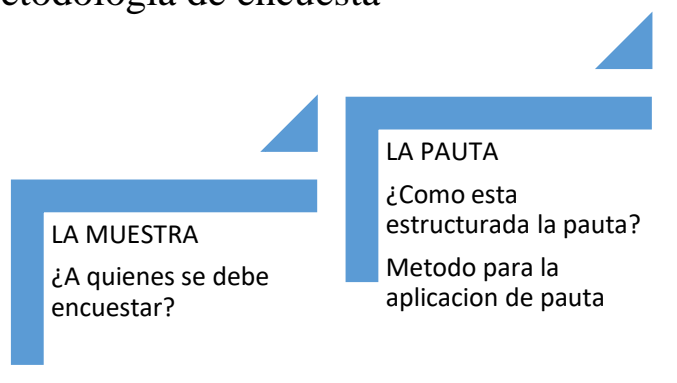

EMPLAZAMIENTO

¿Cual es el mejor lugar para hacer la

encuesta?

Fuente: Elaboración propia 
- La muestra:

- Público Objetivo 1: El segmento en el que se enfoca este estudio son "Estudiantes relacionados al diseño en general, haciendo énfasis en el carreras relacionadas a la impresión 3D”. Para identificarlos éstos deben cumplir con estas características.

- Hombres y mujeres mayores de 18 años

- Estudiantes de carreras a fines

- Que realice una impresión al menos una vez al mes

- Tener interés y curiosidad por el diseño en general

- Tener capacidad de gasto

- Público Objetivo 2: El grupo específico en el que enmarca la muestra son las personas que deben cumplir con estas características.

- Hombres y mujeres mayores de 22 años

- Laboralmente activos

- Asistan al menos una vez al mes una cafetería

- Tener interés y curiosidad por el diseño en general

- Tener capacidad de gasto.

- La pauta: Ambas pautas cuenta con catorce (14) preguntas ligadas entre sí cuya finalidad es obtener el mayor número de datos por parte de los encuestados.

- Emplazamiento: Lugares cerca de los centros universitarios como por ejemplo Surco, La Molina, San Borja.

- Puntos importantes: Se tiene en cuenta las conexiones de las preguntas y respuesta.

El desarrollo del trabajo de campo se encuentra en los anexos 02 hasta anexo 06.

\subsection{Validación de hipótesis}

Nuestra hipótesis para el presente estudio es la siguiente: No encontramos en Lima una cafetería que ofrezca el servicio de impresión 3D, con un ambiente agradable y cómodo, donde se incentive la creatividad. 
Según los resultados de la encuesta entre universitarios y público en general existe un gran interés en usar y probar esta tecnología. Este comportamiento positivo se refleja en cuanto al uso dentro del ámbito profesional y social lo que afianza su validación y aceptación. Un rubro cuya tendencia seguirá creciendo durante los próximos años.

\subsection{Validación de la solución}

Se identificaron dos públicos objetivos: estudiantes universitarios que requieran del servicio de impresión 3D y público en general quienes presentan las siguientes características.

- Estudiantes:

- Hombres y mujeres mayores de 18 años.

- Estudiantes de carreras afines a la impresión 3D.

- Que realicen una impresión al menos una vez al mes.

- Tener interés y curiosidad por el diseño en general.

- Tener capacidad de gasto.

- Público en general (sofisticados y progresistas) interesados en el diseño, tecnología e innovación:

- Hombres y mujeres mayores de 18 años.

- Laboralmente activos.

- Asistan al menos una vez al mes una cafetería.

- Tener interés y curiosidad por la impresión 3 D.

- Tener capacidad de gasto.

Según los resultados obtenidos se puede concluir que para el caso de estudiantes universitarios el conocimiento de impresión 3D es de un 97\% y para el caso de público en general el $46 \%$ les parece interesante el concepto de cafetería con Impresión 3D.

\subsection{Muestreo Poblacional.}

Se seleccionó la muestra empleando el método probabilístico de muestreo.

Para el presente trabajo de investigación se empleó el muestreo aleatorio simple con la siguiente fórmula: 


\section{Dónde:}

N: es el tamaño de la población 1, 027,753 (Ver cap. 4.1.2 Publico en general)

n: es el tamaño de la muestra

p: 0.5 variabilidad positiva

q: 0.5 variabilidad negativa

Z: 1.96 nivel de confianza

E: 0.05 error esperado

$$
n=\frac{Z^{2} p q N}{E^{2}(N-1)+Z^{2} p q}
$$

Como resultado de la aplicación de la formula se obtuvo que el tamaño de la muestra (n) es de 384 encuestas. Se ha tomado en cuenta un 5\% de margen de error, un nivel de confianza de $95 \%$, con una probabilidad de éxito del 50\%, y una probabilidad de fracaso de $50 \%$.

\subsection{Análisis de tendencias y patrones}

Según lo investigado por el instituto estadounidense Gartner, quien viene analizando con éxito desde el año 2005 los comportamientos de la impresión 3D en el mercado, se muestra la curva de tendencias de Julio 2015 adjunta; la cual refleja la evolución de estas tecnologías en la actualidad y las estimaciones de lo que está por venir. En ella se aprecian cambios relevantes especialmente en las áreas de "impresión 3D personal, impresión 3D profesional y medicina".

En el pico de la curva de expectativas están las aplicaciones médicas impresas en 3D. Aunque el mercado se está empezando a familiarizar con ello, son muchos los usos que aún son desconocidos por el público en general. 
Figura 2.2

Análisis de tendencias y patrones

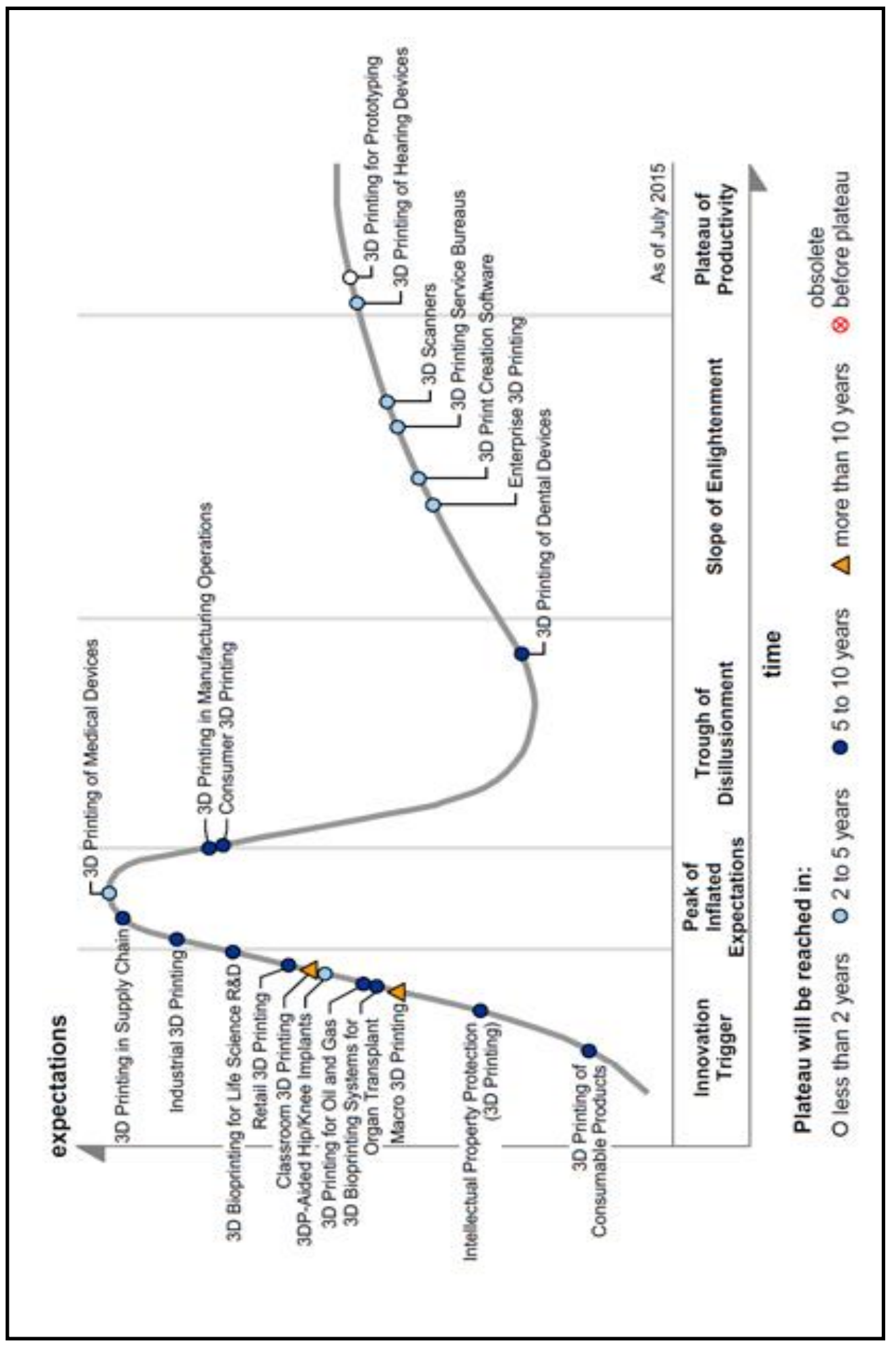

Fuente: Garther (July 2015) 
Igualmente, las tendencias DIY (do it yourself) y DIWO (do it with others) hacen viable que nuestro modelo de negocio pueda mostrar una gran acogida dentro de nuestro mercado objetivo.

Así mismo el core business de nuestro proyecto es el servicio de impresión 3D, sin embargo es importante tener como referencia lo indicado por Peru Retail que estima para el año 2021 unas 3,653 cafeterías que moverán unos US\$255.5 millones.

\subsection{Canvas}

Figura 2.3 Canvas

\begin{tabular}{|c|c|c|c|c|}
\hline $\begin{array}{l}\text { ALIANZAS } \\
\text { - Principales } \\
\text { Universidades } \\
\text { e institutos } \\
\text { afines a las } \\
\text { carreras de } \\
\text { Arquitectura, } \\
\text { Ing Civil, } \\
\text { Mecánica, } \\
\text { Mecátronica, } \\
\text { Eléctrica y } \\
\text { Diseño. } \\
\\
\text { - Proveedores } \\
\text { de Impresoras } \\
\text { 3D e insumos. } \\
\text { Proveedores } \\
\text { de café. }\end{array}$ & $\begin{array}{l}\text { RECURSOS } \\
\text { - Personal con vocación } \\
\text { de servicio y } \\
\text { capacitados en } \\
\text { técnicas de impresión } \\
\text { 3D. } \\
\text { - Muebles y enseres del } \\
\text { local. } \\
\text { - Local y decorado } \\
\text { interior. } \\
\text { - Equipo e insumos } \\
\text { para la impresión 3D. } \\
\text { - Insumos para la venta } \\
\text { de café y bebidas. } \\
\text { - Soporte tecnologico. }\end{array}$ & $\begin{array}{l}\text { - Ambiente } \\
\text { innovador con } \\
\text { excelente nivel } \\
\text { de servicio } \\
\text { orientado } \\
\text { hacia el cliente } \\
\text { que deseen } \\
\text { imprimir } \\
\text { proyectos 3D. }\end{array}$ & $\begin{array}{l}\text { CANALES } \\
\text { - Local. } \\
\text { - Pagina Web. }\end{array}$ & $\begin{array}{l}\frac{\text { SEGMENTO }}{\text { DE }} \\
\text { CLIENTES } \\
\\
\text { - Principalm } \\
\text { ente } \\
\text { estudiantes } \\
\text { afines a la } \\
\text { impresión } \\
\text { 3D y } \\
\text { publico en } \\
\text { general } \\
\text { entre } 18 \text { y } \\
\text { 55 años. }\end{array}$ \\
\hline \multicolumn{3}{|c|}{$\begin{array}{l}\text { COSTOS } \\
\text { - Equipos de impresión 3D. } \\
\text { - Equipos de cafetería } \\
\text { - Personal. } \\
\text { - Local y diseño exterior e interior. } \\
\text { - Seguridad. } \\
\text { - Marketing. }\end{array}$} & \multicolumn{2}{|c|}{$\begin{array}{l}\text { INGRESOS } \\
\text { - Impresión de trabajos 3D. } \\
\text { - Servicio de venta de café y } \\
\text { bebidas. } \\
\text { - Servicio de asesorias y } \\
\text { escaneo. }\end{array}$} \\
\hline
\end{tabular}

Fuente: Elaboración propia 


\section{CAPÍTULO III: PLANEAMIENTO ESTRATÉGICO}

Nuestra misión es acercar la tecnología de impresión 3D fusionado con el servicio de cafetería dentro de un ambiente que incentive la creatividad y diseño.

Nuestra visión es ser el lugar de referencia donde las personas puedan disfrutar de la experiencia de la impresión 3D.

\subsection{Valores y ética.}

- Honestidad: Se dará la confianza a nuestros clientes de que sus diseños no serán reproducidos sin su autorización, respetando los derechos de autor.

- Actitud de servicio: La razón principal es la satisfacción de los clientes escuchando e identificando las necesidades de nuestros clientes.

- Responsabilidad: Conocemos nuestro compromiso con la sociedad de proteger el medio ambiente al emplear materia prima biodegradable y el empleo de productos orgánicos.

- Creatividad: Incentivar en los clientes a diseñar sus propios productos.

- Respeto: Estamos comprometidos con la conservación de las buenas costumbres y las tradiciones.

\subsection{Cultura organizacional.}

- Observación: Estamos conscientes de todo aquello que va más allá de brindarles una grata experiencia a nuestros clientes, percibimos sus necesidades y expectativas y tratamos de cumplirlas a su satisfacción.

- Compromiso: Atender al cliente de la manera más oportuna y responsable, siempre a la vanguardia de la tecnología, con productos de calidad y brindando un servicio eficiente.

- Trabajo en equipo: Todo el personal de la empresa trabaja para alcanzar los objetivos comunes y brindar una experiencia inolvidable a nuestros clientes. 


\subsection{Objetivos Estratégicos.}

- Lograr posicionarnos antes del quinto año como la empresa líder en el mercado de impresión en 3D. En donde uno pueda volver realidad sus ideas y diseños únicos.

- Lograr el crecimiento del negocio a través de alianzas estratégicas con universidades y empresas afines al negocio.

- Generar rentabilidad a los socios.

\subsection{Análisis externo:}

Para el desarrollo del análisis externo nos apoyaremos en la herramienta PESTEL en razón que nos ayudará a entender y evaluar el contexto de la propuesta de nuestro modelo de negocio realizando el análisis: político, legal, circunstancial, económico, geográfico, social, demográfico, cultural, tecnológico, ambiental (PESTEL).

\subsubsection{Político}

El enfrentamiento entre el poder ejecutivo y legislativo así como la propuesta del ejecutivo de adelantar las elecciones está originando incertidumbre dentro del sector empresarial. De igual manera la difusión a través de los medios de comunicación de los casos de corrupción dados a conocer recientemente origina mucho ruido político que afecta negativamente la inversión de capitales.

No obstante el Estado Peruano a través del Ministerio de la Producción viene impulsando la implementación de mecanismos e instrumentos para el desarrollo y fortalecimiento empresarial, en beneficio del emprendedor peruano, como son las StartUps. Además, se otorgan las facilidades legales, tributarias y de patentes para quienes recién empiezan.

En lo que respecta al nivel local o municipal, el efecto podría ser mínimo dependiendo de la ubicación del negocio, ya que actualmente los alcaldes de Santiago de Surco, La Molina y Miraflores continúan otorgando licencias de funcionamiento normalmente. 


\subsubsection{Económico}

El Instituto de Economía y Desarrollo Empresarial (IEDEP) de la Cámara de Comercio de Lima (CCL) informó que la economía peruana crecería 3.2\% al cierre del 2019, lo que significa una reducción de 0.5 puntos porcentuales a lo estimado a comienzos del año, cuando la proyección era de 3.7\%. Esta menor dinámica económica se explica principalmente por el bajo crecimiento de las actividades productivas con alta participación en el producto bruto interno (PBI) y a una evolución menor de la demanda interna, especialmente de la inversión pública". Esto en parte es consecuencia de la actual coyuntura política que ha generado incertidumbre en el consumidor y en el inversionista.

\subsubsection{Social}

El proyecto tendrá un enfoque social, pues se pretende apoyar a los jóvenes estudiantes universitarios que están estudiando carreras de ingeniería, arquitectura y diseño, ofreciéndoles empleo. A la vez seremos un nexo con empresas que requieran de personal especializado en impresión 3D. Finalmente contribuiremos en dar a conocer las oportunidades que ofrece el mundo de impresión 3D y permitir a cualquier persona no conocedora del tema poder hacer realidad su creación. En una segunda etapa se implementará una zona especial para niños y se realizarán campañas para crear pequeñas prótesis a personas con discapacidad y de bajos recursos acorde con nuestra política de responsabilidad social.

\subsubsection{Tecnológico}

Este factor es importante en la evaluación de nuestro negocio en razón del avance constante de la tecnología. Es indispensable estar siempre atentos a los nuevos cambios de software de diseño y de equipos de impresión, para poder adaptarnos rápidamente.

\subsubsection{Ecológico}

Los impactos ambientales del proyecto son mínimos ya que el insumo utilizado (PLA) en la impresión 3D es un bioplástico derivado del almidón de maíz, no toxico y que contribuye al cuidado del medio ambiente. 


\subsubsection{Legal}

En este factor hay que tener en cuenta el DL No 822. "Ley sobre derecho de autor", en el cual se dan las disposiciones que tienen por objeto la protección de los autores de las obras literarias y artísticas y de sus derechohabientes y la aprobación de la ley del nuevo código de protección y defensa al consumidor, estas normas son las más relevantes para el proyecto. Con esta nueva ley, INDECOPI ejerce las funciones de autoridad nacional de protección y defensa del consumidor y, por tanto, le compete el cumplimiento de las disposiciones contenidas en la mencionada norma. Esto conlleva a que el organismo tenga un mayor peso y el consumidor deba ser más respetado, en tal sentido tampoco se realizara la reproducción de los diseños creados por nuestros clientes sin previa autorización.

\subsection{Análisis interno:}

Para el desarrollo del análisis interno nos apoyaremos en la herramienta Porter, en razón que nos ayudará a establecer la estrategia a implementar con la finalidad de que nuestro modelo de negocio sea rentable. Para ello se analizará las cinco fuerzas de Porter: Competidores potenciales, clientes, proveedores, productos sustitutos, barreras de entrada.

\subsubsection{Competidores potenciales:}

Este modelo de negocio es nuevo en el país, por lo que no se cuenta con competencia directa, sin embargo para efectos de estudio vamos a considerar a los locales de impresión en 3D como competencia indirecta. Dentro del rubro la principal competencia de 3D LAB Café son los Laboratorios de las universidades y negocios de impresión 3D.

a. Fab Lab de Universidades:

- ESAN.

- Pontificia Universidad Católica del Perú.

- TECSUP.

- UNI.

b. Empresas: 
Tabla 3.1

Relación de principales competidores

\begin{tabular}{|c|c|c|c|}
\hline EMPRESAS & PAGINA & TELEFONO & DIRECCION \\
\hline 3D Mentes LAB & $\begin{array}{l}\text { https://www.facebook.com/3dme } \\
\underline{\text { nteslab/?ref=br_rs }}\end{array}$ & 918424984 & Miraflores \\
\hline $\begin{array}{l}\text { Studio Código G - } \\
\text { Impresión y Arte 3D }\end{array}$ & $\begin{array}{l}\text { https://www.facebook.com/Studi } \\
\underline{\text { oCodigoG/?ref=br_rs }}\end{array}$ & 987971731 & Santiago de Surco \\
\hline Impresiones 3D Perú & $\begin{array}{l}\underline{\text { https://www.facebook.com/impre }} \\
\underline{\text { siones3dperu/?ref=br_rs }}\end{array}$ & 942157130 & $\begin{array}{l}\text { Av. Velasco Astete, Santiago } \\
\text { de Surco }(3,26 \mathrm{~km})\end{array}$ \\
\hline Crear 4D & https://www.crear4d.com/ & $\begin{array}{l}4444548 \\
994077091\end{array}$ & $\begin{array}{l}\text { Av. República de Panamá } \\
4474 \text { Ofc. } 204 \text {-Surquillo }\end{array}$ \\
\hline 3D Cad Perú & $\begin{array}{l}\text { https://www.3dcadperu.com/tien } \\
\text { da-virtual/ }\end{array}$ & $\begin{array}{l}757-6089- \\
944409294\end{array}$ & $\begin{array}{l}\text { Calle Los Mogaburos } 215 \text { Of } \\
208 \text { 2do. Piso Jesús María }\end{array}$ \\
\hline Skulp 3D Perú & $\underline{\text { http://www.skulp3d.com }}$ & & \\
\hline 3D Toys & $\begin{array}{l}\text { https://www.facebook.com/3dtoy } \\
\text { speru/?ref=timeline_chaining }\end{array}$ & 942157130 & $\begin{array}{l}\text { Av. Velasco astete cuadra } 25 \\
(3,29 \mathrm{~km}) 01 \text { Lima }\end{array}$ \\
\hline
\end{tabular}

Fuente: elaboración propia

\subsubsection{Poder de negociación de clientes}

Los clientes podrían adquirir sus impresoras y fabricar sus propios proyectos de impresión 3D. Sin embargo, en la actualidad aún resulta relativamente oneroso. Esta amenaza se puede reducir al lograr diferenciarnos por el servicio y la experiencia ofrecida.

\subsubsection{Poder de negociación de los proveedores}

Los proveedores de nuestro negocio serán todas aquellas empresas que se dediquen a la venta de equipos y suministros de impresión en $3 \mathrm{D}$ y terciarizaremos los alimentos y bebidas que se expenderán en la cafetería, pues la razón de ser de nuestro negocio es la impresión en 3D. Se seleccionarán las empresas que cuenten con la mejor tecnología, equipos de calidad y el mejor servicio post venta. Entre los principales proveedores de equipos tenemos:

- Krear 3D - Impresoras 3D https://krear3d.com/

- Corporación 3D CAD PERÚ

- $\quad$ Skulp 3D Perú 
- Corporación Crear 4D SAC https://www.crear4d.com/

$\mathrm{Al}$ analizar a nuestros posibles proveedores se pudo determinar que no pueden influir en nuestros precios, en razón de que existen una amplia oferta de insumos y equipos para impresión a un buen precio de mercado tanto en el mercado local como en el extranjero.

\subsubsection{Productos sustitutos}

Si el cliente desea diseñar algo único, personalizado, difícilmente podrá encontrar un servicio sustituto.

\subsubsection{Barreras de entrada}

La barrera de entrada es de nivel medio debido a la inversión inicial que se requiere por el modelo de negocio del presente proyecto, sin embargo, los establecimientos de impresión 3D o cafeterías ya instalados podrían copiar o imitar nuestro modelo de negocio. Y en lo que respecta a la obtención de la licencia de funcionamiento, no representa una barrera significativa de entrada a comparación de otros sectores.

Del análisis de las 5 fuerzas de Porter podemos concluir que las fuerzas más importantes a tener en consideración serían los competidores potenciales y las barreras de entrada. Debido a que es una idea nueva de negocio, no se cuenta con competencia directa, sin embargo se tiene que tener en cuenta las empresas y las fab lab que prestan servicio de impresión 3D como competencia indirecta. Asimismo es un modelo de negocio fácilmente imitable cuya barrera de entrada no es relativamente alta, en tal sentido es atractivo la inversión en este negocio sin embargo el éxito o fracaso del mismo dependerá del constante monitoreo de las mencionadas fuerzas. 


\subsection{Matriz FODA (Fortalezas, oportunidades, debilidades y amenazas)}

Tabla 3.2

Matriz FODA

\section{FORTALEZAS $\quad$ DEBILIDADES}

- Ser los primeros en el Perú en abrir un establecimiento que combine la tecnología 3D con el confort de una cafetería.

- El modelo de negocio de 3D Lab Café es validado por el $97 \%$ del público encuestado.

- Modelo de negocio innovador

- Modelo de negocio poco replicable por la inversión que conlleva implementarlo.

- Personal capacitado enfocado a la atención personalizada y la satisfacción del cliente.

- Ubicación estratégica dentro del casco urbano y fácil accesos para nuestros clientes.

- Equipos a la vanguardia y materia prima que garanticen los acabados y detalles de los modelos impresos, teniendo en cuenta el factor tiempo de impresión.

- Formato que ofrece una atmósfera agradable que motive la creación y la innovación.

\section{OPORTUNIDADES}

- El crecimiento de la demanda en las carreras afines a la impresión 3D

- El 68.9.3\% de Lima Metropolitana pertenece a los Niveles Socioeconómicos A, B y C. (Según CPI 2017)

- La necesidad de reducir costos, puesto que el usuario puede elaborar sus propios prototipos sin invertir en equipos de diseño e impresión.

- No tenemos competencia directa. Poca explotación de este formato de negocio en el mercado local.

- Posicionamiento como pioneros en el mercado.

- Tendencia del uso de la tecnología 3D en la vida cotidiana de las personas en el corto y mediano plazo.

- Los laboratorios que ofrecen servicios de impresión 3D no tienen un servicio personalizado con el público objetivo.

- Público joven que se inicia en este rubro como potencial cliente.

- El $97 \%$ de los estudiantes universitarios encuestados conocen algún servicio referente a la tecnología 3D
- Altos costos de inversión por no tratarse de una tecnología masificada.

- Tiempo de capacitación del personal de acuerdo a la misión y visión de la empresa.

- Marca no conocida en el mercado al ser un negocio nuevo.

- Mantenimiento constante de equipos y renovación de los mismos.

- Poca experiencia en mercado de tecnología por parte de los socios.

- Poca difusión en medios físicos y digitales sobre esta tecnología.

- Fácilmente imitable por los proveedores actuales de impresiones 3D

\section{AMENAZAS}

- No existe una fidelidad por parte de los clientes que solo buscan imprimir sus diseños.

- Contar con pocos proveedores de materiales e insumos.

- Diversificación de nuestro público objetivo en todos los distritos de la ciudad de Lima.

- Desconocimiento del público de este tipo de tecnología y servicios.

- Surgimiento de competidores nacionales y extranjeros.

- Los clientes potenciales (público general) no considera un presupuesto adecuado para este tipo de producto/servicio

- Inseguridad ciudadana.

- La constante actualización de la tecnología

- Inestabilidad en la economía afectaría a nuestros clientes en el uso de nuestro de servicio.

Fuente: Elaboración Propia

\subsection{Estrategia de éxito (FODA cruzado).}

Nuestra estrategia a implementar en nuestro modelo de negocio será la diferenciación del servicio más la experiencia, para lo cual es necesario realizar las siguientes actividades: 
Tabla 3.3

FODA Cruzado

Estrategia ofensiva FO

(MAXI-MAXI)

- Promover el uso de la Impresión 3D en la vida cotidiana de las personas que tengan interés en el diseño y en la creatividad.

- Manejo de redes sociales para captar la demanda de estudiantes afines a la impresión 3D.

- Concentrarse en brindar siempre una experiencia única al cliente.

- Mantenerse siempre informado de los nuevos avances y tendencias de esta tecnología.

- Mantener un alto nivel de servicio y calidad.

- Desarrollar una presencia en eventos relacionados al diseño y la creatividad.

- Establecer alianzas con institutos y universidades.

\section{Estrategia defensiva FA}

\section{(MAXI-MINI)}

- Posicionar la marca con el concepto: "Acercamos la tecnología de impresión 3D a tu vida".

- Establecer alianzas estratégicas con proveedores.

- Desarrollar un plan de fidelización de clientes actuales y clientes potenciales.

- Desarrollar programas informativos para el público universitario y general con el fin de dar a conocer sus beneficios y aplicaciones.

- Lograr posicionamiento y participación en el mercado de impresión 3D como formato de entretenimiento a través de la innovación y diferenciación.

- Desarrollar estrategias de precios competitivos en el mercado interno.
Estrategia adaptativa DO

(MINI-MAXI)

- Alianza estratégica con proveedores de equipos y repuestos de impresión.

- Destacar la innovación del negocio en cada punto de la cadena de valor haciendo uso de las tecnologías.

- Diseñar una atractiva y amigable página web y contratar los servicios de un experto community manager.

Estrategia de supervivencia DA

(MINI-MINI)

- Diseñar e implementar nuevos productos y servicios (por ejemplo talleres) adaptados a las necesidades de los clientes.

- Venta de materia de prima (filamentos de impresión).

- Venta de Impresoras 3 y servicio técnico.

Fuente: Elaboración Propia 


\section{CAPÍTULO IV: PLAN DE MARKETING}

Como se ha mencionado en el desarrollo de los capítulos precedentes la herramienta de impresión 3D no es muy conocida en el público en general, en ese sentido el mercado potencial al que irá dirigido el negocio es muy amplio, aunque por su componente tecnológico, será el público objetivo comprendido entre las edades de 18 y 55 años.

Figura 4.1

Público Objetivo

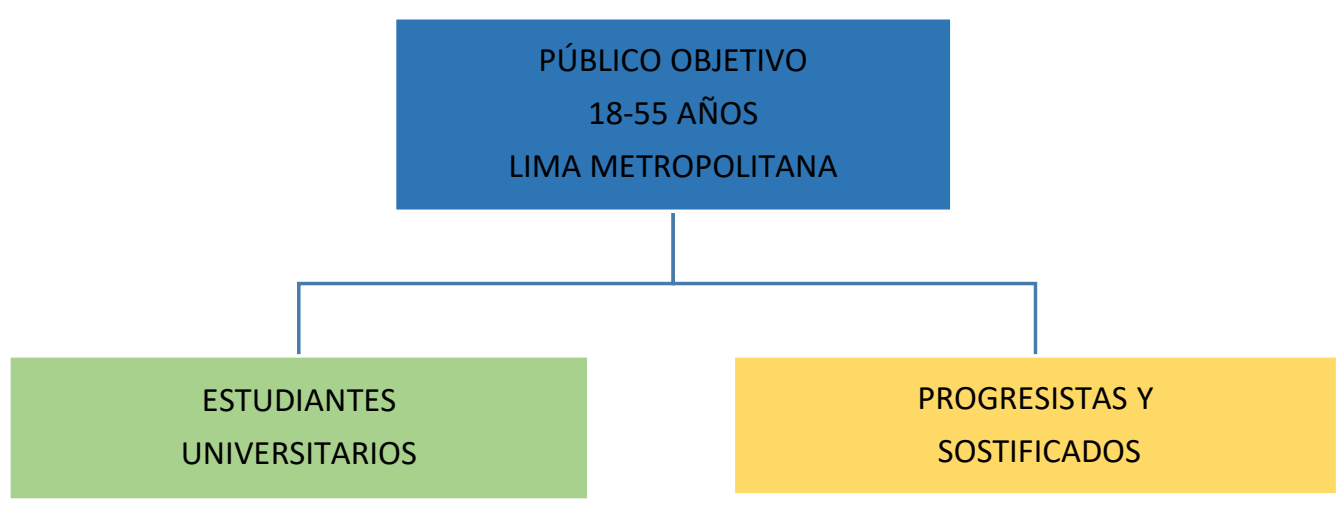

Fuente: Elaboración Propia apoyado en al análisis de los estilos de vida de Arellano. Año2017

\subsection{Mercado objetivo.}

Nuestro mercado objetivo se encuentra conformado por estudiantes de pregrado cuyas carreras se encuentran ligadas a la impresión 3D y las personas sofisticadas y progresistas (según los seis estilos de vida de Arellano) de la ciudad de Lima Metropolitana.

La tendencia refleja la demanda positiva de impresoras debido a su empleo cada vez en aumento en campos diversos como en la medicina, odontología, joyería, calzado, diseño industrial, arquitectura, ingeniería y construcción, automoción, sector aeroespacial, sistemas de información geográfica, ingeniería civil entre otros.

\subsubsection{Estudiantes de Pregrado}

El crecimiento de alumnos de pregrado de carreras afines a la impresión 3D muestra una tendencia positiva en la ciudad de Lima como evidencian datos estadísticos de la 
SUNEDU del 2014 -2016. Ellos constituyen parte importante de nuestra demanda y nos facilitará la difusión de nuestro concepto en las redes sociales.

Figura. 4.2

Alumnos en universidades de Lima de programas afines a la impresión 3D, 2014-2016.

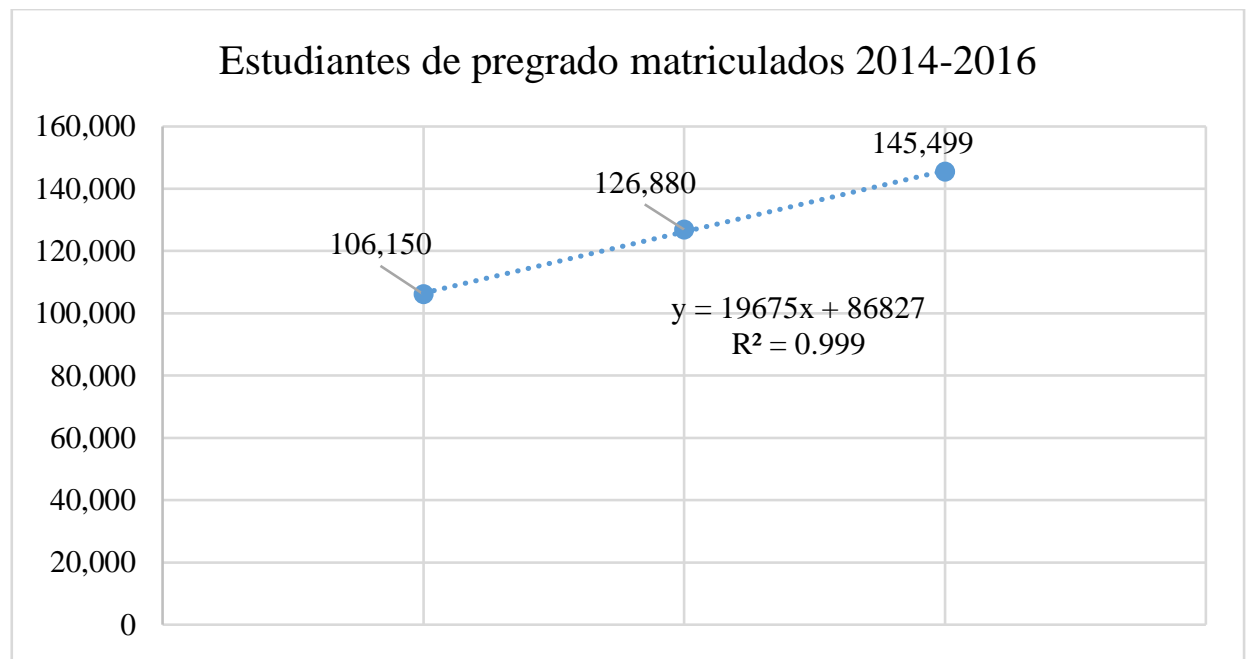

Fuente: Elaboración propia con información de la Superintendencia Nacional de Educación Superior Universitaria (SUNEDU)

Según las cifras indicadas en Fig. 4, hemos podido realizar una regresión lineal simple para proyectar dicha población, obteniendo los siguientes resultados:

Figura. 4.3

\section{Población}

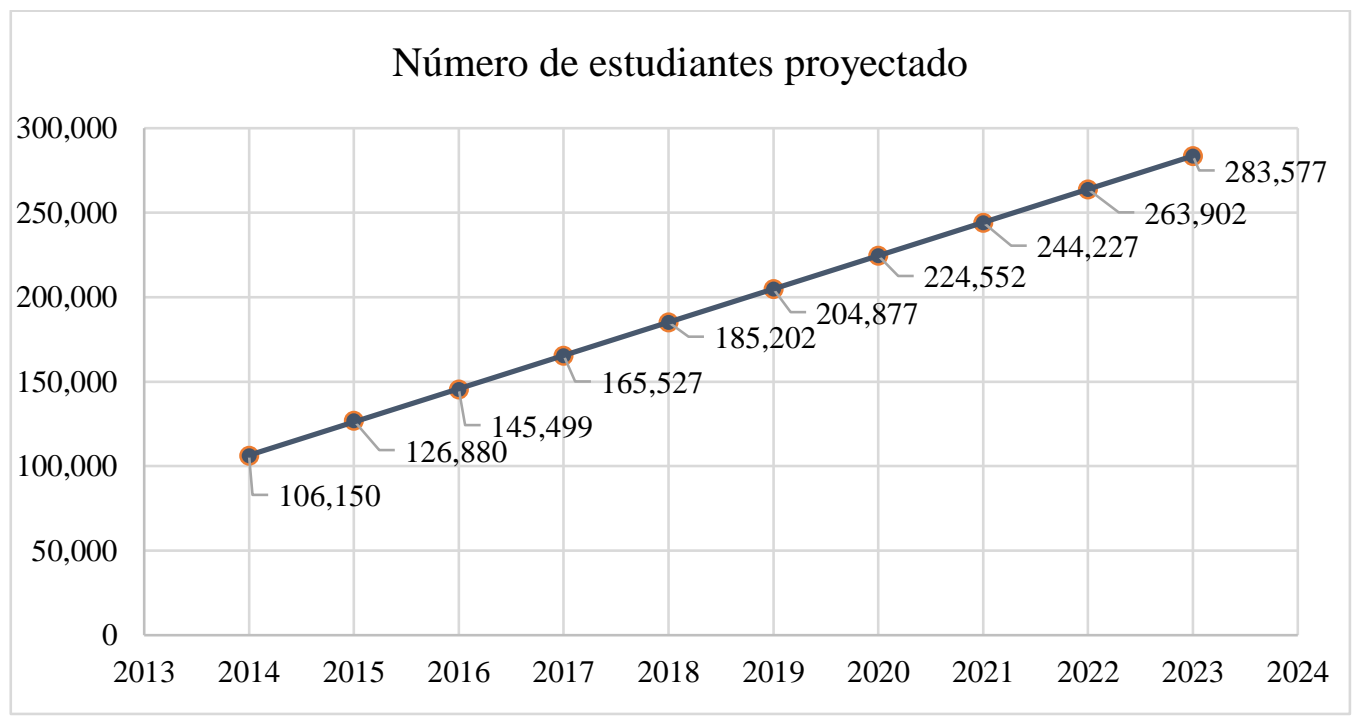

Fuente: Elaboración propia. 
Es importante mencionar que se consideraron solamente los siguientes programas:

- Arquitectura

- Diseño Gráfico e Industrial

- Ingeniería Civil

- Ingeniería Electrónica

- Ingeniería Industrial

- Ingeniería Mecánica

- Ingeniería Mecatrónica

Asimismo, las universidades consideradas para este estudio son:

- Pontifica Universidad Católica.

- Universidad Alas Peruanas.

- Universidad de Ingeniería y Tecnología.

- Universidad de Lima.

- Universidad Nacional de Ingeniería.

- Universidad Nacional Mayor de San Marcos.

- Universidad Peruana de Ciencias Aplicadas.

- Universidad Peruana de Ciencias e Informática.

- Universidad Privada del Norte.

- Universidad Científica del Sur.

- Universidad Continental.

- Universidad San Martín de Porres.

- Universidad Privada César Vallejo.

- Universidad Privada San Ignacio de Loyola.

- Universidad Ricardo Palma.

- Universidad Tecnológica del Perú. 


\subsubsection{Público en general.}

Para determinar el público general del presente proyecto consideramos un estudio realizado por Compañía Peruana de Estudios de Mercado y Opinión Pública (Market Repot de Agosto 2017), el cual nos permite determinar la población de Lima Metropolitana entre 18 y 55 años de edad de los niveles socioeconómicos (NSE) A, B y C.

\section{Tabla 4.1}

Población de Lima Metropolitana entre 18 y 55 años

\begin{tabular}{lrrrrrrr}
\hline \multicolumn{1}{c}{ Años } & Hogares Mls & \multicolumn{1}{c}{$\%$} & Población Mls & \multicolumn{1}{c}{$\%$} & $18-24$ & $25-39$ & \multicolumn{1}{c}{$40-55$} \\
\hline A/B & 751.5 & 27.5 & $2,698.70$ & 26.5 & 297.7 & 606.8 & 597.2 \\
C & $1,106.80$ & 40.5 & $4,334.70$ & 42.4 & 552.8 & 1061.2 & 876.9 \\
D & 664 & 24.3 & $2,430.20$ & 23.8 & 370.6 & 645.8 & 400.5 \\
E & 210.4 & 7.7 & 745.7 & 7.3 & 105.5 & 178.5 & 92.00 \\
TOTAL & $\mathbf{2 , 7 3 2 . 7 0}$ & $\mathbf{1 0 0}$ & $\mathbf{1 0 , 2 0 9 . 3 0}$ & $\mathbf{1 0 0}$ & $\mathbf{1 , 3 2 6 . 6 0}$ & $\mathbf{2 , 4 9 2 . 3 0}$ & $\mathbf{1 , 9 6 6 . 6 0}$ \\
\hline
\end{tabular}

Fuente: CPI Market Repot de agosto 2017.

A su vez, dicho estudio nos permite determinar la compatibilidad del negocio por zonas geográficas Z1, Z2 y Z3 la población según NSE A, B y C en donde se deberá encontrar nuestro público compatible con el presente proyecto y con la ubicación geográfica de nuestro proyecto de negocio.

Tabla 4.2

Análisis por zonas geográficas y en \% según el nivel socioeconómico.

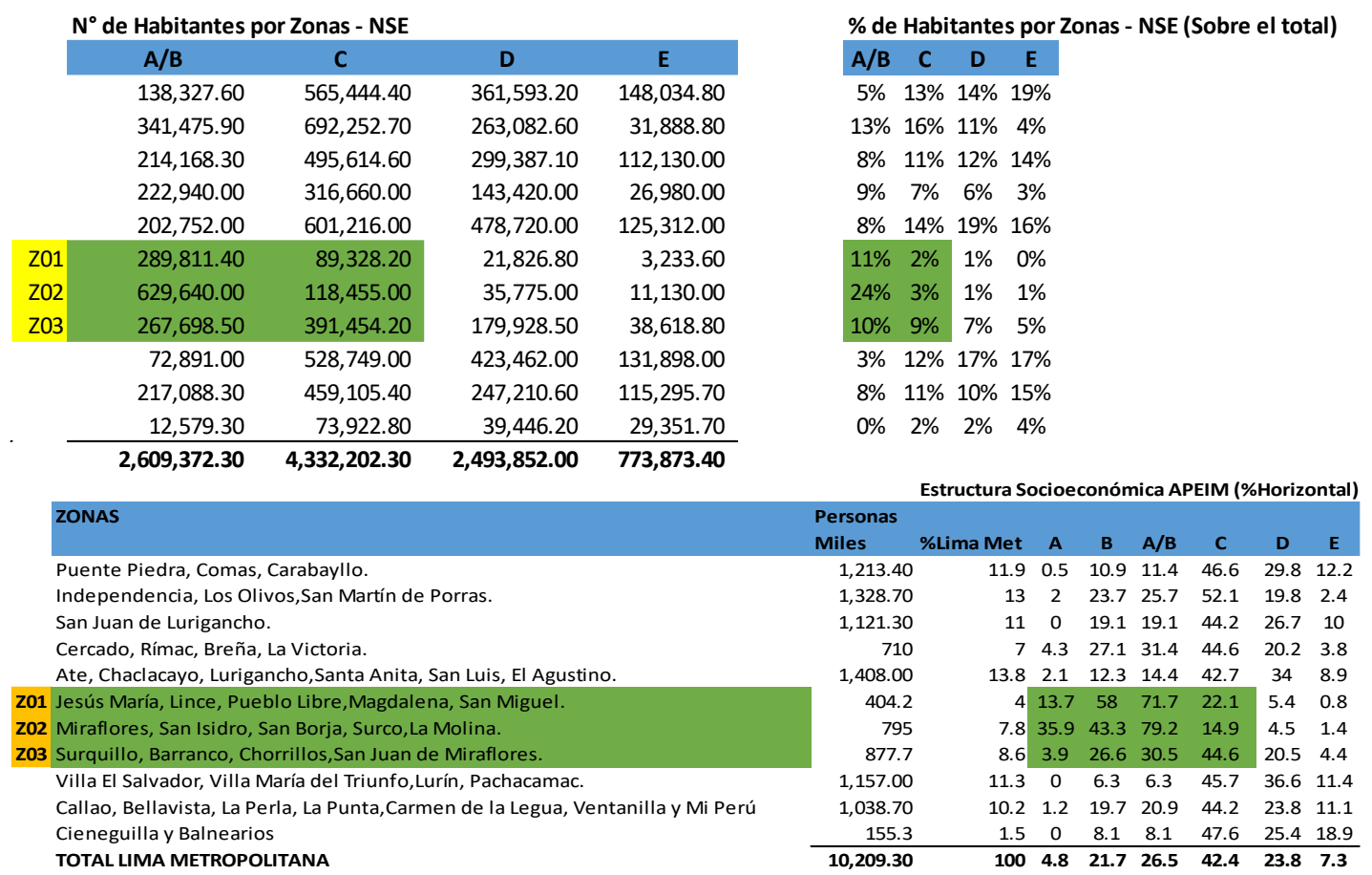

Fuente: CPI Market Repot de Agosto 2017. 
Del cuadro precedente se obtuvo el número de 289,811.40 habitantes de la ZO1 del NSE A y B multiplicando el porcentaje de $71.7 \%$ x 404.2 expresado en miles de personas, el mismo procedimiento se realizó para obtener la cantidad de población del NSE A/B de las zonas Z02 y Z03 y del NSE C.

Asimismo para obtener el porcentaje de habitantes por zonas y por NSE se dividió el número de habitantes por zonas y NSE entre el total de habitantes de cada NSE, como por ejemplo para la ZO1 y NSE A y B: 289,811.40 / 2`609,372.30 = 11\%, el mismo procedimiento se realizó para obtener el porcentaje de los otros NSE y zonas geográficas.

Para encontrar la población por zonas y NSE (ver Tabla 5) multiplicamos el porcentaje obtenido del cálculo anterior por el total de la población de habitantes encontrados del NSE respectivo. Por ejemplo, la población del nivel A/B es de 2,698.70 x $11 \%=299.73$ (expresado en miles) para la ZO1 y nivel A/B, el mismo procedimiento se realizó para obtener el número de habitantes de los otros NSE y zonas geográficas.

Obtenemos el porcentaje de población del NSE A y B entre 18 y 55 años dividiendo el total de la población dentro de este rango entre el total de la población del nivel A y B. Por ejemplo según datos de la Tabla 3: $(297.7+606.8+597.2) / 2,698.70=$ $56 \%$. El mismo procedimiento se realizó para obtener el porcentaje del NSE C. (57\%)

Finalmente se procedió a multiplicar el porcentaje obtenido por el total de personas de cada NSE y de cada zona, lo cual nos permitió obtener nuestra muestra de 1’027,753.02 que son las personas entre 18 y 55 años de edad de los niveles socioeconómicos A/B y C de las zonas 01, 02 y 03 de la ciudad de Lima Metropolitana.

Tabla 4.3

Población de nivel socioeconómico A.B y C entre 18 y 25 años

\begin{tabular}{|lrrrrcccr|}
\hline NSE & Hogares Mls & $\%$ & Población Mls & \multicolumn{1}{c}{ Z01 } & Z02 & Z03 & 18-55 & Pob.General \\
\hline A/B & 751.5 & 27.5 & $2,698.70$ & 299.73 & 651.19 & 276.86 & $56 \%$ & $683,207.61$ \\
C & $1,106.80$ & 40.5 & $4,334.70$ & 89.38 & 118.52 & 391.68 & $57 \%$ & $344,545.42$ \\
\hline D & 664 & 24.3 & $2,430.20$ & & & & & $1,027,753.02$ \\
E & 210.4 & 7.7 & 745.7 & & & & & \\
\hline TOTAL & $\mathbf{2 , 7 3 2 . 7 0}$ & 100 & $10,209.30$ & & & & & \\
\hline
\end{tabular}

Fuente: Elaboración Propia

Tomando una tasa de crecimiento de $1.42 \%$ anual según INEI (Estimaciones y Proyecciones de Población por Departamentos Octubre 2009) y restando el mercado 
potencial de estudiantes obtenemos nuestro mercado potencial de personas entre 18 y 55 años de Lima Metropolitana.

Tabla 4.4

Mercado potencial de personas entre 18 y 55 años

\begin{tabular}{lrrrrr}
\hline \multicolumn{1}{c}{ Años } & $\mathbf{2 0 1 9}$ & $\mathbf{2 0 2 0}$ & $\mathbf{2 0 2 1}$ & $\mathbf{2 0 2 2}$ & $\mathbf{2 0 2 3}$ \\
\hline Población & $1,057,148$ & $1,072,160$ & $1,087,385$ & $1,102,825$ & $1,118,486$ \\
Estudiantes & 204,877 & 224,552 & 244,227 & 263,902 & 283,577 \\
Mercado Potencial & 852,271 & 847,608 & 843,158 & 838,923 & 834,909 \\
\hline
\end{tabular}

Fuente: Elaboración Propia

\section{Utilidad de los estilos de vida de Arellano}

En el presente trabajo hemos considerado los estilos de los sofisticados y progresistas apoyados en el estudio realizado por Arellano Marketing, en el cual se clasifica la población Latinoamericana en función de seis estilos de vida. (Arellano Marketing, 2014). Esta información es útil ya que nos brinda un factor adicional del $30 \%$ (suma de progresistas: $24 \%$ y sofisticados: $6 \%$ de la ciudad de Lima) que al multiplicarlo nos permitirá afinar un poco más nuestro mercado disponible, el cual está desarrollado en el capítulo 7.2 Estimación de la demanda.

\subsubsection{Los Sofisticados (afortunados)}

Segmento mixto, con un nivel de ingreso más alto que el promedio. Son muy modernos, educados, liberales, cosmopolitas y valoran mucho la imagen personal. Son innovadores en el consumo, y también son cazadores de tendencias. Les importa mucho su estatus, siguen la moda y son asiduos consumidores de productos "light". En su mayoría son más jóvenes que el promedio de la población.

\subsubsection{Los progresistas}

Hombres que buscan permanentemente el progreso personal o familiar. Aunque están en todos los niveles socioeconómicos, en su mayoría son obreros y empresarios emprendedores (formales e informales). Los mueve el deseo de revertir su situación y avanzar, y están siempre en busca de oportunidades. Son extremadamente prácticos y modernos, tienden a estudiar carreras cortas para salir a producir lo antes posible. 
En el cuadro siguiente podemos apreciar la distribución de los diferentes estilos de vida por ciudades del Perú según estudio de Arellano del 2011.

Figura 4.4

Perfiles de los estilos de vida

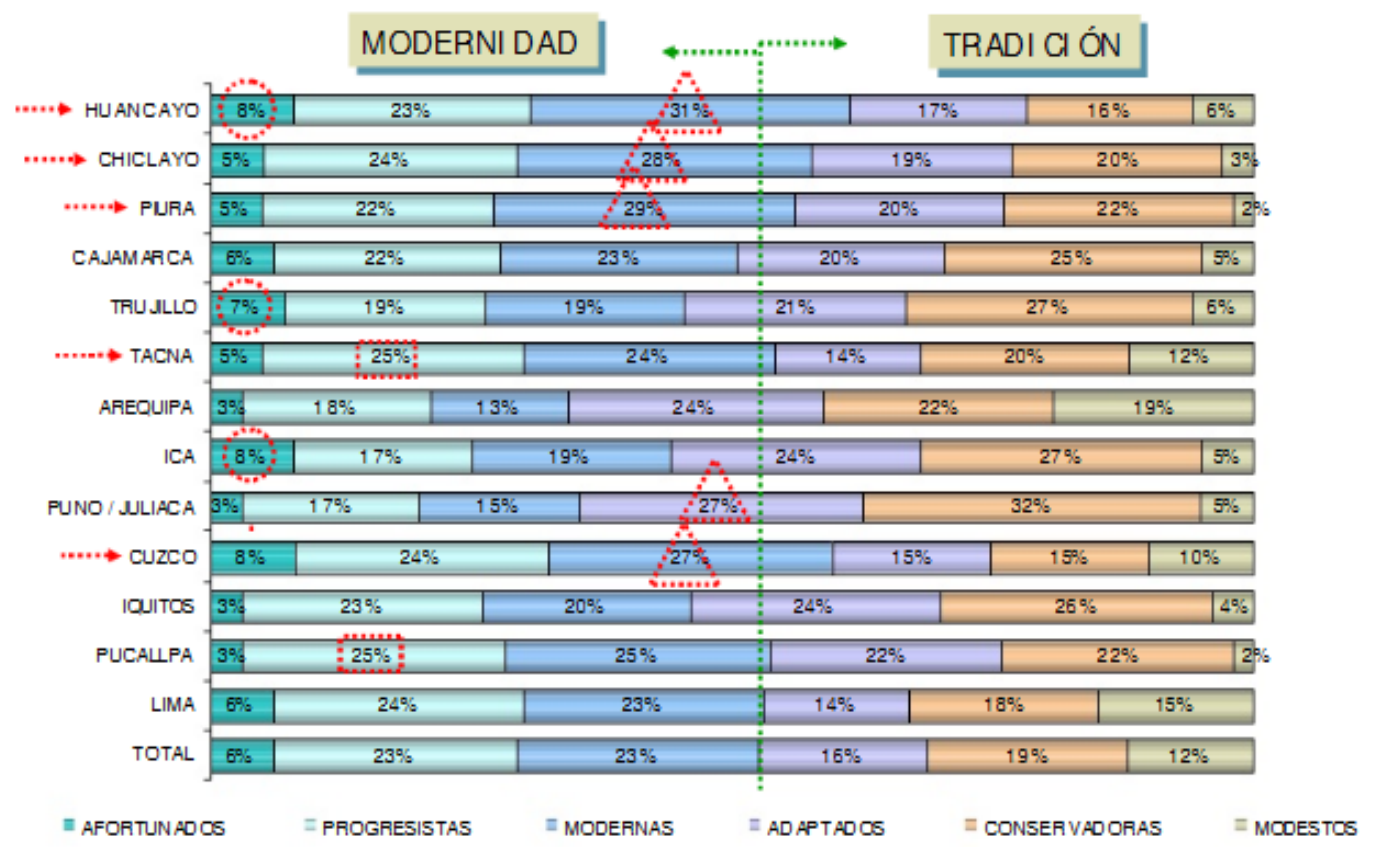

Fuente: Estilos de vida de Arellano del 2011.

\subsection{Servicio}

Todo esto nos lleva a ofrecer nuestro modelo de negocio hacia dos tipos de clientes: los estudiantes de pregrado que como se ha comentado están bien informados del concepto de impresión 3D y el público en general (Progresistas y Sofisticados), que desea conocer y experimentar con la impresión 3D en un lugar con ambiente creativo e innovador.

Para lo cual aplicaremos el Customer Journey Map de nuestro local, esta herramienta consiste en monitorear el comportamiento, detectar necesidades y problemas que tienen los clientes a través de los puntos de contacto durante el proceso del servicio, el cual nos servirá para mejorar nuestros procesos e identificar oportunidades de mejoras. 
Figura 4.5

Customer Journey Map de nuestro local

\begin{tabular}{|c|c|c|c|c|c|c|c|c|}
\hline & ESTUDIANTES & $\begin{array}{l}\text { PÚBLICO EN } \\
\text { GENERAL }\end{array}$ & \multicolumn{6}{|c|}{ ESTUDIANTES Y PÚBLICO EN GENERAL } \\
\hline $\begin{array}{l}\text { ¿Cuando? } \\
\text { momento }\end{array}$ & $\begin{array}{l}\text { Necesidad de } \\
\text { impresión 3d }\end{array}$ & $\begin{array}{l}\text { Curiosidad } \\
\text { sobre la } \\
\text { impresión 3d }\end{array}$ & $\begin{array}{l}\text { Ingreso al } \\
\text { local }\end{array}$ & $\begin{array}{c}\text { Recepció } \\
\text { n del } \\
\text { trabajo }\end{array}$ & $\begin{array}{l}\text { Asesoría de } \\
\text { diseño e } \\
\text { impresión }\end{array}$ & $\begin{array}{l}\text { Necesidad } \\
\text { del servicio } \\
\text { de cafetería }\end{array}$ & $\begin{array}{c}\text { Pago del } \\
\text { servicio y } \\
\text { entrega del } \\
\text { producto }\end{array}$ & $\begin{array}{l}\text { Post } \\
\text { venta }\end{array}$ \\
\hline $\begin{array}{l}\text { Puntos de } \\
\text { contacto }\end{array}$ & $\begin{array}{l}\text { Recomendación } \\
\text { de conocidos, } \\
\text { pagina web y } \\
\text { redes sociales }\end{array}$ & $\begin{array}{l}\text { Local, } \\
\text { recomendación } \\
\text { de conocidos, } \\
\text { redes sociales }\end{array}$ & $\begin{array}{l}\text { Asesores y } \\
\text { ambiente } \\
\text { interno del } \\
\text { local }\end{array}$ & Asesores & Ase & Barista & Ase & $\begin{array}{c}\text { Asesores, } \\
\text { pagina } \\
\text { web, } \\
\text { redes } \\
\text { sociales }\end{array}$ \\
\hline $\begin{array}{l}\text { Expectativ } \\
\text { a } \\
\text { ¿Qué es lo } \\
\text { que } \\
\text { espero? }\end{array}$ & $\begin{array}{c}\text { Buenas } \\
\text { recomendaciones, } \\
\text { opiniones } \\
\text { favorables del } \\
\text { servicio y buen } \\
\text { diseño de la } \\
\text { página web }\end{array}$ & $\begin{array}{c}\text { Buena } \\
\text { presentación } \\
\text { externa del } \\
\text { local y diseño } \\
\text { de la página } \\
\text { web }\end{array}$ & $\begin{array}{l}\text { Cálida } \\
\text { bienvenida, } \\
\text { rapidez en la } \\
\text { atención e } \\
\text { información }\end{array}$ & $\begin{array}{l}\text { Eficiente } \\
\text { atención } \\
\text { y empatía }\end{array}$ & $\begin{array}{c}\text { Explicació } \\
\text { n clara }\end{array}$ & $\begin{array}{l}\text { Cordial } \\
\text { atención }\end{array}$ & $\begin{array}{c}\text { Producto } \\
\text { de calidad } \\
\text { y en el } \\
\text { tiempo } \\
\text { prometido }\end{array}$ & $\begin{array}{c}\text { Buenas } \\
\text { recomend } \\
\text { aciones, } \\
\text { opiniones } \\
\text { favorable } \\
\text { s del } \\
\text { servicio }\end{array}$ \\
\hline
\end{tabular}

Fuente: Elaboración propia

Los estudiantes vendrán a buscar nuestro servicio porque existe una demanda insatisfecha en tal sentido nos haremos conocidos por ofrecer un nuevo servicio de impresión 3D. Y por otro lado divulgaremos nuestro concepto dentro del público en general como un lugar diferente en donde tomar un café te pueda permitir crear algo único y diferente.

Figura 4.6

Tendencia de la demanda de impresión 3D

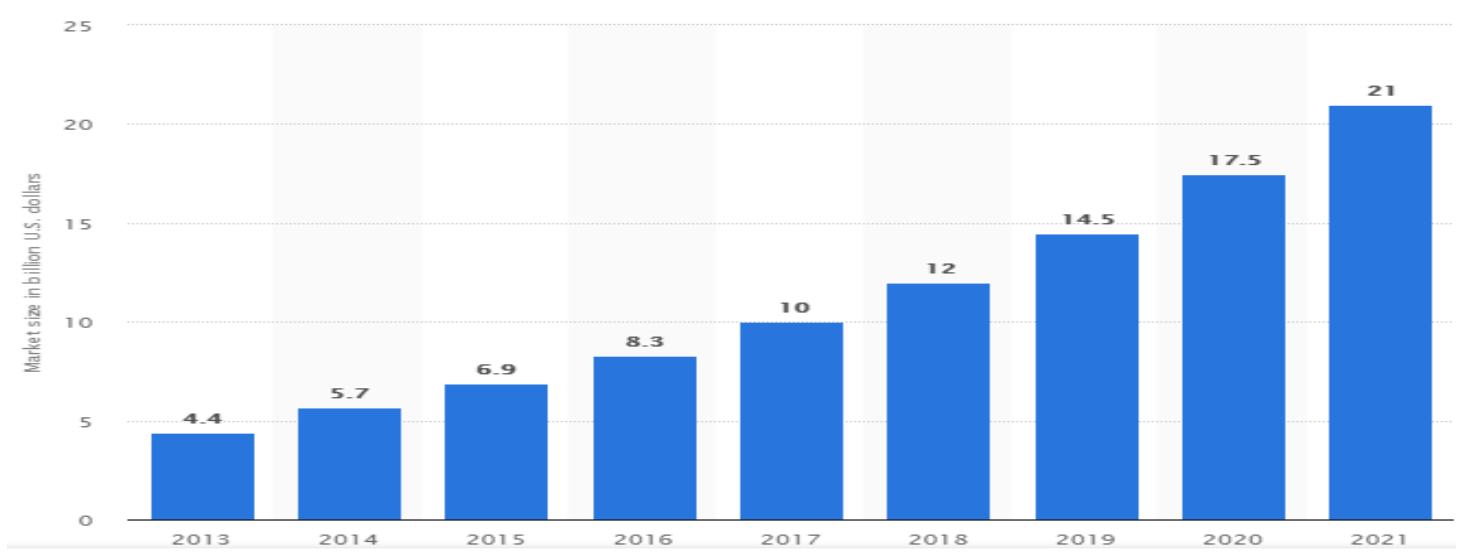

Fuente: Citi Research; University of Oxford; CBRE Group; Consumer Technology Association; UPS August 2017

La tendencia refleja la demanda positiva de impresoras debido a su empleo cada vez en aumento en campos diversos como en la medicina, odontología, joyería, calzado, 
diseño industrial, arquitectura, ingeniería y construcción, automoción, sector aeroespacial, sistemas de información geográfica, ingeniería civil entre otros.

El servicio principal que la empresa va a llevar a cabo consistirá en la impresión tridimensional de objetos. Ésta se llevará a cabo en impresoras semiprofesionales.

En este sentido podemos encontrarnos varios tipos de clientes para los que habrá que disponer de distintos servicios:

- Aquel que dispone físicamente del objeto que quiere replicar: En este caso dispondremos de escáneres manuales los cuales permitirán "trasladar" el objeto a un software de diseño y luego a la impresora. En este caso el servicio consistirá en escaneo más impresión.

- Aquel que tiene una idea de un objeto que pretende imprimir. Tendremos dos soluciones en función de lo avanzada que esté dicha idea:

- La idea está diseñada y listo para impresión: El servicio consistirá en la impresión del objeto.

- El cliente tiene la idea, pero necesita diseñarla: Nuestro equipo de asesores se encargará de su diseño. En este caso el servicio será diseño más impresión.

A su vez se ofrecerá la venta de bebidas y otros propios de un local de cafetería, todo esto dentro de un ambiente que brinde al cliente toda una experiencia de creatividad y de innovación.

\subsection{Precio}

Nuestro precio de venta será de S/ 1.80 soles por gramo de material de impresión utilizado. Este precio se ha obtenido considerando el peso de material usado ya que es fácilmente calculable a través del software de nuestras impresoras, el cual permite demostrar de manera sencilla la información del costo total del producto a nuestros clientes. Nuestro precio se mantiene dentro del rango de precios que varía entre $1.20 \mathrm{y}$ 1.90 soles por gramo de aquellas empresas locales que solo se dedican a dar el servicio de impresión, de acuerdo al detalle siguiente: 
Figura 4.7

Precios del mercado de impresión 3D

\begin{tabular}{|l|c|}
\multicolumn{1}{|c|}{ Empresa } & Precio sol/gr \\
\hline Skulp 3D & 1.40 \\
\hline Crear 4D & 1.90 \\
\hline FAB LAB PUCP & 1.20 \\
\hline Impresiones 3D & 1.90 \\
\hline REY & Sin Respuesta \\
\hline Desarrollo 3D & Sin respuesta \\
\hline FAB LAB TECSUP & Sin respuesta \\
\hline
\end{tabular}

Fuente: Elaboración propia

Asimismo, respecto al precio del servicio de asesoría y/o escaneado será de S/. 20.00 la hora. Durante los servicios de impresión 3D, es normal que se produzcan algunos trabajos fallidos debido a factores externos, los cuales serán asumidos por la empresa como parte de nuestro proceso de aprendizaje.

\subsection{Distribución}

El servicio de impresión 3D se realizará en nuestro local, donde se entregaran todos los trabajos de impresión 3D, con la finalidad de implementar nuestra estrategia de brindar una experiencia única al cliente y en forma paralela impulsar las ventas de la cafetería. Sin embargo, se usará nuestra página web para la recepción de trabajos online, con la finalidad de dar facilidades a nuestros clientes, a través de la cual se responderán a dichos requerimientos mediante una cotización. Todo servicio de impresión 3D se realizará previa cancelación total de la cotización, ya sea de manera online o presencial.

\subsection{Publicidad y promoción}

Para el desarrollo de este punto se emplea la técnica de las $6 \mathrm{M}$ de la comunicación con la finalidad de hacer una campaña integral que considere principalmente las necesidades de nuestro público objetivo.

- Misión: Nuestro plan de comunicación debe lograr que nuestra marca (servicio diferenciado de impresión 3D) sea difundida con la finalidad de ganar participación en el mercado e incrementar el volumen de ventas. 
- Mercado: Está definido por los estudiantes afines a la impresión 3D y el público general.

- Mensaje: Debe ser muy creativo, claro y preciso de lo que se quiere comunicar según nuestros dos públicos objetivo sobre el concepto y los beneficios de la impresión 3D. Este mensaje debe hacer referencia a lo que nosotros queremos ofrecer: un espacio donde uno pueda hacer impresiones 3D dentro de un ambiente donde fluya la creatividad y el co-working.

- Medios: Se utilizaran los medios personales como las recomendaciones de clientes, de profesionales, nuestros asesores como fuerza de ventas, correos, cupones de descuento, volantes y medios masivos como revistas, ferias especializadas, SEO (search engine optimización) y redes sociales.

- Moneda: El presupuesto destinado para nuestra campaña de promoción es de 36,000 mil soles al año, que cubrirán las actividades indicadas en el párrafo anterior.

- Medida: la evaluación de la campaña se verá reflejado en el incremento de nuestras ventas, número de visitas en la página web, participación de mercado.

Para llegar a nuestro público objetivo contaremos con un community manager quien nos implementará nuestra página web y realizará la actividad de difundir nuestro negocio a través del uso intensivo de las principales redes sociales (Facebook, YouTube, WhatsApp, Instagram, Influencers, etc). Se proporcionara incentivos a los clientes para crear lealtad a la marca como por ejemplo tarjeta del cliente frecuente, cupones de descuento. Es importante hacerle saber al cliente la importancia de sus experiencias y de que la empresa está pendiente de su satisfacción: ¿están satisfechos con el servicio?, ¿los productos cubrieron las expectativas? Es importante darnos a conocer como negocio que emplea insumos que son comprados a distribuidores que operan bajo altos parámetros de calidad, con lo cual se espera que nuestros clientes obtengan una gratificante experiencia de servicio y esto sea nuestro mejor marketing para garantizar que nos recuerden y recomienden, pues un cliente satisfecho es un multiplicador muy potente en las redes sociales como por ejemplo el efecto rebote de un comentario positivo de algunos líderes de opinión. 
En el corto plazo se contactará con algunos estudios de arquitectura/ingeniería para ofrecer nuestros servicios, así como también a Universidades y Centros de Enseñanza con la finalidad de dar a conocer nuestra marca.

Otro de los segmentos a los que se podría ofrecer nuestro servicio será los centros de Ortopedias a las que se visitarán y entregaremos información del servicio de impresión y la aplicación de esta tecnología en el ámbito de prótesis. 


\section{CAPÍTULO V: PLAN DE OPERACIONES}

Queremos ser un establecimiento reconocido por brindar un buen servicio al cliente con la entrega de productos de calidad con una excepcional infraestructura, lo que permitirá que nuestra marca logre posicionarse en Lima metropolitana.

En el futuro expandiremos nuestro local hacia algunas provincias del territorio nacional, dándonos a conocer como un establecimiento generador de empleo que brinda una alternativa diferente a los jóvenes estudiantes y profesionales al ofrecer servicios innovadores. Nos comprometemos a:

- Brindar un ambiente cálido y confortable a nuestros clientes.

- Dar a nuestra comunidad un espacio que estimule la creatividad y la innovación.

- Atender adecuadamente a cada uno de los clientes.

- Brindar servicios de excelente calidad, respetando el medio ambiente.

\subsection{Políticas Operacionales}

\subsubsection{Calidad.}

Tenemos que diferenciarnos del resto por el nivel de servicio ofrecido al cliente. Nuestro servicio se sustenta en brindar la mejor calidad posible para trabajos de nivel básico e intermedio. Esto implica contar con buenos equipos de impresión, desktops, software y monitores adecuados para realizar un buen trabajo de diseño y creación. Asimismo, en cuanto a los insumos y materia prima utilizados en la cafetería, seleccionaremos a nuestros proveedores con capacidad de garantizar la inocuidad de los alimentos, poniendo énfasis especialmente en los granos de café.

Los asesores de diseño y creación contarán con una constante actualización de los programas y técnicas de impresión a fin de proporcionar un correcto asesoramiento en los proyectos de impresión y diseño. En cuanto a la elaboración y la atención de productos alimenticios se tendrán un constante cuidado en todas las fases de la preparación de los alimentos. 


\subsubsection{Proceso.}

El proceso se centrará en diseño, escaneo e impresión 3D de productos de complejidad básica a intermedia con material acrilonitrilo butadieno estireno (ABS) o poliácido láctico (PLA) No podremos realizar impresiones complejas debido al alto costo de inversión de estos equipos. Por ejemplo, una impresora industrial de alta gama podría costar USD 350,000. Asimismo estamos considerando un promedio de tiempo de impresión 2.40 horas por producto, tal como está detallado en el cálculo del punto de equilibrio. Para este proceso se ha identificado el cuello de botella en las horas uso de impresoras y horas de asesoría.

La técnica más empleada es el modelado de deposición fundida (o FDM por sus siglas en inglés) que emplea un filamento de plástico (ABS o PLA) que pasa por una boquilla que calienta el material a $200{ }^{\circ} \mathrm{C}$. La boquilla se desplaza, de acuerdo con la trayectoria previamente programada, hacia adelante, atrás o los lados, y deposita el material en una plataforma. La boquilla se eleva y capa por capa se va conformando la pieza. En nuestro negocio utilizaremos $\mathrm{ABS}$ que es un termoplástico derivado del petróleo y PLA material que se obtiene a partir de productos naturales como el almidón del maíz o la caña de azúcar, en razón que es biodegradable y no emite gases tóxicos durante la impresión.

\subsubsection{Planificación.}

En esta fase vamos a establecer el equipo de trabajo encargado de determinar todas las actividades que realizaremos durante la implementación de nuestro modelo de negocio, definiendo con el máximo detalle posible las tareas a realizar y los recursos necesarios para llevar a buen término el proyecto.

Una vez que nuestro proyecto sea aprobado se plasmara en un contrato, estableciendo en las clausulas las responsabilidades y beneficios de cada uno de los socios.

Las actividades que se tienen que desarrollar para poner en ejecución nuestro proyecto de negocio han sido plasmadas en un diagrama de Gantt, herramienta que nos permitirá planificar y programar cada una de las actividades, así como también realizar el seguimiento y control del progreso de cada una de estas, determinado las siguientes: 
- Alquiler de local

- Adquisición de equipos

- Adquisición de insumos

- Remodelación del local

- Contratación y capacitación de personal

- Gestión de permisos y licencias

- Creación de página web y uso de redes sociales

\subsubsection{Inventarios.}

Los insumos o materia prima necesarios para la implementación y poner en marcha nuestro proyecto de negocio se divide en dos ramas muy diferenciadas: insumos para la impresión 3D e insumos para la cafetería. Sin embargo, debido a la facilidad de poderlos conseguir, no justifica el tener un volumen elevado en inventarios. Por lo que es importante contar con una base de datos que nos permita conocer con exactitud los consumos diarios, semanales o mensuales a fin de disponer de un stock mínimo adecuado que nos permita una constante atención de acuerdo al detalle siguiente:

* Artículos para impresión 3D (stock de tres meses)

- Carrete de filamento de PLA de 12 colores

- Carrete de filamento de ABS de 12 colores

- Pinturas acrílicas

- Extrusores

Artículos para la cafetería

- Café

- Leche evaporada y en polvo

- Azúcar y edulcorantes

- Chocolate

- $\quad$ Pulpa de fruta

- Agua

- Gaseosas

- Sándwiches

- Empanadas

- Postres 


\subsection{Equipos, actividades y procesos.}

En el funcionamiento del negocio se tendrán que adquirir los equipos necesarios, realizando un estudio de mercado que nos permita obtener y adquirir la mejor tecnología acorde con los estándares de calidad que requerimos para brindar un excelente servicio a nuestros clientes y minimizar los costos de nuestro proyecto. Los equipos a adquirir se detallan a continuación:

\subsubsection{Equipo}

\subsubsection{Equipo para impresión 3D}

Para la selección de los artículos que componen el proceso de impresión se ha tenido en cuenta aquellas características que nos permitirán responder a la demanda de nuestros clientes, teniendo en consideración el precio versus la calidad y velocidad de impresión. Para lo cual se requiere los artículos siguientes:

- Impresoras Zortrax M200. Esta impresora cuenta con un extrusor de diseño propio, base calefectada para impresión con ABS y PLA. Además, dispone de sistema de autocalibrado, para asegurar un perfecto nivelado de la superficie de impresión. Se caracteriza por poder imprimir un volumen de impresión 200 x 200 x 180 mm.

- Impresoras Zortrax M300. Esta impresora es la hermana mayor de la Zortrax M200, es una de las impresoras 3D más populares y muy fácil de operar. Se caracteriza por poder imprimir un volumen de 300 x 300 x $300 \mathrm{~mm}$ y por incluir de serie las cubiertas laterales para mantener la temperatura interna de la impresora, permite realizar proyectos pequeños con excelente precisión.

- 3D Scanner Pro XYZ.

- Computadoras para diseño 3D tipo Work Stations.

- $\quad$ Software de diseño.

- $\quad$ Monitores.

\subsubsection{Equipo para la cafetería}

- Máquina de café. 
- Refrigeradora.

- Parrilla eléctrica.

- Microondas.

- Licuadora industrial.

- Congeladora exhibidora.

- $\quad$ Set de menaje y utensilios de cocina.

\subsubsection{Equipo de oficina y mobiliario del local}

- Equipos de cómputo.

- Televisores.

- $\quad$ Equipo de sonido.

- Escritorio.

- Impresora oficina.

- Caja registradora.

- Mesas.

- Sillas.

- Cámaras de vigilancia.

\subsubsection{Diseño y capacidad de Instalaciones.}

La ubicación del negocio será seleccionada estratégicamente a fin de poder satisfacer las exigencias o requerimientos de los clientes, para lo cual es necesaria un área promedio de $100 \mathrm{~m}^{2}$. Este local será arrendado mensualmente y se ambientara para brindar una atmosfera de creación e innovación, en ese sentido es necesario una decoración e iluminación adecuada.

El local deberá estar divido en dos partes:

- Una zona dedicada para la inspiración, creación e impresión 3D.

- Una zona de cafetería la cual se encuentra característicamente ambientada, donde los clientes puedan degustar un excelente café o de la variedad de bebidas y snacks que ofrecemos, el cual puede ser junto a la barra o sentados en mesas debidamente acondicionadas y con envases ecológicos que disminuyan el riesgo que el líquido puede derramarse y dañar los equipos de cómputo. 


\subsubsection{Macro Localización}

En lo que respecta a la macro localización, nuestro negocio 3D LAB \& CAFÉ estará ubicado en el Perú en el departamento y provincia de Lima.

\subsubsection{Micro Localización (ubicación del local)}

Para el desarrollo del estudio de micro localización se ha utilizado el método Brown y Gibson, que combina factores objetivos posibles de cuantificar con factores subjetivos que se pueden valorar en términos relativos. La aplicación de este enfoque se inicia con una etapa inicial de eliminación de todas aquellas alternativas que no cumplen con los requisitos mínimos exigidos a la localización del proyecto.

Este proceso consta de las cuatro siguientes etapas:

- Asignar un valor relativo a cada factor objetivo (FO), para cada localización optativa viable.

- Estimar un valor relativo de cada factor subjetivo (FS), para cada localización optativa viable.

- Combinar los factores objetivos y subjetivos, asignándoles una ponderación relativa, para obtener una medida de preferencia de localización (MPL).

- Seleccionar la ubicación que tenga la máxima medida de preferencia de localización.

La evaluación se ha realizado en cinco distritos de Lima teniendo en consideración los factores cualitativos y cuantitativos, en base al estudio de mercado de acuerdo al detalle siguiente:

- Santiago de Surco.

- San Borja.

- $\quad$ Miraflores.

- San Luis.

- $\quad$ San Isidro.

Desarrollando el mencionado método se ha tomado en consideración los siguientes factores: 
a. Factores Cualitativos:

- Disponibilidad. - Que cumpla los estándares requeridos como área de $100 \mathrm{M} 2$, cuente con estacionamientos adyacentes al local, que sea en esquina y que los transeúntes puedan visualizar el interior del local.

- Ubicación. - Que se encuentre cerca de universidades, en avenidas principales de alto tránsito, movimiento comercial.

- Seguridad. - Que se encuentre en zonas estratégicas tenga un alto índice de seguridad ciudadana.

- Competencia. - Que en el área del negocio haya una mínima presencia de negocios similares en impresión 3D y servicio de cafetería.

- Transporte. -Que la ubicación del negocio cuente con ciclo vías cercanas y con accesibilidad a líneas de transporte público.

b. Factor Cuantitativo:

El costo del $\mathrm{m}^{2}$ en alquiler

El primer paso es asignar el valor relativo al factor objetivo mediante la siguiente formula:

$$
F O_{i}=\frac{\frac{1}{C t_{i}}}{\sum_{i=1}^{n} \frac{1}{C t_{i}}}
$$

$\mathrm{Ci}=$ Costo por $\mathrm{m}^{2}$

Tabla 5.1

Factor Objetivo

\begin{tabular}{l|rrr}
\hline \multicolumn{1}{c|}{ LOCALIZACION } & Ci M2 & 1/Ci & \multicolumn{1}{c}{ FOi } \\
\hline Santiago de Surco & 15.40 & 0.0649 & 0.1669 \\
San Borja & 11.30 & 0.0885 & 0.2275 \\
Miraflores & 14.00 & 0.0714 & 0.1836 \\
San Luis & 10.30 & 0.0971 & 0.2495 \\
San Isidro & 14.90 & 0.0671 & 0.1725 \\
TOTAL & & 0.389061 & 1 \\
\hline
\end{tabular}

Fuente: Elaboración propia

Como siguiente paso se ha determinado los factores subjetivos, asignando un puntaje de acuerdo a la importancia considerada de acuerdo al cuadro siguiente: 
Tabla 5.2

Índice de importancia

\begin{tabular}{l|c}
\hline FACTOR & INDICE DE IMPORTANCIA RELATIVA (Wj) \\
\hline DISPONIBILIDAD & 0.3 \\
UBICACIÓN & 0.3 \\
SEGURIDAD & 0.1 \\
COMPETENCIA & 0.1 \\
TRANSPORTE & 0.2 \\
\hline
\end{tabular}

Fuente: Elaboración propia

Como siguiente paso a los factores cualitativos se le ha asignado valores de acuerdo a los expertos, lo que permite comparar y obtener el índice de los factores cualitativos.

Tabla 5.3

Índice de factores cualitativos

\begin{tabular}{|c|c|c|c|c|c|c|c|c|c|c|c|c|c|c|c|}
\hline \multirow[b]{2}{*}{ LOCALIZACION } & \multicolumn{3}{|c|}{ DISPONIBILIDAD } & \multicolumn{3}{|c|}{ UBICACIÓN } & \multicolumn{3}{|c|}{ SEGURIDAD } & \multicolumn{3}{|c|}{ COMPETENCIA } & \multicolumn{3}{|c|}{ TRANSPORTE } \\
\hline & \multicolumn{2}{|l|}{ Comp } & Rij & Comp & \multicolumn{2}{|c|}{\begin{tabular}{l|l}
$\sum$ & Rij \\
\end{tabular}} & Comp & \multirow[t]{2}{*}{$\Sigma$} & \multirow{2}{*}{\begin{tabular}{l|} 
Rij \\
0.13
\end{tabular}} & Comp & \multirow{2}{*}{\begin{tabular}{|r|}
$\Sigma$ \\
1
\end{tabular}} & \multirow{2}{*}{\begin{tabular}{|l|} 
Rij \\
0.14 \\
\end{tabular}} & Comp & \multirow[t]{2}{*}{$\Sigma$} & \multirow{2}{*}{\begin{tabular}{|l|} 
Rij \\
0.14 \\
\end{tabular}} \\
\hline Santiago de Surco & 1 & 0 & 0.14 & 1 & & 0.25 & 0 & & & 1 & & & 1 & & \\
\hline San Boria & 0 & 1 & 0.14 & 1 & 14 & 0.13 & 1 & & 0.25 & 1 & & 0.14 & 0 & & 0.14 \\
\hline Miraflores & 1 & 1 & 0.29 & 1 & ( & 0.25 & 1 & & 0.25 & 1 & 2 & 0.29 & 1 & & 0.29 \\
\hline San Luis & 1 & 0 & 0.14 & 1 & ( & 0.13 & 1 & & 0.13 & 0 & & 0.14 & 0 & & 0.14 \\
\hline San Isidro & 1 & 1 & 0.29 & 1 & 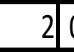 & 0.25 & 1 & 2 & 0.25 & 1 & 4 & 0.29 & 1 & & 0.29 \\
\hline TOTAL & Total & & 1 & Total & 8 & 1 & Total & 8 & 1 & Total & 7 & 1 & Total & & 1 \\
\hline & 0.14 & 0.25 & 0.13 & 0.14 & 0.14 & & 0.3 & & & 0.17 & & & & & \\
\hline & 0.14 & 0.13 & 0.25 & 0.14 & 0.14 & & 0.3 & & & 0.15 & & & & & \\
\hline & 0.29 & 0.25 & 0.25 & 0.29 & 0.29 & & 0.1 & & & 0.27 & & & & & \\
\hline & 0.14 & 0.13 & 0.13 & 0.14 & 0.14 & & 0.1 & & 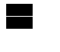 & 0.14 & & & & & \\
\hline & 0.29 & 0.25 & 0.25 & 0.29 & 0.29 & & 0.2 & & & 0.27 & & & & & \\
\hline
\end{tabular}

Luego se realiza una combinación de los factores objetivos y subjetivos, asignando una ponderación relativa, para calcular la Medida de Preferencia de Localización. (MPL)

Tabla 5.4

Resultado de la medida de preferencia de localización

\begin{tabular}{lc}
\hline DISTRITOS & MPLi $=\mathrm{K}(\mathrm{FOi})+(1-\mathrm{k})(\mathrm{FSi})$ \\
\hline Santiago de Surco & $(0.50 * 0.17)+(0.50 * 0.17)=0.17$ \\
San Borja & $(0.50 * 0.23)+(0.50 * 0.15)=0.19$ \\
Miraflores & $(\mathbf{0 . 5 0} * \mathbf{0 . 1 8})+(\mathbf{0 . 5 0} * \mathbf{0 . 2 7})=\mathbf{0 . 2 3}$ \\
San Luis & $(0.50 * 0.25)+(0.50 * 0.14)=0.19$ \\
San Isidro & $(0.50 * 0.17)+(0.50 * 0.27)=0.22$ \\
\hline
\end{tabular}

Fuente: Elaboración propia 
La demanda inicial está relacionada de manera estratégica en base a los resultados de las encuentras del estudio de mercado dirigido a Público General y Estudiantes Universitarios por separado que hayan utilizado el servicio de impresión 3D, personas interesadas en el diseño y desarrollo profesional. Se debe tener en cuenta que las preguntas eran abiertas.

En el Público General se interpreta lo siguiente:

a. La primera alternativa elegida por los encuestados son Miraflores, Barranco y San Isidro con un $24 \%$ de respuestas.

b. La segunda alternativa elegida por los encuestados son Miraflores, San Borja y La Molina con un $16 \%$ de respuestas.

c. En las respuestas siguientes, la mayoría incluyen al distrito Miraflores.

Tabla 5.5

Resultado de Ubicación del negocio según encuesta

\begin{tabular}{l|lc}
\hline \multicolumn{1}{c|}{ RESPUESTA } & \multicolumn{1}{|c}{ INTERPRETACIÓN } & \%Part. \\
\hline Miraflores, Barranco, San Isidro & Acceso & $24.00 \%$ \\
Miraflores, San Borja, La Molina & Acceso & $16.00 \%$ \\
\hline Miraflores, San Isidro, Magdalena, La Molina & Acceso & $8.00 \%$ \\
\hline Miraflores, San Miguel & Acceso & $8.00 \%$ \\
\hline Pueblo Libre, San Miguel y Magdalena & Acceso & $4.00 \%$ \\
\hline Miraflores, Surco, San Borja, San Isidro & Acceso & $4.00 \%$ \\
\hline Miraflores, San Isidro, La Molina & Acceso & $4.00 \%$ \\
\hline Miraflores, San Borja & Concurrencia de colegas & $4.00 \%$ \\
\hline Miraflores, Barranco, Chorrillos & Demanda & $4.00 \%$ \\
\hline San Isidro & Acceso & $4.00 \%$ \\
\hline Miraflores, Surco & Acceso & $4.00 \%$ \\
\hline Surco, San Borja, Miraflores, San Isidro & Acceso & $4.00 \%$ \\
\hline Miraflores, San Isidro & Demanda & $4.00 \%$ \\
\hline Miraflores, Jesús Maria & Acceso & $4.00 \%$ \\
\hline Miraflores, San Isidro & Acceso & $4.00 \%$ \\
\hline
\end{tabular}

Fuente: Elaboración propia

En estudiantes universitarios se interpreta que aquellos que participaron en las encuestas y cuyas carreras están en relación asisten a campus cerca de Miraflores como ESAN, IDAT, IPAD, POUSSIN, TLS, USIL, UTEC y UTP cuya participación es mayor al $70 \%$. 
Tabla 5.6

Resultado de participación de estudiantes universitarios

\begin{tabular}{l|lc}
\hline Universidad & \multicolumn{1}{|c}{ Distrito } & \% Participación \\
\hline ESAN & Surco & $18 \%$ \\
IDAT & Lince & $11 \%$ \\
IPAD & Miraflores & $11 \%$ \\
POUSSIN & Jesús María & $11 \%$ \\
PUCP & San Miguel & $10 \%$ \\
TECSUP & Santa Anita & $9 \%$ \\
TLS & Surco - Magdalena & $9 \%$ \\
USIL & Miraflores - Magdalena & $7 \%$ \\
UTEC & Barranco & $7 \%$ \\
UTP & Lince & $\mathbf{7 \%}$ \\
Total & & $\mathbf{1 0 0 \%}$ \\
\hline
\end{tabular}

Fuente Elaboracion propia

La afección de la demanda sobre la ubicación del negocio se ve beneficiada desde diferentes puntos de vista:

- Conglomeración de estudiantes y profesionales en un lugar de fácil acceso.

- Acciones de publicidad puntual y dirigida estratégicamente por perfil de consumidor y demografía.

- La concurrencia de turistas y profesionales que llegan del extranjero significa valor para la demanda del proyecto.

De acuerdo al análisis anterior se puede concluir que el Distrito de Miraflores es la mejor opción para la ubicación de 3D Lab \& Café para facilitar el acceso tanto a profesionales y estudiantes. Además, es considerado un Distrito de los más modernos de la ciudad, donde las principales marcas de tecnología tienen sus mejores Centros de Atención.

La llegada de marcas de tecnología reconocidas a nivel mundial como Xiaomi, refuerzan la percepción de un distrito moderno y atractivo para marcas innovadoras.

Del análisis expuesto se puede concluir que el alquiler del local deberá estar ubicado en el distrito de Miraflores, debiendo estar cerca de las avenidas principales, estación de metropolitano y en camino a muchas de las universidades mencionadas en el estudio, lo que hace que sea un espacio de fácil acceso y perfecto para puntos de reunión. 


\section{Figura 5.1}

Mapa referencial de la ubicación del negocio

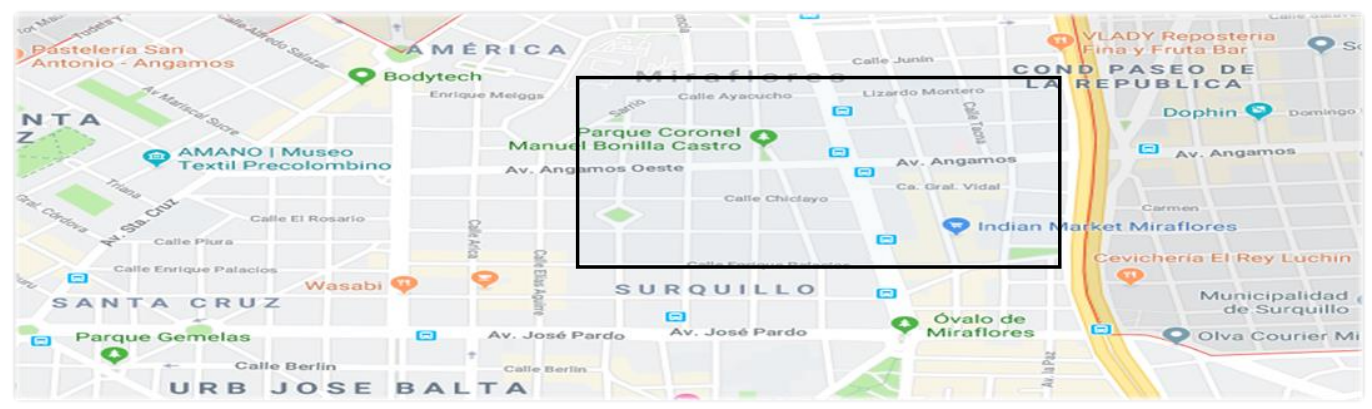

Fuente: Elaboracion propia

\subsubsection{Equipos de trabajo y apoyo.}

Los equipos de trabajo y apoyo que influirán directa o indirectamente en el logro de los objetivos de nuestro negocio son los siguientes:

- Distribuidores de equipos e insumos para impresión 3D y de café.

- Universidades e institutos.

- $\quad$ Empresas comerciales que requieren servicio de impresión 3D.

- Municipalidad.

\subsubsection{Gestión de proveedores, compras y stock.}

Es prioritario realizar alianzas con proveedores y empresas complementarias a nuestro proyecto de negocio que nos permitan disminuir costos en la producción, así como en la obtención de insumos de calidad manteniendo un stock mínimo. 


\subsubsection{Implementación de las actividades por fases. Cadena de valor.}

Figura 5.2

Cadena de Valor

\begin{tabular}{|c|c|c|c|c|c|}
\hline $\begin{array}{l}\text { ADMINISTRA } \\
\text { CIÓN }\end{array}$ & \multicolumn{5}{|c|}{$\begin{array}{l}\text { Dirección, planificación, objetivos de crecimiento y rentabilidad, contabilidad y } \\
\text { gestión de calidad }\end{array}$} \\
\hline RRHH & \multicolumn{5}{|c|}{$\begin{array}{l}\text { Selección y contratación, formación orientada al servicio al cliente y estructura } \\
\text { organizativa }\end{array}$} \\
\hline TECNOLOGÍA & \multicolumn{5}{|c|}{ Mejoras en las técnicas de diseño e impresión 3D y equipamiento. } \\
\hline COMPRAS & \multicolumn{5}{|c|}{ Políticas de compras y relaciones con los proveedores. } \\
\hline & $\begin{array}{l}\text { Recepción y } \\
\text { almacenamiento } \\
\text { de materias } \\
\text { primas } \\
\text { (alimentos } \\
\text { preparados e } \\
\text { insumos de } \\
\text { impresión 3d). }\end{array}$ & $\begin{array}{l}\text { Transformación } \\
\text { en producto o } \\
\text { servicio final. }\end{array}$ & $\begin{array}{l}\text { Servicio } \\
\text { de } \\
\text { atención al } \\
\text { cliente. }\end{array}$ & $\begin{array}{l}\text { Medios para } \\
\text { vender los } \\
\text { productos y } \\
\text { servicios. }\end{array}$ & $\begin{array}{l}\text { Vinculación de } \\
\text { clientes. }\end{array}$ \\
\hline & $\begin{array}{l}\text { Manipulación. } \\
\text { Almacenamiento } \\
\text { Conservación. } \\
\text { Inventario. }\end{array}$ & $\begin{array}{l}\text { Cotización. } \\
\text { Diseño, escaneo } \\
\text { e impresión). } \\
\text { Limpieza. } \\
\text { Control de } \\
\text { calidad. } \\
\text { Presentación } \\
\text { final del } \\
\text { producto y/o } \\
\text { servicio. }\end{array}$ & $\begin{array}{l}\text { Atención. } \\
\text { Organizaci } \\
\text { ón del } \\
\text { trabajo. } \\
\text { Manto de } \\
\text { equipo. } \\
\text { Creación } \\
\text { de } \\
\text { experienci } \\
\text { as. }\end{array}$ & $\begin{array}{l}\text { Publicidad. } \\
\text { Promoción. } \\
\text { Redes } \\
\text { sociales. } \\
\text { Web. } \\
\text { Creación de } \\
\text { necesidades. }\end{array}$ & $\begin{array}{l}\text { Fidelidad. } \\
\text { Base de datos. } \\
\text { Personalizació } \\
\text { n. } \\
\text { Servicio } \\
\text { adicionales. } \\
\text { Ofrecimiento } \\
\text { de nuevas } \\
\text { tendencias. }\end{array}$ \\
\hline $\begin{array}{l}\text { ACTIVIDADE } \\
\text { S PRIMARIAS }\end{array}$ & $\begin{array}{l}\text { Logística } \\
\text { interna. }\end{array}$ & \multicolumn{2}{|c|}{$\begin{array}{l}\text { Área de impresión y } \\
\text { cafetería. }\end{array}$} & Marketing. & Post venta. \\
\hline
\end{tabular}

Fuente: Elaboración propia

\subsubsection{Proceso de elaboración de bienes y/o prestación de servicio.}

\subsubsection{Servicio de Impresión $3 D$ en el local o a través de la página web}

- Recepción y bienvenida al cliente en el local: El asesor de diseño y creación recibe al cliente en la puerta y le informa sobre los servicios brindados respectos a impresión 3D.

- Recepción del proyecto: El asesor de diseño y creación recibe el proyecto del cliente, asesora técnicamente si fuera necesario y absuelve sus preguntas; 
igualmente, hace sugerencias para mejorar el proyecto, desarrollar este punto es de vital importancia pues nos permitirá diferenciarnos al brindar un valor agregado que sea percibido por el cliente como único y exclusivo.

- Luego de la evaluación del proyecto entrega los costos y tiempo que demandaría la impresión del proyecto traído por el cliente.

- Cobro del proyecto: El asesor procede a realizar el cobro y emite el comprobante de pago ya sea físico (en el local) o mediante cobro desde la página web (virtual).

- Entrega del proyecto: El asesor de diseño y creación notificará al cliente que su proyecto está listo; acto seguido, entregará el comprobante de pago (físico o virtual) y preguntará si está conforme con el servicio, a la vez que solicitará y registrará los datos del cliente para nuestra base de datos.

\subsubsection{Servicio de Cafetería}

- Recepción y bienvenida al cliente: $\mathrm{El}$ asesor de diseño y creación recibe al cliente en la puerta y le informa sobre los servicios brindados, si es el de cafetería le invita a elegir entre las mesas disponibles o a estar junto a la barra, y les da un tiempo prudente para que se acomoden de la mejor manera. Igualmente, pregunta si desean algo en especial y promociona el servicio de impresión 3D.

- Recepción, preparación y cobro de la orden: El barista recibe la orden del mismo cliente, realiza la preparación y cobro del mismo.

- Entrega del pedido: El barista entregara los productos solicitados según orden de los clientes. Cuando parezca que han terminado de consumir, se acercará a preguntar si desean algo más y si todo ha estado como lo esperaban. Hará un pequeño sondeo sobre la calidad de los productos y servicios recibidos de cafetería. 


\subsubsection{Flujograma de la actividad.}

Figura 5.3

Flujograma de la Actividad

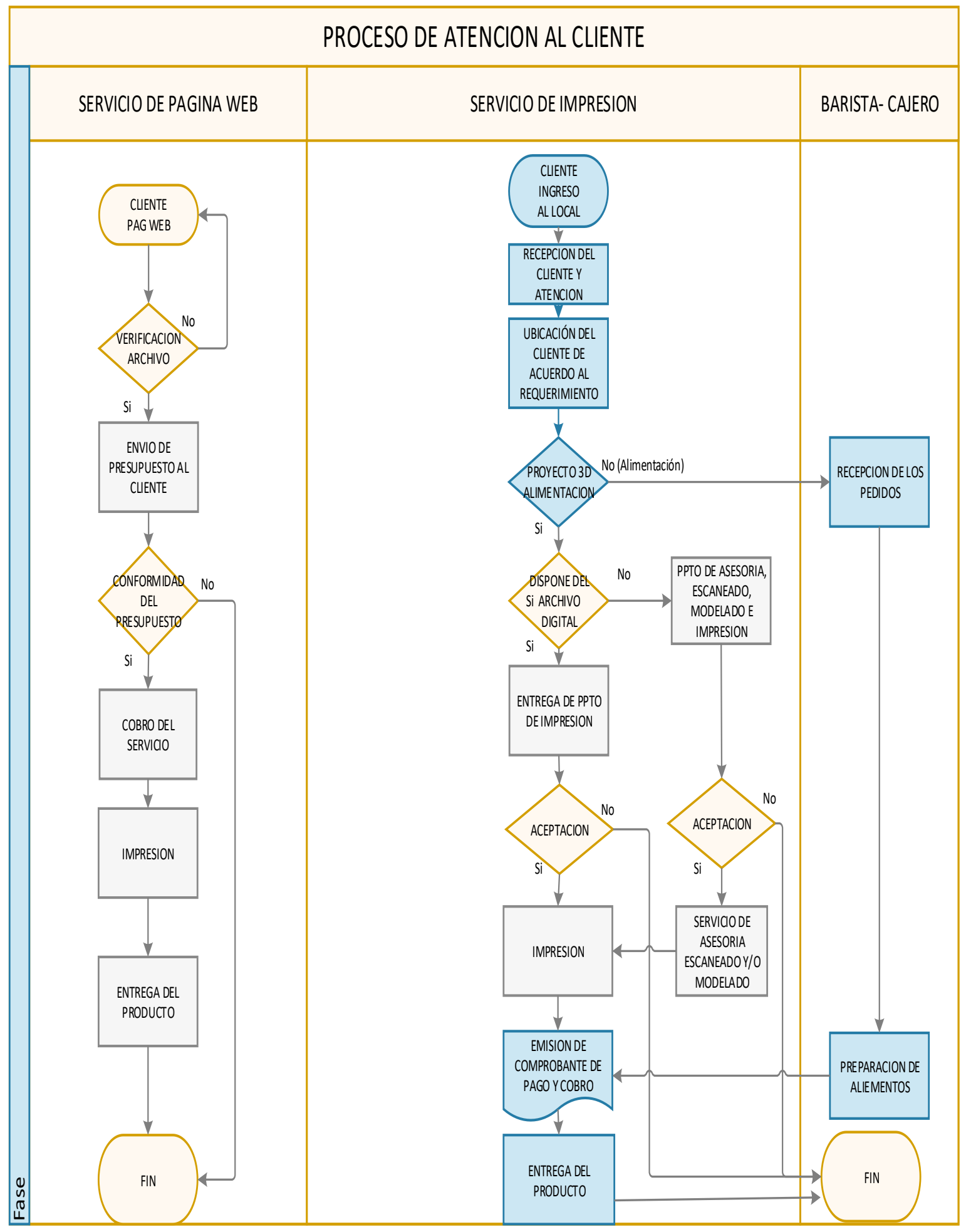

Fuente: Elaboración propia 


\subsubsection{Diagrama de Gantt.}

Figura 5.4

Diagrama de Gantt

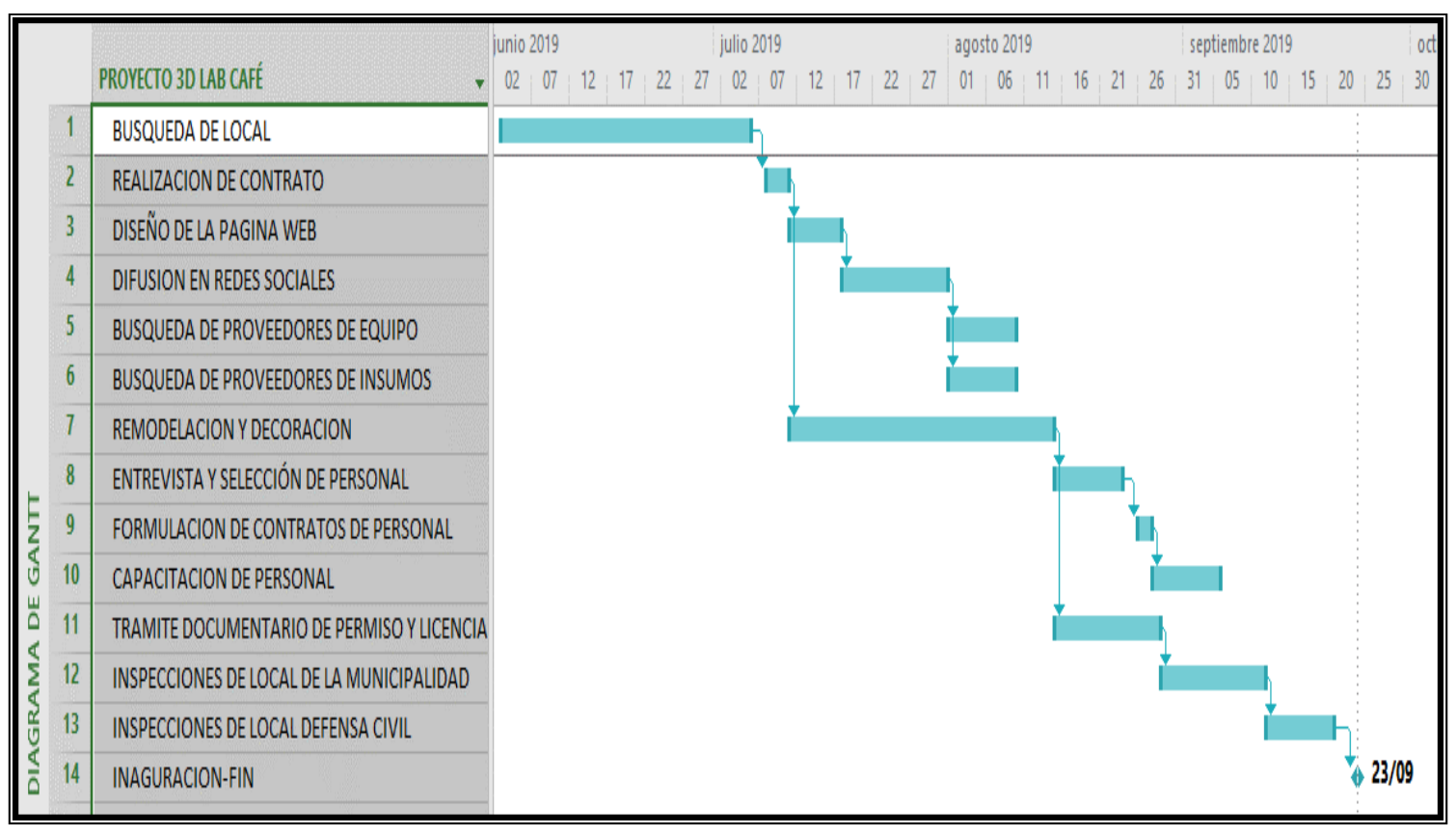

Fuente: Elaboración propia

\subsubsection{Balance Scorecard:}

A través de esta herramienta de planificación y dirección enlazaremos las estrategias y objetivos con indicadores y metas para realizar con éxito la formulación e implantación estratégica en las cuatro áreas críticas del negocio: desempeño financiero, conocimiento del cliente, procesos internos de negocio y aprendizaje y crecimiento. 
Figura 5.5

Balance Scorecard
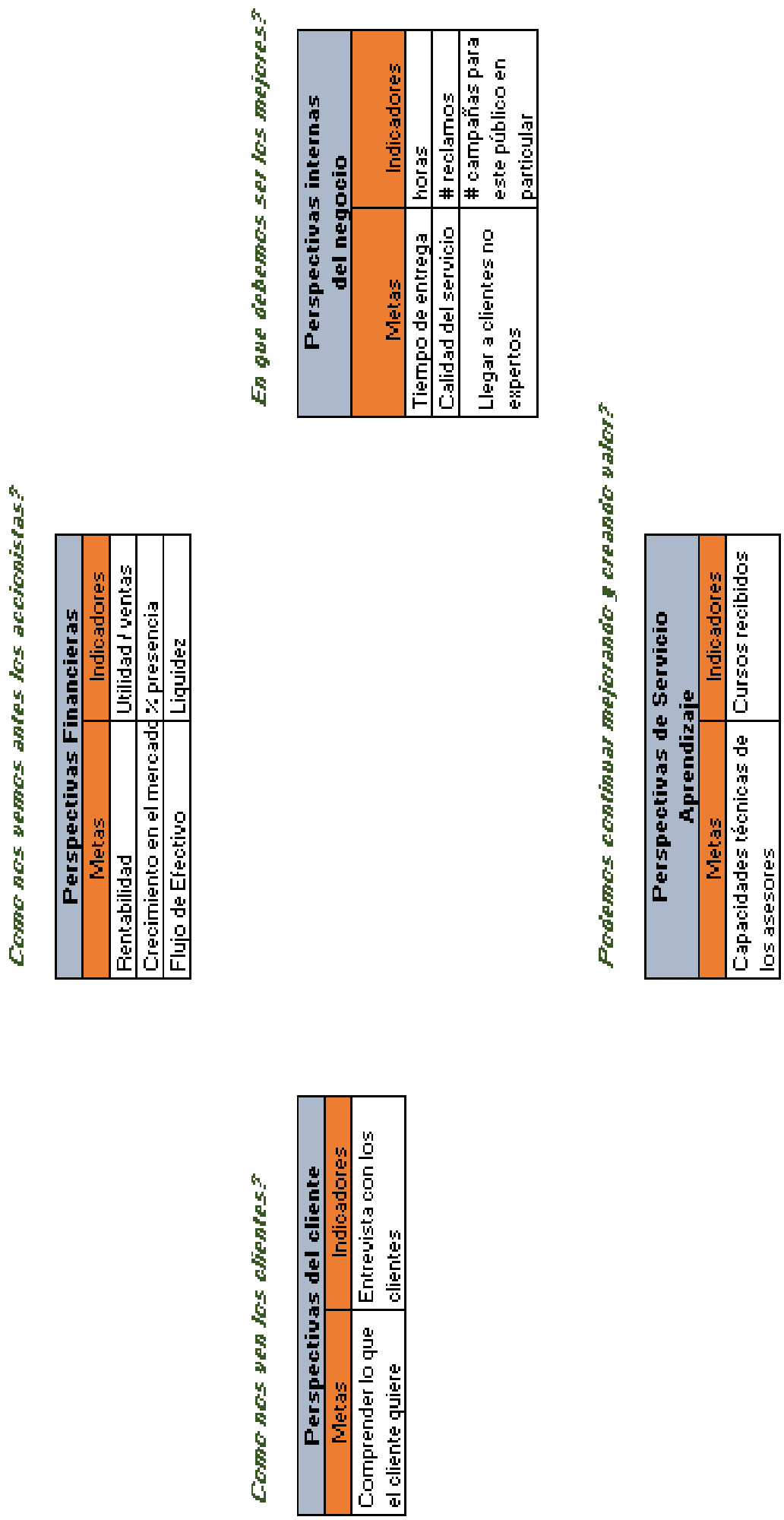

Fuente: Elaboración propia. 


\section{CAPÍTULO VI: ESTRUCTURA ORGANIZACIONAL Y RECURSOS HUMANOS}

\subsection{Naturaleza y Objetivos organizacionales}

Como ya hemos comentado en párrafos anteriores, nuestra empresa debe ser una organización que debe buscar su objetivo estratégico y diferenciador el cual consiste en brindar un excelente servicio al cliente otorgándole el mejor ambiente en cuanto se refiere a comodidad e instalaciones modernas que motiven la creatividad. Por lo tanto nuestra organización debe tener muy en claro este propósito y debe partir desde los socios del proyecto. Debe existir una constante retroalimentación para ir ajustándose a las necesidades de nuestros clientes.

Los principios básicos de la cultura organizacional serán los siguientes:

- Ofrecer un buen entorno de trabajo y tratar a los demás con respeto y dignidad.

- Mantener siempre satisfechos y contentos a nuestros clientes y empleados.

- Garantizar la excelencia en los trabajos de impresión, modelado, diseño y escaneo.

- Otorgar bebidas y snacks de calidad, sanos y saludables.

- Contribuir positivamente hacia nuestra comunidad y entorno

- Reconocer que la rentabilidad es esencial para nuestro éxito en el futuro.

Figura 6.1

Organigrama del negocio

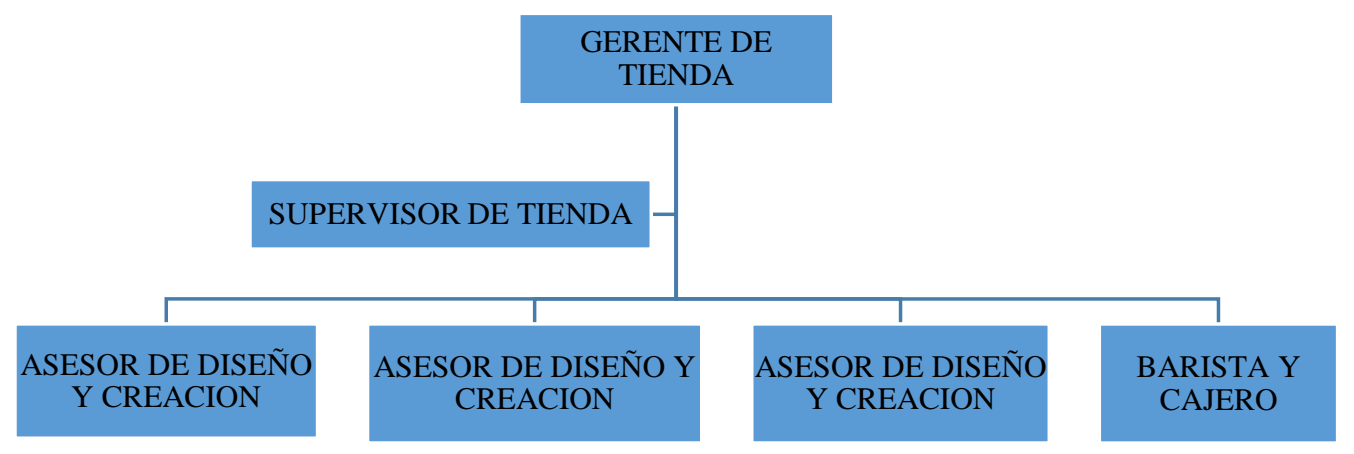

Fuente: Elaboración propia. 


\subsection{Diseño de Puestos y}

- necesidades del cliente, las cuales son cambiantes.

- Todos los asesores deberán ser capaces de poder también trabajar en la caja y en el servicio de cafetería.

- Trabajar conjuntamente con el supervisor para lograr los objetivos y mejorar siempre la experiencia del cliente.

- Responsables del mantenimiento de las impresoras 3D.

\subsubsection{Barista y cajero:}

Personal a tiempo parcial con jornada de 6 horas diarias. Se requieren tener 2 turnos diarios. La responsabilidad del puesto es:

- Encargado atender los requerimientos de cafetería por parte de los clientes, mostrando siempre una excelente actitud de servicio.

- Trabajar conjuntamente con el supervisor para lograr los objetivos y mejorar siempre la experiencia del cliente.

- Deberán ser capaces de poder también trabajar en la caja, asimismo es responsable del mantenimiento del sector de cafetería.

- Coordinar permanentemente con el supervisor de tienda el stock de insumos necesarios para la cafetería.

\subsection{Gestión del talento}

Los empleados que formaran parte del equipo serán estudiantes universitarios afines a las carreras de Diseño Industrial o Ingeniería. Con un buen conocimiento de diseño y técnicas de impresión 3D. Deseable con experiencia previa de atención al cliente y que demuestren una sólida actitud de atención y servicio.

Son ellos quienes darán la cara de nuestro negocio hacia nuestros clientes, por lo tanto deben ser hospitalarios, siempre mostrar una sonrisa y saber lo que el cliente desea y responder sus inquietudes. Para lograr esto tanto el supervisor como el gerente se enfocarán en siempre capacitar y fortalezar estas habilidad blandas de su personal a cargo.

Debido a que serán en su mayoría estudiantes universitarios, se debe preveer que trabajaran a tiempo parcial (3 turnos de cuatro horas cada uno). 
Se impulsará el concepto de empleado del mes para los asesores. Para desarrollarlo se tratará que el cliente llene una encuesta voluntaria que califique la atención recibida del asesor. Igualmente se considerará la evaluación de sus pares. El incentivo será un bono adicional de S/. 400.00 a fin de mes.

\subsection{Estructura de gastos de RRHH}

Debido al tamaño del modelo de negocio, este último clasifica como pequeña empresa debido al número de empleados (menor a 10 trabajadores) y ventas anuales mayores a 150 UIT. Decreto Ley 1086.

Esto nos lleva a considerar el costo del salario para nuestra empresa en $1.5 \%$ sobre la remuneración liquida del trabajador debido a los beneficios laborales establecidos de acuerdo a normas vigentes. Para lo cual se ha considerado los siguientes salarios:

Tabla 6.1

Salarios de los empleados

\begin{tabular}{|c|c|c|c|c|c|c|c|}
\hline Empleados & Cantidad & Importe & $\begin{array}{c}\text { \# de } \\
\text { turnos }\end{array}$ & factor & $\begin{array}{c}\text { Costo } \\
\text { Salarial }\end{array}$ & Mes & Total \\
\hline Gerente de tienda & 1 & $3,500.00$ & 1 & 1.5 & $5,250.00$ & 14 & $73,500.00$ \\
\hline Supervisor & 1 & $2,300.00$ & 1 & 1.5 & $3,450.00$ & 14 & $48,300.00$ \\
\hline Asesor de Diseño & 3 & 700 & 3 & 1.5 & $9,450.00$ & 12 & $113,400.00$ \\
\hline Barista-Caja & 1 & $1,200.00$ & 2 & 1.5 & $3,600.00$ & 12 & $43,200.00$ \\
\hline $\begin{array}{l}\text { Bono empleado del } \\
\text { mes }\end{array}$ & & & & & 500 & 12 & $6,000.00$ \\
\hline Total anual S/ & & & & & & & $284,400.00$ \\
\hline
\end{tabular}

Fuente: Elaboración Propia. 


\section{CAPÍTULO VII: PLAN ECONÓMICO FINANCIERO}

La evaluación del plan económico financiero se hará dentro de un horizonte de 5 años, el cual consideramos tiempo suficiente para demostrar la buena rentabilidad del proyecto. Es importante indicar que los datos que se presentan a continuación se basan en el escenario esperado de participación de mercado tanto para nuestro público estudiantil como para el público general. Más adelante mostraremos la situación pesimista y optimista siempre basándonos en la participación de mercado que queremos lograr.

Luciano Crippa, director de Investigación y Consultoría de IDC América Latina estima la siguiente participación por sectores en la industria de la impresión 3D a nivel mundial:

Tabla 7.1

Participación de industrias que utilizan la impresión 3D

\begin{tabular}{l|r}
\hline \multicolumn{1}{c|}{ Sector } & \multicolumn{2}{c}{ \%Mercado } \\
\hline Automotriz & $30.00 \%$ \\
Aeroespacial y Defensa & $17.80 \%$ \\
Diseño de componente & $7.50 \%$ \\
Arquitectura y Diseño & $6.90 \%$ \\
Otras industrias & $37.80 \%$ \\
\hline
\end{tabular}

Fuente: Crippa, 2917.

El crecimiento de la impresión 3D crece cada año en un 30\%. Si bien parte de estas impresoras son usadas en el ambiente corporativo, se registra una tendencia al aumento de firmas proveedoras que dan servicios de impresión 3D para el usuario final, con productos personalizados para entretenimiento o regalos, y para Pymes que recurren a la tercerización del servicio de impresión, asimismo se está empleando en otras industrias como la médica, prótesis, implantes, comida, investigación.

Actualmente el tamaño del mercado local de impresiones 3D no cuenta con un dato exacto más allá de la competencia y empresas que se pueden mapear en lo que conlleva la investigación.

El mercado limeño está compuesto de la siguiente manera.

a. Empresas proveedoras de equipos y materiales: 
b. Empresas que prestan servicio de impresión 3D: incluidos las FAB de las universidades.

c. Empresa que usan impresión 3D en sus procesos:

Este análisis nos da un panorama más amplio y nos ayuda a concluir que la cadena de suministro de este negocio en el Perú está consolidándose cada año ya que van apareciendo nuevas empresa, propuestas y tecnologías.

La inversión en nuestro mercado no sólo es a nivel de implementación de equipos e infraestructura, sino también de promoción de esta tecnología, los eventos que promueven los Fab Lab, congresos, talleres, capacitaciones, desarrollo de proyectos y prototipos genera una réplica en las otras aristas de la cadena a través de mayores ingresos, para proveedores, profesionales de diseño, mayor demanda, mejor oferta.

La participación para el mercado de estudiantes y público en general es conservadora y nos hemos basado en la retroalimentación recibida de nuestras visitas a 3D Lab Fab México, Lima Makers y Sala VEO 3D de la Universidad Católica del Perú.

Tabla 7.2

Participación para el mercado de estudiantes y público general

\begin{tabular}{l|rrrrr}
\hline Participación Mercado & 2019 & 2020 & 2021 & 2022 & 2023 \\
\hline Estudiantes & $1.50 \%$ & $1.50 \%$ & $1.75 \%$ & $1.75 \%$ & $2.00 \%$ \\
Público general & $0.20 \%$ & $0.25 \%$ & $0.30 \%$ & $0.35 \%$ & $0.40 \%$ \\
\hline
\end{tabular}

Fuente: Elaboración Propia.

\subsection{Inversiones.}

\section{Activo Fijo}

El principal rubro en las inversiones lo constituye la inversión en equipos y la remodelación del local. Esta inversión es necesaria para crear una atmósfera única que inivite al cliente a vivir un momento de creatividad sumandose a ello el de brindar una experiencia agradable a los sentidos todo con la finalidad de lograr que nuestros clientes entren a nuestra tienda, experimenten la impresión 3D, regresen y difundan nuestro concepto. 
Los costos de remodelación de nuestro local se han estimado en USD 250.00 por metro cuadrado. Este monto fue proporcionado según consulta realizada a la empresa $3 \mathrm{~F}$ Ingeniería SAC. Esta cifra incluye tanto los materiales como la mano de obra.

El local será alquilado y se ubicará en el distrito de Miraflores, con un costo de alquiler de USD 3,000 mensuales. Debera contar con un area de aproximadamente 100 metros cuadrados lo suficientemente amplio para lograr un ambiente cómodo y confortable al cliente. A continuación se muestra un cuadro resumen de las inversiones. (Referirse al anexo 04 para mayor detalle).

Tabla 7.3

Resumen de inversion inicial

\begin{tabular}{l|r}
\hline Resumen de Inversión Inicial & \multicolumn{1}{|c}{ Soles } \\
\hline Inversión en Instalaciones & 82,500 \\
\hline Inversión en muebles y enseres & 20,200 \\
\hline Estudio de mercado & 4,000 \\
\hline Inversión en equipos & 247,060 \\
\hline Alquiler (2 meses adelantado y 1 mes garantía) & 29,700 \\
\hline Gastos Fijos (3 meses antes de apertura) & 35,375 \\
\hline Permisos & 3,500 \\
\hline Inversión inicial & $\mathbf{4 2 2 , 3 3 5}$ \\
\hline
\end{tabular}

Fuente: Elaboración propia

\subsection{Estimación de la Demanda.}

Para la elaboración de nuestra demanda, partiremos de los datos obtenidos del Estudio de mercado desarrollado en el punto 4.1. Mercado objetivo.

De las respuestas obtenidas de nuestra encuesta podemos encontrar los resultados finales para ambos públicos los cuales constituyen el total de nuestra demanda.

\section{Estudiantes}

Tabla 7.4

Demanda de estudiantes

\begin{tabular}{l|rrrrr}
\hline & 2019 & 2020 & 2021 & 2022 & 2023 \\
\hline Mercado Potencial & 204,877 & 224,552 & 244,227 & 263,902 & 283,577 \\
Mercado Disponible & 56,281 & 61,685 & 67,090 & 72,495 & 77,900 \\
Mercado Objetivo & $\mathbf{8 4 4}$ & $\mathbf{9 2 5}$ & $\mathbf{1 , 1 7 4}$ & $\mathbf{1 , 2 6 9}$ & $\mathbf{1 , 5 5 8}$ \\
\hline
\end{tabular}

Fuente: Elaboración propia 
El mercado disponible se obtiene a partir de los resultados obtenidos en las encuestas:

- $\quad 97 \%$ estudiantes conocen de impresión 3D

- $\quad 59 \%$ estudiantes usan al menos un servicio (impresión, modelado, escaneado)

- $48 \%$ estudiantes hacen uso del servicio de impresión 3D

El mercado objetivo se obtiene a partir de la participación de mercado señalada a inicios del presente capítulo. Finalmente calculamos nuestra demanda del público estudiantil con respecto a la frecuencia de visita según resultados de encuestas:

Tabla 7.5

Demanda de público en general

\begin{tabular}{r|rrrrr}
\hline & 2019 & 2020 & 2021 & 2022 & 2023 \\
\hline Bimestral (64\%) & 3,242 & 3,553 & 4,508 & 4,872 & 5,983 \\
Anual (20\%) & 169 & 185 & 235 & 254 & 312 \\
Mensual (10\%) & 1,013 & 1,110 & 1,409 & 1,522 & 1,870 \\
& $\mathbf{4 , 4 2 4}$ & $\mathbf{4 , 8 4 8}$ & $\mathbf{6 , 1 5 2}$ & $\mathbf{6 , 6 4 8}$ & $\mathbf{8 , 1 6 4}$ \\
\hline
\end{tabular}

Fuente: Elaboración propia.

\section{Público general}

Para calcular nuestro público general hemos proyectado la población de Lima del año 2017 según la cifra indicada en el capítulo 4.1.2. Para la tasa de crecimiento usamos la cifra de referencia del INE de 1.42\% (Boletín \#37, INEI, Estimaciones y Proyecciones de Población por Departamento, Sexo y Grupos Quinquenales de Edad 1995-2025)

De la población obtenida restamos nuestro mercado potencial de estudiantes hallado y obtenemos nuestro mercado potencial de público general.

Tabla 7.6

Mercado potencial

\begin{tabular}{l|rrrrr}
\hline \multicolumn{1}{c|}{ Años } & 2019 & 2020 & 2021 & 2022 & 2023 \\
\hline Población & $1,057,148$ & $1,072,160$ & $1,087,385$ & $1,102,825$ & $1,118,486$ \\
Estudiantes & 204,877 & 224,552 & 244,227 & 263,902 & 283,577 \\
Mercado Potencial & 852,271 & 847,608 & 843,158 & 838,923 & 834,909 \\
\hline
\end{tabular}

Fuente: Elaboración propia.

Igualmente de los resultados de encuestas obtenemos nuestro mercado disponible:

- Idea del Negocio 46\%

- $\quad$ Probabilidad visita $48 \%$ 
- Estilos de Vida (Nivel Socio Económico) 30\%

Y de la participación de mercado estimada obtenemos el mercado objetivo.

Tabla 7.7

Particiapción en el mercado

\begin{tabular}{l|rrrrr}
\hline & 2019 & 2020 & 2021 & 2022 & 2023 \\
\hline Mercado Disponible & 56,454 & 56,146 & 55,851 & 55,570 & 55,304 \\
Mercado Objetivo & $\mathbf{1 1 3}$ & $\mathbf{1 4 0}$ & $\mathbf{1 6 8}$ & $\mathbf{1 9 4}$ & $\mathbf{2 2 1}$ \\
\hline
\end{tabular}

Fuente: Elaboración propia.

Finalmente obtenemos nuestra demanda de público general según la frecuencia de visita de las encuestas realizadas:

Tabla 7.8

Demanda del publico en general

\begin{tabular}{r|rrrrr}
\hline & 2019 & 2020 & 2021 & 2022 & 2023 \\
\hline Quincenal 40\% & 1,084 & 1,347 & 1,609 & 1,867 & 2,124 \\
Semanal 28\% & 1,644 & 2,044 & 2,440 & 2,832 & 3,221 \\
Mensual 32\% & 434 & 539 & 643 & 747 & 849 \\
& $\mathbf{3 , 1 6 1}$ & $\mathbf{3 , 9 3 0}$ & $\mathbf{4 , 6 9 1}$ & $\mathbf{5 , 4 4 6}$ & $\mathbf{6 , 1 9 4}$ \\
\hline
\end{tabular}

Fuente: Elaboración propia.

Con respecto a la demanda de productos de cafetería, estamos siendo conservadores asumiendo que solamente el $40 \%$ de nuestros clientes demandaran este servicio y que el gasto promedio sería de 25 soles por cliente. Es importante indicar que el negocio de cafetería es secundario respecto al servicio de impresión. Nosotros como empresa tendremos proveedores que nos suministrarán los productos terminados, a excepción del café y los jugos los cuales si serán preparados in situ. Hemos considerado tener una ganancia de $50 \%$ sobre el precio de los productos comprados a dichos proveedores.

Tabla 7.9

Ingreso promedio en cafeteria

\begin{tabular}{l|rrrrr}
\hline & 2019 & 2020 & 2021 & 2022 & 2023 \\
\hline Público total & 7,585 & 8,779 & 10,844 & 12,094 & 14,358 \\
Público cafetería (40\%) & 3,034 & 3,511 & 4,337 & 4,837 & 5,743 \\
Ingreso estimado (25 soles) & 75,851 & 90,420 & 115,040 & 132,151 & 161,600 \\
\hline
\end{tabular}

Fuente: Elaboración propia. 
Las ganancias del negocio tendrán que venir principalmente del servicio de impresión 3D. Complementándose en menor porcentaje con el servicio de escaneo y asesoría de diseño así como la venta de café, bebidas, ensaladas, sándwiches, postres, entre otros.

Tabla 7.10

Proyeccion de porcentaje de ganancias del negocio

\begin{tabular}{l|rrrrr}
\hline Año & 2019 & 2020 & 2021 & 2022 & 2023 \\
\hline Ingresos por impresión & $85 \%$ & $85 \%$ & $86 \%$ & $86 \%$ & $86 \%$ \\
Ingresos por diseño/escaneado & $6 \%$ & $6 \%$ & $6 \%$ & $6 \%$ & $6 \%$ \\
Ingresos cafetería & $9 \%$ & $9 \%$ & $8 \%$ & $8 \%$ & $8 \%$ \\
Ingreso ventas & $\mathbf{1 0 0 \%}$ & $\mathbf{1 0 0 \%}$ & $\mathbf{1 0 0 \%}$ & $\mathbf{1 0 0 \%}$ & $\mathbf{1 0 0 \%}$ \\
\hline
\end{tabular}

Fuente: Elaboración propia.

\section{Importancia de los estudiantes en la estructura de los ingresos}

La participación de estudiantes en los resultados de ingresos por ventas de impresión es considerable debido a que hacen un mayor uso, principalmente en periodos de entrega de trabajos parciales y finales. Asimismo estos trabajos consumen un mayor tiempo de impresión (aproximadamente 3.5 horas) debido a que son trabajos un poco más complejos que las impresiones del público general (entre 60 y 90 minutos aproximadamente). Finalmente estamos estimando lograr una participación de mercado entre $1.5 \%$ a $2.0 \%$ mucho mayor que la participación dentro del público general $(0.2 \%$ a $0.4 \%)$.

Tabla 7.11

Participacion de estudiantes en los resultados

\begin{tabular}{l|rrrrr}
\hline & 2019 & 2020 & 2021 & 2022 & 2023 \\
\hline Estudiantes & $83 \%$ & $81 \%$ & $75 \%$ & $74 \%$ & $75 \%$ \\
Público general & $17 \%$ & $19 \%$ & $25 \%$ & $26 \%$ & $25 \%$ \\
\hline
\end{tabular}

Fuente: Elaboración propia.

\subsection{Capacidad Instalada de Impresión y Diseño.}

Nuestro local trabajará 6 días a la semana con 3 turnos de 4 horas cada uno y con un día a la semana para realizar un mantenimiento preventivo a las impresoras y limpieza del local, labor que será realizada por ambos socios.

Empleamos 12 máquinas para garantizar una continua atención y contaremos con 3 asesores dedicados al asesoramiento de diseños solicitados por los clientes. Según los 
resultados de las encuestas, estamos considerando que los trabajos de los estudiantes tendrán un tiempo promedio de impresión de 3.5 horas al ser más complejos, mientras que para el público general será de 1 hora el tiempo promedio de impresión para los dos primeros años. Esperamos que a partir del tercer año el tiempo promedio sea de 1.5 horas.

Los trabajos que requieran un escaneo y modelado será un $11 \%$ del total la demanda de trabajos de estudiantes y un $50 \%$ para el público general. Asumimos que la mayoría de estudiantes ya tienen conocimientos de escaneo y modelado por lo tanto vendrán con sus trabajos listos para imprimir mientras que para el público general es probable que se necesite emplear más horas de escaneo y modelado en aquellos trabajos de mayor complejidad. Estas cifras son aproximadas y fueron proporcionadas en nuestra visita a 3D LAB FAB México.

Vemos que en el escenario esperado contamos con un buen margen para hacer frente a un aumento inesperado de trabajos de impresión y horas de asesoría de diseño. Es importante contar con este margen para poder enfrentar proyectos de impresión que demoren más de 3.5 horas o personas que deseen imprimir más de un proyecto lo cual podría ocasionar un cuello de botella en nuestras operaciones.

Tabla 7.12

Utilizacion de la capacidad instalada

\begin{tabular}{|c|c|c|c|c|c|}
\hline \multicolumn{4}{|c|}{ Capacidad de Operación (Impresión y Diseño) } & & \\
\hline \multicolumn{2}{|l|}{ Horas de atención al día } & & 12 & & \\
\hline \multicolumn{2}{|l|}{ Días a la semana } & & 6 & & \\
\hline \multicolumn{2}{|l|}{ Total horas al año } & & 3,744 & & \\
\hline \multicolumn{2}{|l|}{ \# impresoras } & & 12 & & \\
\hline \multicolumn{2}{|l|}{ Horas total de impresión } & & 44,928 & & \\
\hline \multicolumn{2}{|l|}{ Horas de diseño (3 asesores) } & & 11,232 & & \\
\hline & 2019 & 2020 & 2021 & 2022 & 2023 \\
\hline Total Estudiantes + P.General & 7,585 & 8,779 & 10,844 & 12,094 & 14,358 \\
\hline 3.5 horas promedio imp. estud. & 15,483 & 16,970 & 21,533 & 23,267 & 28,574 \\
\hline 1 hora promedio imp. público & 3,161 & 3,930 & 7,037 & 8,169 & 9,291 \\
\hline Total de horas & 18,644 & 20,900 & 28,570 & 31,436 & 37,865 \\
\hline Uso de capacidad instalada impresoras & $41 \%$ & $47 \%$ & $64 \%$ & $70 \%$ & $84 \%$ \\
\hline 2 horas escaneo y modelado estud. & 973 & 1,067 & 1,353 & 1,463 & 1,796 \\
\hline 0.25 horas asesoría público & 790 & 983 & 1,173 & 1,361 & 1,549 \\
\hline 1 hora escaneo y modelado público & 1,581 & 1,965 & 2,346 & 2,723 & 3,097 \\
\hline & 3,344 & 4,014 & 4,872 & 5,547 & 6,442 \\
\hline Uso de capacidad horas hombre asesores & $30 \%$ & $36 \%$ & $43 \%$ & $49 \%$ & $57 \%$ \\
\hline
\end{tabular}

Fuente: Elaboración propia.

\subsection{Estado de Resultados.}


Nuestras ganancias principales (aproximadamente 80\%) provienen de la impresión 3D y se calcula a partir de la cantidad de gramos de material de impresión usados. También tenemos ingresos en menor medida por las horas de diseño y/o modelado. En lo que se refiere al consumo de cafetería estamos asumiendo un costo promedio del $50 \%$ de las ventas de cafetería. Igualmente estamos considerando un incremento del $3 \%$ anual para gastos administrativos, operativos, publicidad y gastos fijos.

Para el cálculo de capital de trabajo hemos realizado un estimado basado en la estacionalidad para el primer año. Considerando que los meses de mayor afluencia serían aquellos en la que los estudiantes tienen que entregar trabajos parciales y finales de ciclo.

No contamos con un capital de trabajo sofisticado que utilice cuentas $x$ cobrar/pagar ni tampoco inventarios debido a que nuestro negocio en este aspecto es simple. Los pagos se harán en forma casi inmediata (efectivo o uso de tarjetas de débito y/o crédito), es decir no tenemos desfases entre los pagos de costos y los flujos de ingresos. Este capital de trabajo será recuperado en el quinto año si se decidiera liquidar la empresa.

En lo que respecta a inventarios contaremos con un stock mínimo de carretes de filamento de impresión el cual se consigue fácilmente en el mercado local. Ver anexo cálculo de capital de trabajo para el primer año.

Tabla 7.13

Estado de resultados en soles

\begin{tabular}{|l|rl}
\hline Costo directo cafetería & $\mathbf{5 0 \%}$ & ingresos cafetería \\
\hline Precio hora de diseño/escaneado & 20 & soles \\
\hline Precio venta impresión (gramos) & 1.80 & soles \\
\hline Costo impresión por gramo material usado & 0.10 & soles \\
Gasto administrativo (tasa de incremento) & $3 \%$ & \\
Gasto operativo (tasa de incremento) & $3 \%$ & \\
Gastos fijos y de marketing (tasa de incremento) & $3 \%$ & \\
\hline
\end{tabular}


(Continua)

\begin{tabular}{|l|rrrrr}
\hline Año & 2019 & 2020 & 2021 & 2022 & 2023 \\
\hline Ingresos por impresión & 738,311 & 852,462 & $1,200,263$ & $1,360,302$ & $1,687,638$ \\
\hline Ingresos por diseño/escaneado & 51,079 & 62,454 & 78,490 & 91,471 & 110,145 \\
\hline Ingresos cafetería & 75,851 & 90,420 & 115,040 & 132,151 & 161,600 \\
\hline Ingreso ventas & $\mathbf{8 6 5 , 2 4 1}$ & $\mathbf{1 , 0 0 5 , 3 3 6}$ & $\mathbf{1 , 3 9 3 , 7 9 3}$ & $\mathbf{1 , 5 8 3 , 9 2 4}$ & $\mathbf{1 , 9 5 9 , 3 8 3}$ \\
\hline Costos directos & & & & & \\
Insumos de Impresión & & & & & \\
Cafetería & 41,017 & 8,708 & 11,904 & 13,098 & 15,777 \\
\hline Gastos operativos & 37,925 & 45,210 & 57,520 & 66,075 & 80,800 \\
\hline Total costo directo & 174,600 & 179,838 & 185,233 & 190,790 & 196,514 \\
\hline & $\mathbf{2 5 3 , 5 4 3}$ & $\mathbf{2 3 3 , 7 5 6}$ & $\mathbf{2 5 4 , 6 5 7}$ & $\mathbf{2 6 9 , 9 6 4}$ & $\mathbf{2 9 3 , 0 9 1}$ \\
\hline Utilidad bruta & & & & & \\
\hline Gastos administrativos & $\mathbf{6 1 1 , 6 9 8}$ & $\mathbf{7 7 1 , 5 8 0}$ & $\mathbf{1 , 1 3 9 , 1 3 6}$ & $\mathbf{1 , 3 1 3 , 9 6 0}$ & $\mathbf{1 , 6 6 6 , 2 9 2}$ \\
\hline Gastos de marketing & & & & & \\
\hline Depreciación & 121,800 & 125,454 & 129,218 & 133,094 & 137,087 \\
\hline Gastos financieros & 80,400 & 82,812 & 85,296 & 87,855 & 90,491 \\
\hline Gastos de alquiler y servicios & 53,537 & 53,537 & 53,537 & 53,537 & 53,537 \\
\hline Total gastos & 65,960 & 55,342 & 42,814 & 28,030 & 10,585 \\
\hline Utilidad antes de impuestos & 141,500 & 145,745 & 150,117 & 154,621 & 159,259 \\
\hline Impuesto a la Renta (30\%) & $\mathbf{4 6 3 , 1 9 7}$ & $\mathbf{4 6 2 , 8 9 0}$ & $\mathbf{4 6 0 , 9 8 2}$ & $\mathbf{4 5 7 , 1 3 7}$ & $\mathbf{4 5 0 , 9 5 9}$ \\
\hline Utilidad Neta (soles) & & & & & \\
\hline & $\mathbf{1 0 3 , 9 5 1}$ & $\mathbf{2 1 6 , 0 8 3}$ & $\mathbf{4 7 4 , 7 0 8}$ & $\mathbf{5 9 9 , 7 7 6}$ & $\mathbf{8 5 0 , 7 3 3}$ \\
\hline
\end{tabular}

Fuente: Elaboración propia.

La inversión del proyecto en soles es la siguiente:

\begin{tabular}{l|rr}
\hline Capital de Trabajo (efectivo de los socios) & $\mathbf{1 1 2 , 2 9 8}$ & $\mathbf{2 1 \%}$ \\
\hline Activo Fijo (financiado por préstamo Banco) & 422,000 & $79 \%$ \\
\hline Total & $\mathbf{5 3 4 , 2 9 8}$ & $\mathbf{1 0 0 \%}$ \\
\hline
\end{tabular}

\subsection{Financiamiento.}

Para cubrir la inversión inicial, ambos socios solicitarán un préstamo personal al Banco con una tasa de interés de $18 \%$ el cual se pagará al completar el 5 to año.

Ver Anexo $\mathrm{N}^{\circ} 07$ Cronograma de financiamiento.

\subsection{Costo de Capital.}

Para determinar el costo de capital hemos utilizado la metodología CAPM, para lo cual se ha utilizado el S\&P 500 y los Bonos del Tesoro Americano (US 5Y T note) de los últimos cinco (05) años de acuerdo al detalle siguiente: 
Tabla 7.14

Costo de capital

\begin{tabular}{l|lll}
\hline S\&P 500 & \multicolumn{3}{|l}{ Inflación USA } \\
\hline Enero-Mayo, 2019 & $1.94 \%$ & Enero-Mayo, & $1.76 \%$ \\
Dec. 31, 2018 & $-4.38 \%$ & 2019 & $2.40 \%$ \\
Dec. 31, 2017 & $21.83 \%$ & 2018 & $2.10 \%$ \\
Dec. 31, 2016 & $11.96 \%$ & 2016 & $1.30 \%$ \\
Dec. 31, 2015 & $1.38 \%$ & 2015 & $0.10 \%$ \\
Promedio & $\mathbf{6 . 5 5 \%}$ & Promedio & $\mathbf{1 . 5 3 \%}$ \\
\hline
\end{tabular}

Fuente: Elaboración propia.

\section{Inflación Perú}

\begin{tabular}{l|r}
\hline Enero-Mayo, 2019 & $\mathbf{2 . 2 5 \%}$ \\
\hline $\mathbf{2 0 1 8}$ & $2.48 \%$ \\
$\mathbf{2 0 1 7}$ & $1.40 \%$ \\
$\mathbf{2 0 1 6}$ & $3.23 \%$ \\
$\mathbf{2 0 1 5}$ & $4.40 \%$ \\
Promedio & $\mathbf{2 . 7 5 \%}$ \\
\hline
\end{tabular}

\section{US 5YR}

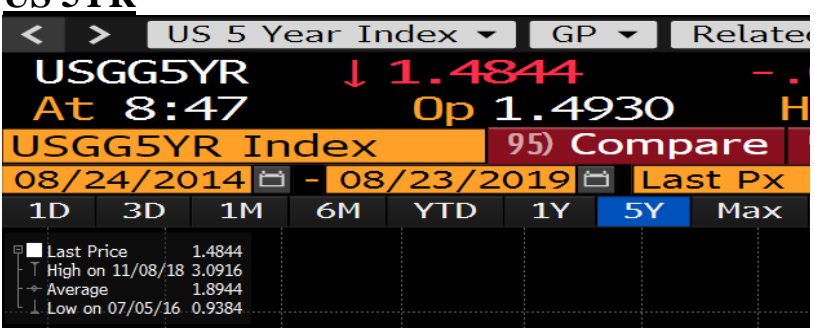

\section{Capital Asset Pricing Model (CAPM)}

http://pages.stern.nyu.edu/ adamodar/New_Home_Page/datafile/Betas.html https://gestion.pe/economia/riesgo-pais-peru-seis-puntos-basicos-cerro-0-93-puntosporcentuales-270997

https://ycharts.com/indicators/sp_500_total_return_annual

Beta desapalancado

0.96 (computer services average 2015-2019)

Beta apalancado

3.49

Bono del Tesoro Americano 5 años

$1.89 \%$

Retorno promedio anual SP\&500

$6.55 \%$ (fuente Bloomberg)

Prima de Riesgo

$4.66 \%$

Riesgo país

$0.93 \%$

Inflación relativa Peru/USA

Cok en USD

1.01

Cok en Soles

Asimismo para convertir el Cok (Costo de Capital) de dólares a moneda nacional se empleó la siguiente formula: $\mathrm{COK}$ en $\mathrm{S} /=\mathrm{COK} \$ \mathrm{X}(1+$ inf Perú $) /(1+$ inf USA). 
Tabla 7.15

Costo promedio de capital

\begin{tabular}{l|rccc}
\hline \multicolumn{1}{c|}{ Financiamiento } & Importe S/. & Participación & $\mathrm{Kd}$ & $\mathrm{Kc}$ \\
\hline Aporte de socios & 112,298 & $21 \%$ & $18 \%$ & $19.28 \%$ \\
Banco & 422,000 & $79 \%$ & & \\
WACC & $14.00 \%$ & & & \\
Impuesto a la renta & $30 \%$ & & & \\
\hline
\end{tabular}

Fuente: Elaboración propia.

\subsection{Flujo de Efectivo.}

La depreciación de instalaciones se realiza a 20 años y los equipos y muebles a 5 años.

Tabla 7.16

Flujo de efectivo en soles.

\begin{tabular}{l|rrrrrr}
\hline \multicolumn{1}{c|}{ Año } & $\mathbf{0}$ & $\mathbf{1}$ & $\mathbf{2}$ & $\mathbf{3}$ & $\mathbf{4}$ & $\mathbf{5}$ \\
\hline Inversión & 534,298 & & & & & \\
\hline Utilidad antes de impuestos & & 148,501 & 308,690 & 678,154 & 856,823 & $1,215,332$ \\
Depreciación Instalaciones & & 4,125 & 4,125 & 4,125 & 4,125 & 4,125 \\
\hline $\begin{array}{l}\text { Depreciación Equipos y Muebles } \\
\text { Utilidad de operación antes de }\end{array}$ & & 49,412 & 49,412 & 49,412 & 49,412 & 49,412 \\
imp. & 534,298 & 202,038 & 362,227 & 731,691 & 910,360 & $1,268,869$ \\
\hline $\begin{array}{l}\text { Impuesto a la renta (30\%) } \\
\text { Utilidad de operación desp. imp. }\end{array}$ & & 44,550 & 92,607 & 203,446 & 257,047 & 364,600 \\
\hline
\end{tabular}

\begin{tabular}{lrrrrr}
\hline \multicolumn{1}{c}{ Años } & \multicolumn{1}{c}{$\mathbf{1}$} & $\mathbf{2}$ & $\mathbf{3}$ & $\mathbf{4}$ & \multicolumn{1}{c}{$\mathbf{5}$} \\
\hline ROI & $19 \%$ & $40 \%$ & $89 \%$ & $112 \%$ & $159 \%$ \\
ROA & $20 \%$ & $41 \%$ & $75 \%$ & $78 \%$ & $86 \%$ \\
ROE & $68 \%$ & $90 \%$ & $110 \%$ & $90 \%$ & $84 \%$ \\
\hline
\end{tabular}

\begin{tabular}{|l|r|}
\hline \multicolumn{2}{|c|}{ Indicadores } \\
\cline { 1 - 1 } VAN (S/.) & $1,024,139$ \\
\hline TIR & $58.40 \%$ \\
\hline
\end{tabular}

Fuente: Elaboración propia.

Los cálculos presentados son basados en nuestro escenario esperado. Se demuestra que el proyecto es altamente atractivo financieramente con un TIR muy superior al WACC y con una recuperación de la inversión durante el tercer año de operaciones. 
Los indicadores de retorno sobre la inversión, retorno sobre el activo y retorno sobre el patrimonio muestran cifras que complementan las buenas perspectivas financieras que tiene el proyecto.

\section{Escenario pesimista}

En un escenario pesimista la participación de mercado de estudiantes y público general no aumentaría. Esto se podría originar por nuevos negocios similares al nuestro que entran en el mercado. Es importante decir que bajo este escenario el precio de venta podría bajar hasta 1.70 soles/gramo. Bajo este escenario todavía logramos un VAN positivo y un TIR aún superior al WACC sin embargo el periodo de recuperación de la inversión se materializa prácticamente en el cuarto año.

\begin{tabular}{l|rrrrr}
\hline Participación Mercado & 2019 & 2020 & 2021 & 2022 & 2023 \\
\hline Estudiantes & $1.00 \%$ & $1.00 \%$ & $1.00 \%$ & $1.00 \%$ & $1.00 \%$ \\
Público general & $0.30 \%$ & $0.30 \%$ & $0.30 \%$ & $0.30 \%$ & $0.30 \%$ \\
\hline
\end{tabular}

\begin{tabular}{l|rrrrrr}
\hline \multicolumn{1}{c}{ Año } & 0 & $\mathbf{1}$ & $\mathbf{2}$ & $\mathbf{3}$ & $\mathbf{4}$ & \multicolumn{1}{c}{$\mathbf{5}$} \\
\hline Inversión & 562,829 & & & & & \\
Utilidad antes de impuestos & & 24,452 & 108,557 & 268,011 & 337,456 & 412,632 \\
Depreciación Instalaciones & & 4,125 & 4,125 & 4,125 & 4,125 & 4,125 \\
Depreciación Equipos y Muebles & & 49,412 & 49,412 & 49,412 & 49,412 & 49,412 \\
Utilidad de operación antes de imp. & 562,829 & 77,989 & 162,094 & 321,548 & 390,993 & 466,169 \\
Impuesto a la renta (30\%) & & 7,336 & 32,567 & 80,403 & 101,237 & 123,790 \\
\hline Utilidad de operación desp. imp. & 562,829 & 70,653 & 129,527 & 241,145 & 289,756 & 342,379 \\
\hline
\end{tabular}

\begin{tabular}{|l|r|}
\hline \multicolumn{1}{|c|}{ Indicadores } & \\
\hline VAN (S/.) & 117,777 \\
\hline TIR & $20.18 \%$ \\
\hline
\end{tabular}

\section{$\underline{\text { Escenario optimista }}$}

En un escenario optimista la participación de mercado aumenta desde el segundo año en forma constante debido a que la idea del negocio es muy bien acogida por el mercado y ciertamente no tenemos competencia. Bajo este escenario podemos maniobrar sin ningún problema nuestro precio de venta. 


\begin{tabular}{|c|c|c|c|c|c|c|}
\hline Participación Mercado & \multicolumn{2}{|c|}{2019} & 2020 & 2021 & 2022 & 2023 \\
\hline Estudiantes & \multicolumn{2}{|c|}{$1.00 \%$} & $1.50 \%$ & $2.00 \%$ & $2.50 \%$ & $3.00 \%$ \\
\hline Público general & \multicolumn{2}{|c|}{$0.30 \%$} & $0.35 \%$ & $0.40 \%$ & $0.45 \%$ & $0.50 \%$ \\
\hline Año & 0 & 1 & 2 & 3 & 4 & 5 \\
\hline Inversión & 562,829 & & & & & \\
\hline Utilidad antes de impuestos & & 24,452 & 528,078 & 937,324 & $1,438,953$ & $2,018,033$ \\
\hline Depreciación Instalaciones & & 4,125 & 4,125 & 4,125 & 4,125 & 4,125 \\
\hline Depreciación Equipos y Muebles & & 49,412 & 49,412 & 49,412 & 49,412 & 49,412 \\
\hline Utilidad de operación antes de imp. & 562,829 & 77,989 & 581,615 & 990,861 & $1,492,490$ & $2,071,570$ \\
\hline Impuesto a la renta $(30 \%)$ & & 7,336 & 158,423 & 281,197 & 431,686 & 605,410 \\
\hline Utilidad de operación desp. imp. & 562,829 & 70,653 & 423,192 & 709,664 & $1,060,804$ & $1,466,160$ \\
\hline
\end{tabular}

\begin{tabular}{|l|r|}
\cline { 1 - 1 } Indicadores & \\
\hline VAN (S/.) & $1,718,181$ \\
\hline TIR & $70.00 \%$ \\
\hline
\end{tabular}

\subsection{Balance General.}

Los inventarios consideran 3 meses de carretes de material de impresión. Es política de la empresa repartir dividendos todos los años.

Tabla 7.17

Balance General en soles

\begin{tabular}{|c|c|c|c|c|c|}
\hline & 2019 & 2020 & 2021 & 2022 & 2023 \\
\hline \multicolumn{6}{|l|}{ Activo } \\
\hline \multicolumn{6}{|l|}{ Circulante } \\
\hline Caja & 230,615 & 299,396 & 455,853 & 650,161 & 925,083 \\
\hline \multirow[t]{2}{*}{ Inventarios } & 10,254 & 11,840 & 16,670 & 18,893 & 23,439 \\
\hline & 240,869 & 311,235 & 472,523 & 669,054 & 948,523 \\
\hline \multicolumn{6}{|l|}{ No circulante } \\
\hline Edificación (remodelación) & 82,500 & 82,500 & 82,500 & 82,500 & 82,500 \\
\hline Equipos & 247,060 & 247,060 & 247,060 & 247,060 & 247,060 \\
\hline \multirow[t]{2}{*}{ (-) Depreciación acumulada } & $-53,537$ & $-107,074$ & $-160,611$ & $-214,148$ & $-267,685$ \\
\hline & 276,023 & 222,486 & 168,949 & 115,412 & 61,875 \\
\hline Total activo & 516,892 & 533,721 & 641,472 & 784,466 & $1,010,398$ \\
\hline \multicolumn{6}{|l|}{ Pasivos } \\
\hline \multicolumn{6}{|l|}{ A largo plazo } \\
\hline Cuenta por pagar socio & 363,014 & 293,410 & 211,278 & 114,361 & 0 \\
\hline Total pasivo & 363,014 & 293,410 & 211,278 & 114,361 & $\mathbf{0}$ \\
\hline \multicolumn{6}{|l|}{ Capital contable } \\
\hline Capital social & 112,298 & 112,298 & 112,298 & 112,298 & 112,298 \\
\hline Resultados del ejercicio & 103,951 & 216,083 & 474,708 & 599,776 & 850,733 \\
\hline Dividendos $(60 \%)$ & $-62,370$ & $-129,650$ & $-284,825$ & $-359,866$ & $-510,440$ \\
\hline Resultado acumulado & 41,580 & 128,013 & 317,896 & 557,807 & 898,100 \\
\hline Total capital contable & 153,878 & 240,311 & 430,194 & 670,105 & $1,010,398$ \\
\hline Total pasivo y capital contable & 516,892 & 533,721 & 641,472 & 784,466 & $1,010,398$ \\
\hline
\end{tabular}

Fuente: Elaboración propia. 


\subsection{Punto de Equilibrio.}

El punto de equilibrio se define como lo mínimo que se deberá producir y vender en un período determinado para cubrir los sueldos y costos. Es decir cuando la utilidad del período es cero (no registramos pérdidas ni ganancias).

Debido a que las impresiones 3D son el "core business" del proyecto, generando más del $80 \%$ de los ingresos, su peso relativo se usará para obtener los costos fijos propios del proceso de impresión y por consiguiente analizar el punto de equilibrio de las impresiones 3D.

\section{Tabla 7.18}

Punto de Equilibrio de las impresiones 3D.

\begin{tabular}{l|rrrrr}
\hline Año & 2019 & 2020 & 2021 & 2022 & 2023 \\
\hline Ingresos por impresión & $85 \%$ & $85 \%$ & $86 \%$ & $86 \%$ & $86 \%$ \\
Ingresos por diseño/escaneado & $6 \%$ & $6 \%$ & $6 \%$ & $6 \%$ & $6 \%$ \\
Ingresos cafetería & $9 \%$ & $9 \%$ & $8 \%$ & $8 \%$ & $8 \%$ \\
Ingreso ventas & $\mathbf{1 0 0 \%}$ & $\mathbf{1 0 0 \%}$ & $\mathbf{1 0 0 \%}$ & $\mathbf{1 0 0 \%}$ & $\mathbf{1 0 0 \%}$ \\
\hline
\end{tabular}

\begin{tabular}{lrrrrrr}
\hline & $\mathbf{2 0 1 9}$ & $\mathbf{2 0 2 0}$ & $\mathbf{2 0 2 1}$ & $\mathbf{2 0 2 2}$ & $\mathbf{2 0 2 3}$ \\
\hline Peso relativo de impresión sobre ventas totales & 0.85 & 0.85 & 0.86 & 0.86 & 0.86 \\
\hline $\begin{array}{l}\text { Costos Fijos (gastos operativos, administrativos, } \\
\text { financieros, alquiler y servicios) }\end{array}$ & 503,860 & 506,379 & 507,382 & 506,535 & 503,445 \\
Costos Fijos de Impresión & 429,944 & 429,378 & 436,931 & 435,021 & 433,623 \\
\hline Precio venta (S/gr) & 1.80 & 1.85 & 1.91 & 1.97 & 2.03 \\
\hline Demanda impresión (gr.) & 238,858 & 231,595 & 228,805 & 221,170 & 214,038 \\
\hline Costo unitario materia prima (S/gr) & 0.100 & 0.103 & 0.106 & 0.109 & 0.113 \\
\hline Punto de equilibrio en cantidad gramos & 252,908 & 245,219 & 242,264 & 234,180 & 226,628 \\
\hline Consumo promedio de producto terminado (gr) & 53 & 53 & 53 & 53 & 53 \\
\hline Punto de equilibrio en unidades impresas 3D & 4,790 & 4,644 & 4,588 & 4,435 & 4,292 \\
\hline
\end{tabular}

Fuente: Elaboración propia.

Del cuadro precedente obtenemos la demanda de impresión en gramos dividiendo el costo fijo entre el precio de venta. Con la información obtenida empleamos la formula siguiente para calcular nuestro punto de equilibrio en gramos.

Punto de equilibrio $=$ Costo Fijo / (Precio de venta - Costo variable unitario)

Finalmente para obtener nuestro punto de equilibrio en número de impresiones hemos considerado un tiempo promedio de impresión entre las horas de impresión estudiantes y horas de impresión público y el consumo promedio de 22 gramos por hora. 
Con esta información obtenemos que un producto terminado consume 53 gramos de material.

\begin{tabular}{l|r}
\hline horas promedio impresión estudiantes & 3.5 \\
\hline horas promedio impresión público & 1.3 \\
\hline Promedio horas para un producto & 2.40 \\
Consumo promedio de $22 \mathrm{gr} / \mathrm{hora}$ & \\
Impresión promedio contiene en gr. & 53 \\
\hline
\end{tabular}

Nota: Información proporcionada por Lima Makers quienes utilizan impresoras Zortrax para sus trabajos. Asimismo para cada año de operación se ha realizado un ajuste por inflación anual del 3\%. Para el precio de venta y el costo unitario.

\subsection{Liquidación del negocio.}

Para lograr obtener un valor referencial de los flujos de ingresos después del quinto año, hemos empleado una regresión lineal simple sobre los flujos de los primeros cinco años como se muestra a continuación y expresados en soles:

Figura 7.1

Proyección de flujos de ingresos

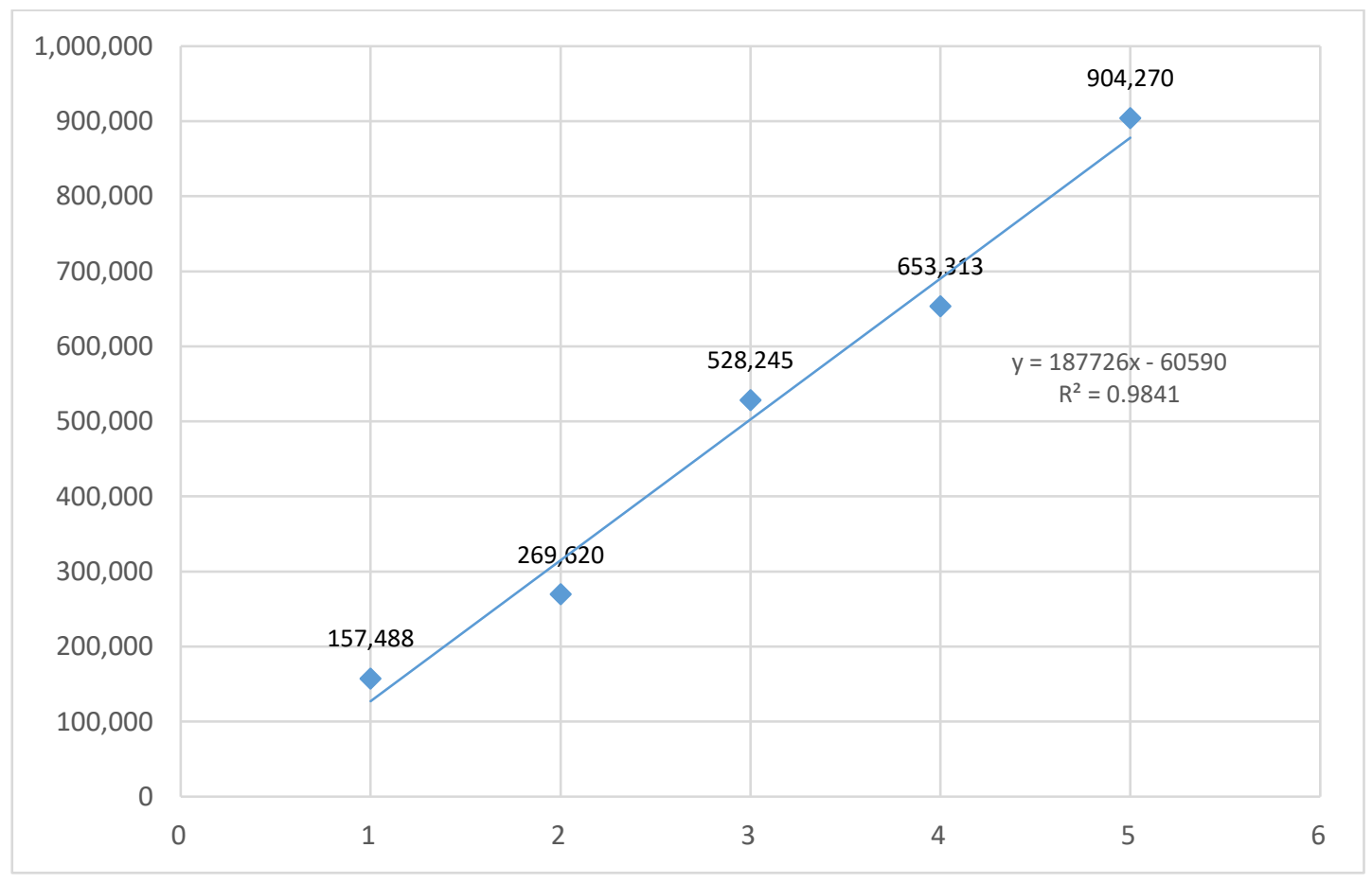

Fuente: Elaboración propia 
Con la ecuación obtenida proyectamos los flujos de los siguientes cinco años (2024 - 2028):

\begin{tabular}{|r|r|r|}
\hline \multicolumn{1}{|c|}{ Año } & Flujo Efectivo \\
\cline { 2 - 3 } 1 & 19 & 157,488 \\
\cline { 2 - 3 } 2 & 20 & 269,620 \\
\cline { 2 - 3 } 3 & 21 & 528,245 \\
\hline 4 & 22 & 653,313 \\
\hline 5 & 23 & 904,270 \\
\hline 6 & 24 & $1,568,931$ \\
\hline 7 & 25 & $1,882,982$ \\
\hline 8 & 26 & $2,197,033$ \\
\cline { 2 - 3 } 9 & 27 & $2,511,084$ \\
\cline { 2 - 3 } 10 & 28 & $2,825,135$ \\
\cline { 2 - 3 } & &
\end{tabular}

Al final del quinto año será necesario renovar los equipos de impresión 3D (impresoras, scanners, desktops, monitores, software entre otros equipos tecnológicos) y adquirir equipos adicionales así como nuevos asesores de diseño para hacer frente a la demanda aún creciente del negocio.

No pensamos obtener un valor de reventa de estos equipos al quinto año ya que los mismos serán donados para que sean usados en algún colegio público para lograr que niños con escasos recursos puedan tener contacto con esta tecnología y de esta manera incentivar su creatividad y difundir en ellos los beneficios de esta herramienta.

Durante la vida del proyecto es fuertemente probable que lleguen a nuestro país franquicias muy similares a nuestro modelo de negocio como las mencionadas en capítulos anteriores. Esto lleva a los socios a estar preparados para ya sea asociarnos y poder crecer más rápidamente en Lima y provincias con nuevos locales o vender nuestro negocio a alguna franquicia internacional.

El valor de venta de la empresa se basa en los flujos proyectados después del quinto año que según los cálculos obtenidos es de aproximadamente 11 millones de soles. A este importe tendríamos que adicionar el valor de nuestra marca a ese momento según nuestra participación y liderazgo en el mercado.

Sin embargo esta idea de negocio no podrá generar flujos rentables infinitos. Llegará un momento en que esta tecnología será accesible a la gran mayoría debido al bajo costo de los equipos de impresión y también al concepto y uso de esta herramienta 
que se habrá expandido en la población y será una herramienta más en casa usada para resolver problemas diarios.

Creemos que en 10 años la idea de negocio habrá alcanzado la madurez y en 15 años estaremos entrando en un proceso de declive. Es muy probable que el negocio termine como sus antecesores, las cabinas de internet, que en la actualidad siguen existiendo pero sin ser negocios rentables sino más bien de subsistencia.

\section{Figura 7.2}

Flujos proyectados del negocio a 10 años

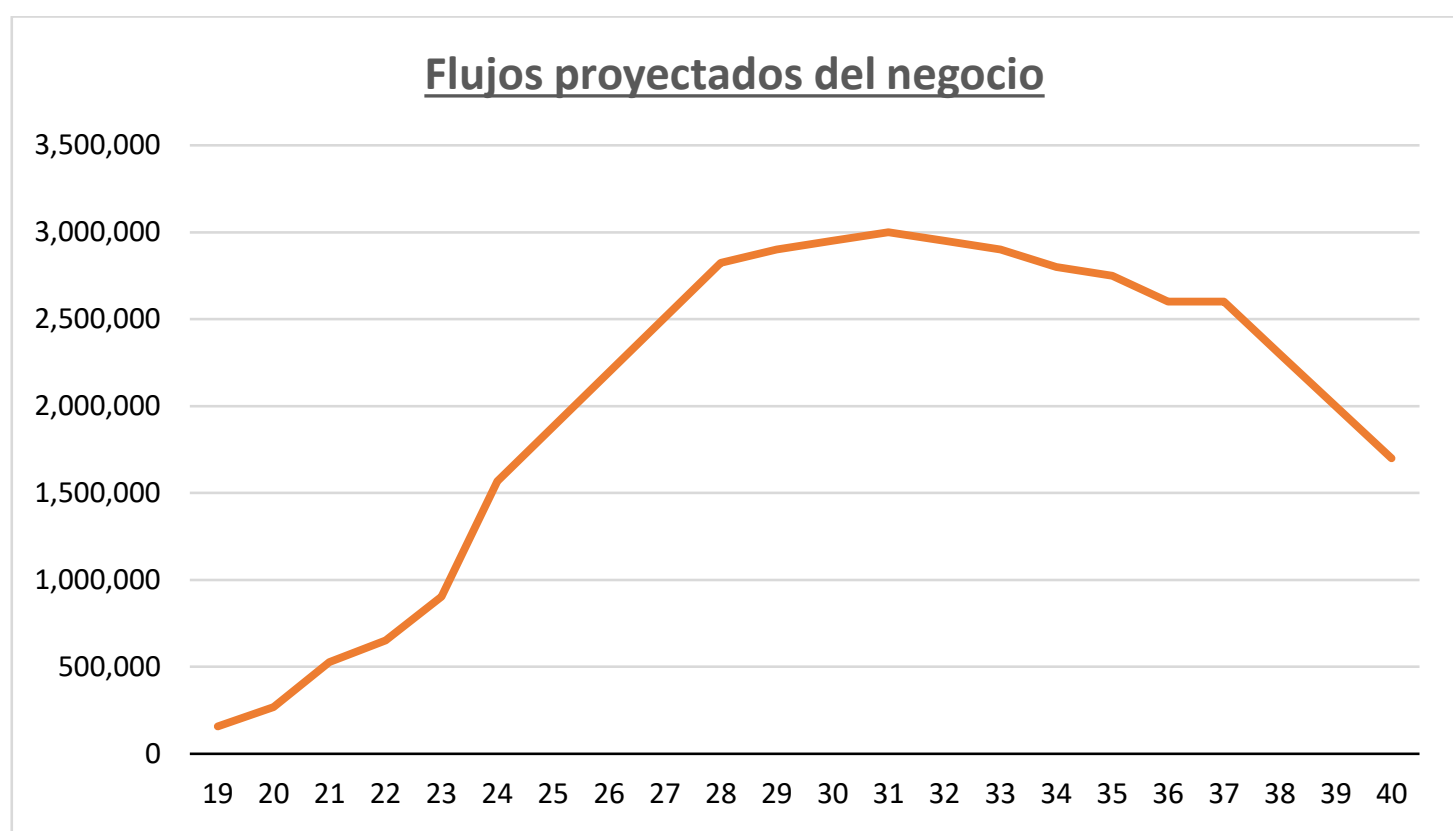

Fuente: Elaboración propia 


\section{CONCLUSIONES}

- El modelo de negocio de 3D LAB \& CAFÉ es único en la ciudad de Lima (no contamos con competencia directa). Por lo tanto, tendremos ventaja al ser los primeros en explotar este concepto en el Perú.

- Existe una demanda por satisfacer a nivel de estudiantes (universidades e institutos) que necesitan hacer sus impresiones de trabajos en 3D.

- A pesar que la impresión 3D es poco conocido por el público en general, los resultados de las encuestas muestran un gran optimismo en conocer este concepto, tal cual se viene demostrando en otros países en donde este modelo de negocio se viene desarrollando y ganando popularidad.

- Para la implementación de nuestro negocio es primordial crear un espacio confortable, original e innovador donde el cliente viva toda una experiencia al momento de usar la tecnología de impresión 3D.

- Trabajar en crear la necesidad de fabricar en 3D. Despertar en el público sus capacidades creativas y enseñarles a transformar sus ideas en objetos que puedan tocar y disfrutar.

- Analizando los resultados financieros dentro del escenario esperado, se concluye que el proyecto genera una buena rentabilidad. 


\section{RECOMENDACIONES.}

A continuación, detallaremos las recomendaciones:

- Se recomienda comenzar con el proyecto lo más pronto posible, debido a que se podría perder la ventaja de ser los primeros en iniciar este modelo de negocio.

- El proyecto puede también extenderse hacia niños entre 7 y 12 años con el propósito de enseñarles a fabricar sus propios juguetes contribuyendo de esta manera a incentivar su creatividad.

- Este proyecto puede también captar la demanda de empresas que acudan a nosotros para desarrollar impresiones de mediana complejidad.

- Dentro de la responsabilidad social de la empresa, se pueden crear campañas de fabricación de prótesis para personas de bajos recursos que sufran algún tipo de discapacidad.

- Es primordial de siempre hacer un constante seguimiento a los cambios de esta tecnología de impresión 3D ya que hay muchas mejoras que se harán en el futuro en cuanto a velocidad de impresión y capacidad de imprimir en diversos materiales.

- La participación en eventos o exposiciones de Impresión 3D e Innovación es de vital importancia para que el negocio se haga conocido más rápidamente.

- Estamos convencidos que el desarrollo de esta tecnología llevará la sociedad a la Tercera Revolución Industrial: “Dejar de ser consumidores para ser creadores”.

- Estamos seguros que esta idea de negocio tiene posibilidades de crecimiento de al menos 10 años ya que la impresión 3D como hobby es un concepto que todavía no está desarrollado en nuestra sociedad. 


\section{REFERENCIAS}

MOLEÓN RODRÍGUEZ, Francisco Javier. (2010). “Plan de Negocio de Impresión”, Universidad de León de España, Facultad de Administración de Empresas.

SUAREZ, Juan Javier, “Plan de negocios para empresa de impresión 3D”, Universidad de Aconcagua, Facultad de Ciencias Económicas y Jurídicas, 2015.

Vazhnov, Andrei. (2015) Impresión 3D: ¿Cómo va a cambiar el mundo?, London, Palgarave Macmillan.

BCRP, (2016). Departamento de Estadísticas de Precios Subgerencia de Estadísticas Macroeconómicas Gerencia de Información y Análisis Económico, Indicadores del Mercado Inmobiliario.

INEI, (2014). Encuesta Nacional a Egresados Universitarios y Universidades.

Banco de la Nación, (2014). Reporte Diario de Mercado Sub Gerencia Estudios Económicos y Financieros. 
ANEXOS 


\section{Anexo 1: Visita al local 3d Lab Fab de México.}

El local se encuentra ubicado en Calle Tonalá 89, esquina Álvaro Obregón, Ciudad de México.

\section{PERSONAL:}

El local cuenta con dos empleados para la atención del público que requiere de café, trago, piqueo o sándwich y un técnico operador de las máquinas de impresión y escáner, quien a la vez es responsable de la coproducción de los artículos.

\section{EQUIPO:}

- El local cuenta con una impresora Zortrax m200, tres impresoras básicas y dos escáneres, para la producción de trabajos de impresión en 3D.

- Cuenta con equipo y mobiliario propio de un café restaurant.

- El ambiente del local es sencillo y austero, cuenta con una buena distribución interna.

\section{MATERIA PRIMA:}

Utilizan filamentos de termoplástico entre los que destacan:

ABS: el acrilonitrilo butadieno estireno es uno de los termoplásticos más usados en la impresión 3D. No es biodegradable, pero es muy tenaz, duro y rígido, con resistencia química y la abrasión, pero que sufre con la exposición a rayos UV. Es soluble en acetona y su densidad es de $1,05 \mathrm{~g} / \mathrm{cm}^{3}$. Requiere una temperatura de cabezal de unos $240^{\circ} \mathrm{C} \mathrm{y} \mathrm{de}$ bandeja de $110^{\circ} \mathrm{C}$. Por ejemplo, las piezas de LEGO están hechas de ABS.

PLA: el ácido poliláctico es otro de los filamentos estrella de la impresión 3D. Es biodegradable y normalmente se obtiene de almidón de maíz, por lo que al derretirse huele casi a comida y puede usarse para recipientes de comida. La textura de las piezas no queda tan suave como con el ABS, pero sí más brillantes y las esquinas salen mejor. $\mathrm{Su}$ densidad es de entre 1,2 y $1,4 \mathrm{~g} / \mathrm{cm}^{3}$. La temperatura necesaria para su impresión es de unos $210^{\circ} \mathrm{C}$ con la cama a unos $60^{\circ} \mathrm{C}$.

HIPS: el poliestireno de alto impacto es un material muy parecido al ABS, y que requiere los mismos perfiles de temperaturas. Suele usarse en combinación con el ABS para hacer piezas con espacios huecos, usando el HIPS como soporte que luego se eliminará con DLimoneno, con el que es soluble mientras que a él la acetona no le afecta. Al igual que el 
ABS soporta mal la luz UV y su densidad es de $1,04 \mathrm{~g} / \mathrm{cm}^{3}$. Hemos usado las mismas temperaturas que con el ABS.

\section{MODELOS DE DISEÑO:}

Los usuarios de estos productos normalmente son estudiantes de ingeniería y arquitectura, quienes envían sus diseños vía web y otros llevan personalmente sus diseños para imprimir, en estos casos el operador participa conjuntamente con el cliente en la coproducción del diseño. A la vez en el local el operador también se dedica a la impresión de sus propios diseños los cuales son ofrecidos al público para la venta.

\section{MANTENIMIENTO:}

El mantenimiento básico de las impresoras es realizado por el técnico encargado de la operación, pues cuenta con la capacitación del fabricante de las impresoras y cuando requiere de un mantenimiento más especializado las impresoras son enviadas al fabricante para la inspección y cambio de componentes. 


\section{FOTOS}

\section{EQUIPOS DE IMPRESION}
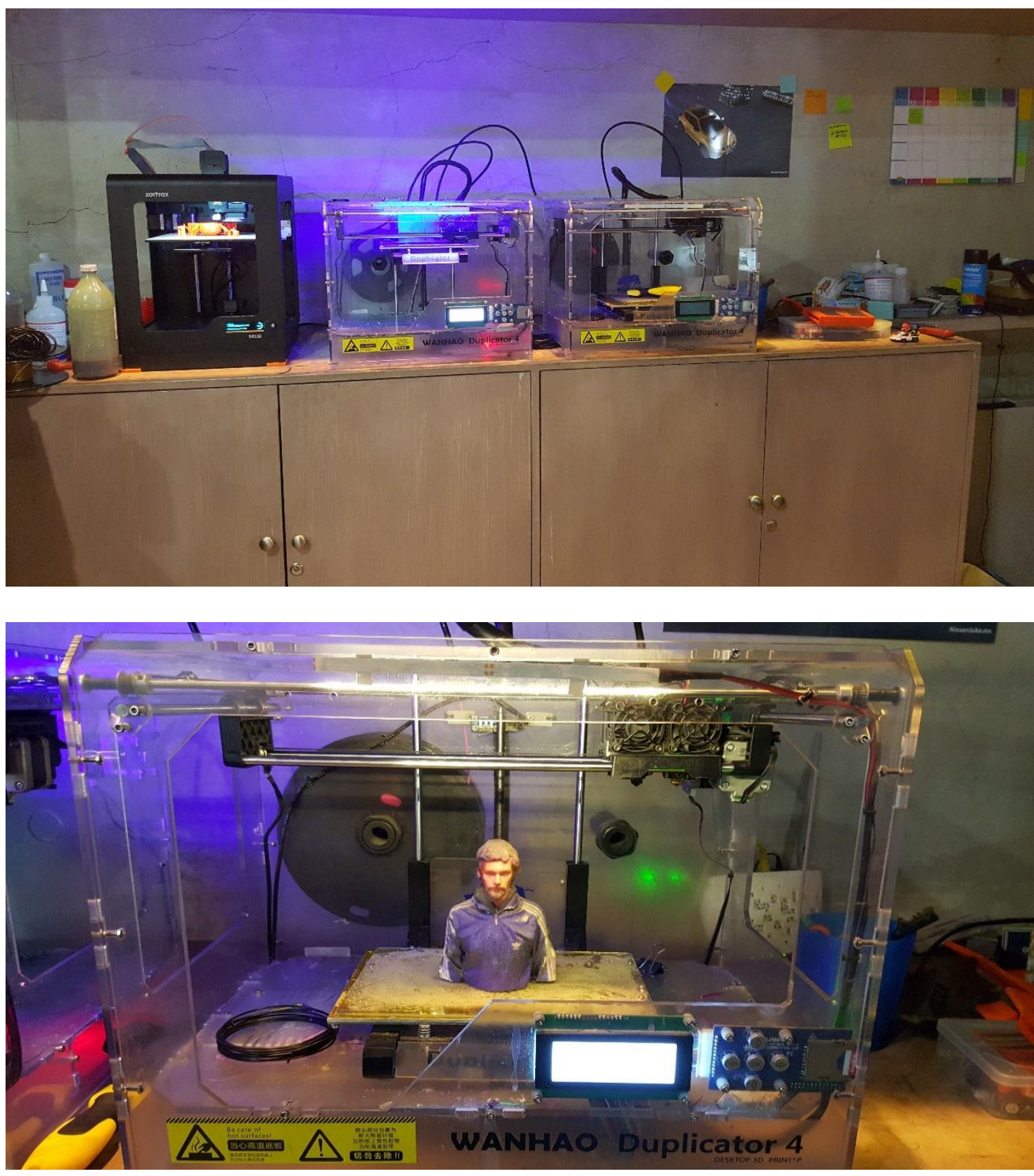

ESCANER 3D 


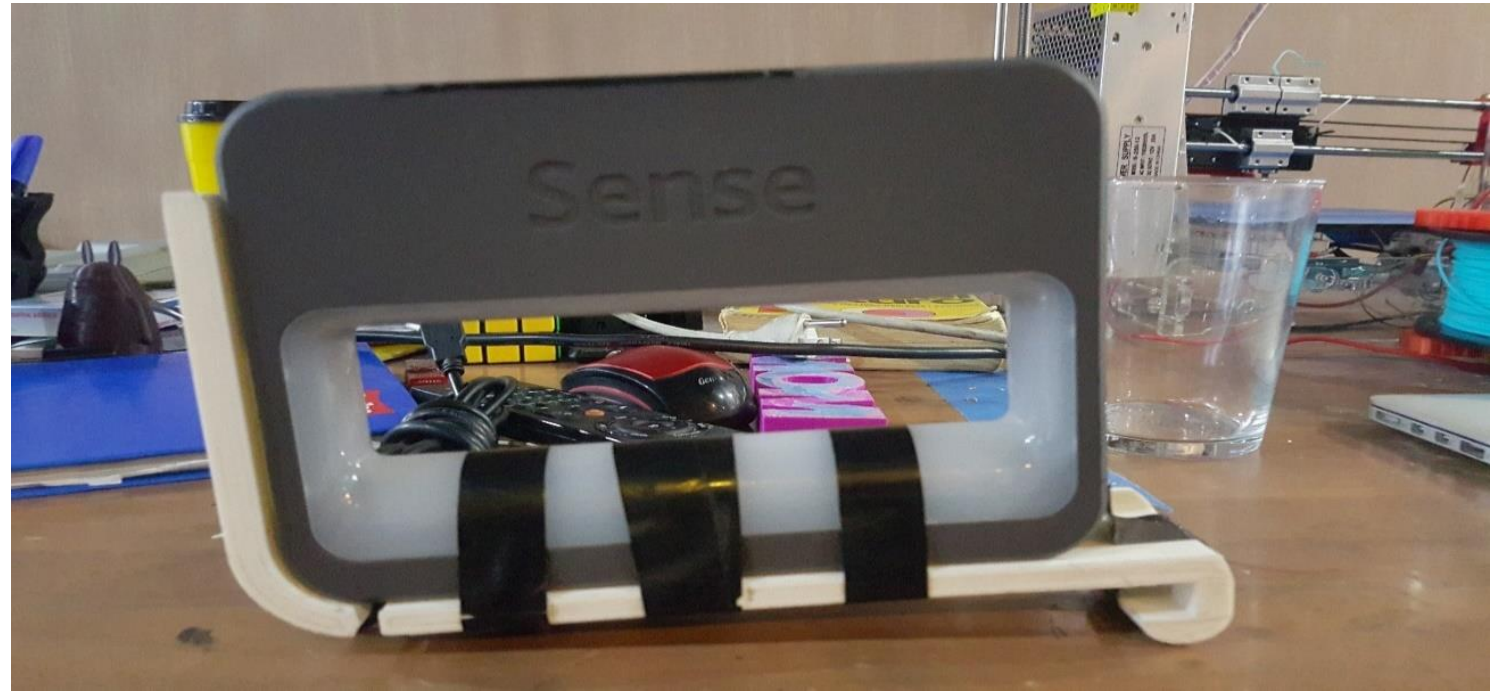

INSUMOS DE IMPRESION

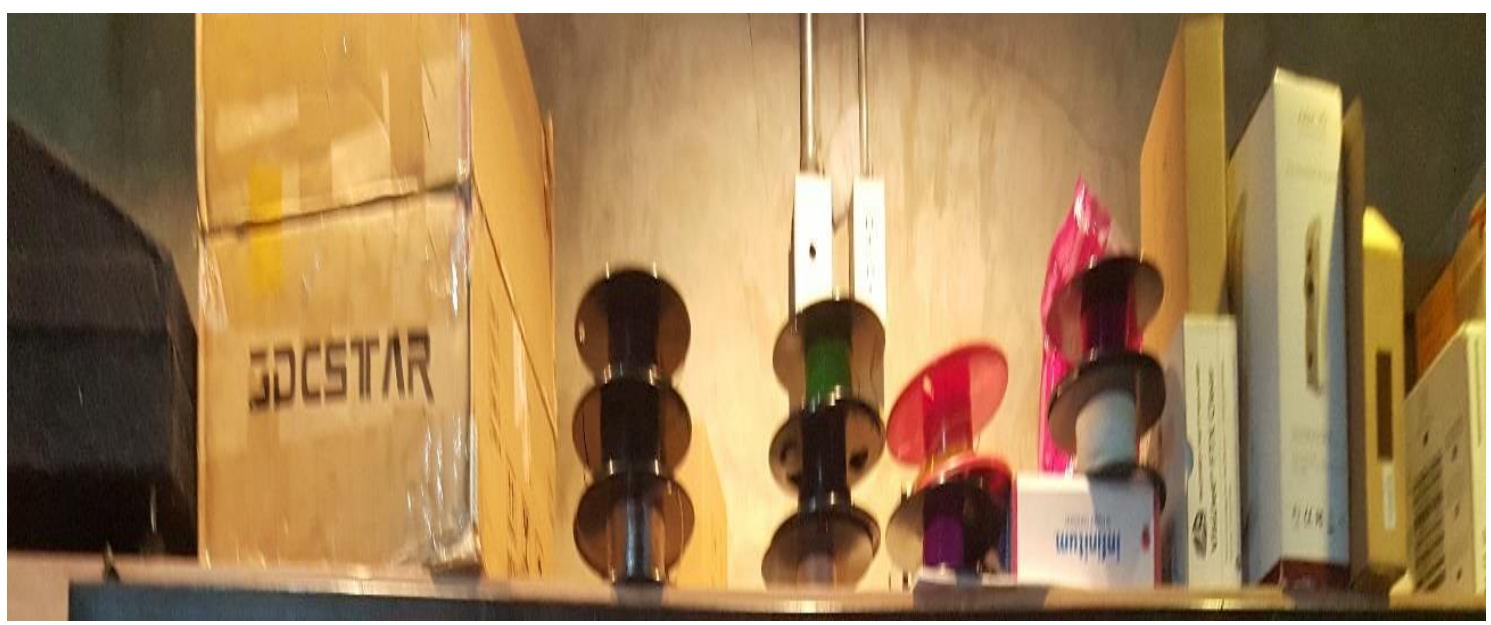

PRODUCTOS TERMINADOS

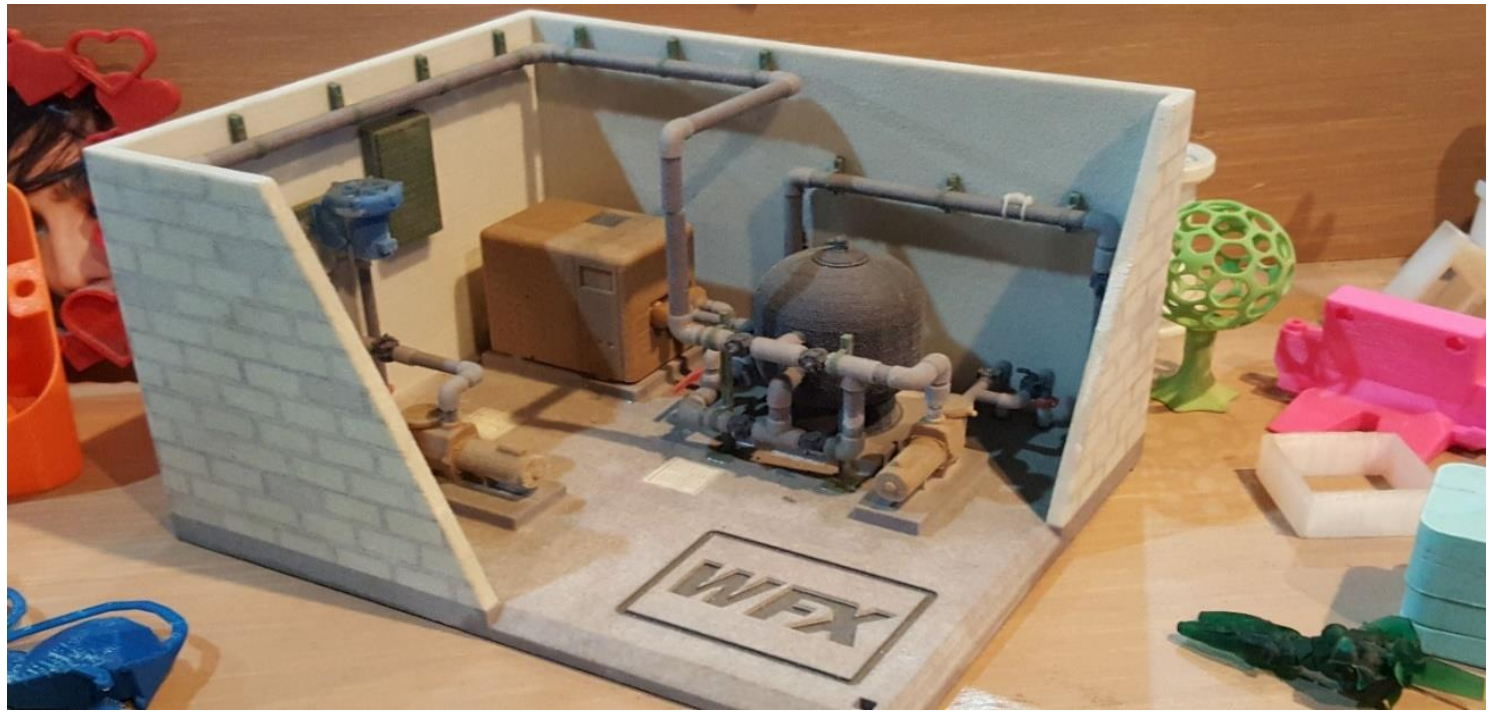



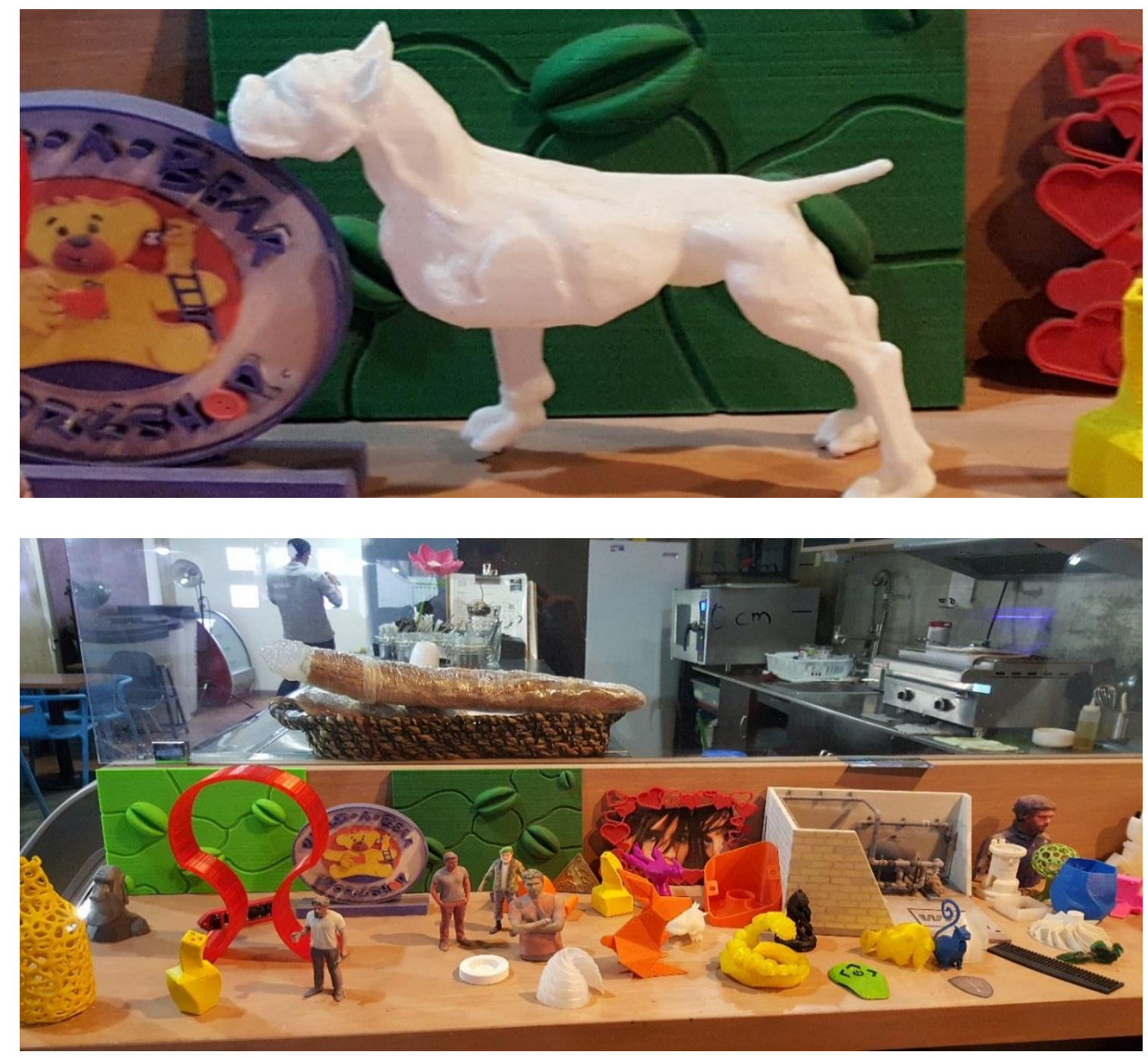

\section{VISTAS DEL INTERIOR DEL LOCAL}

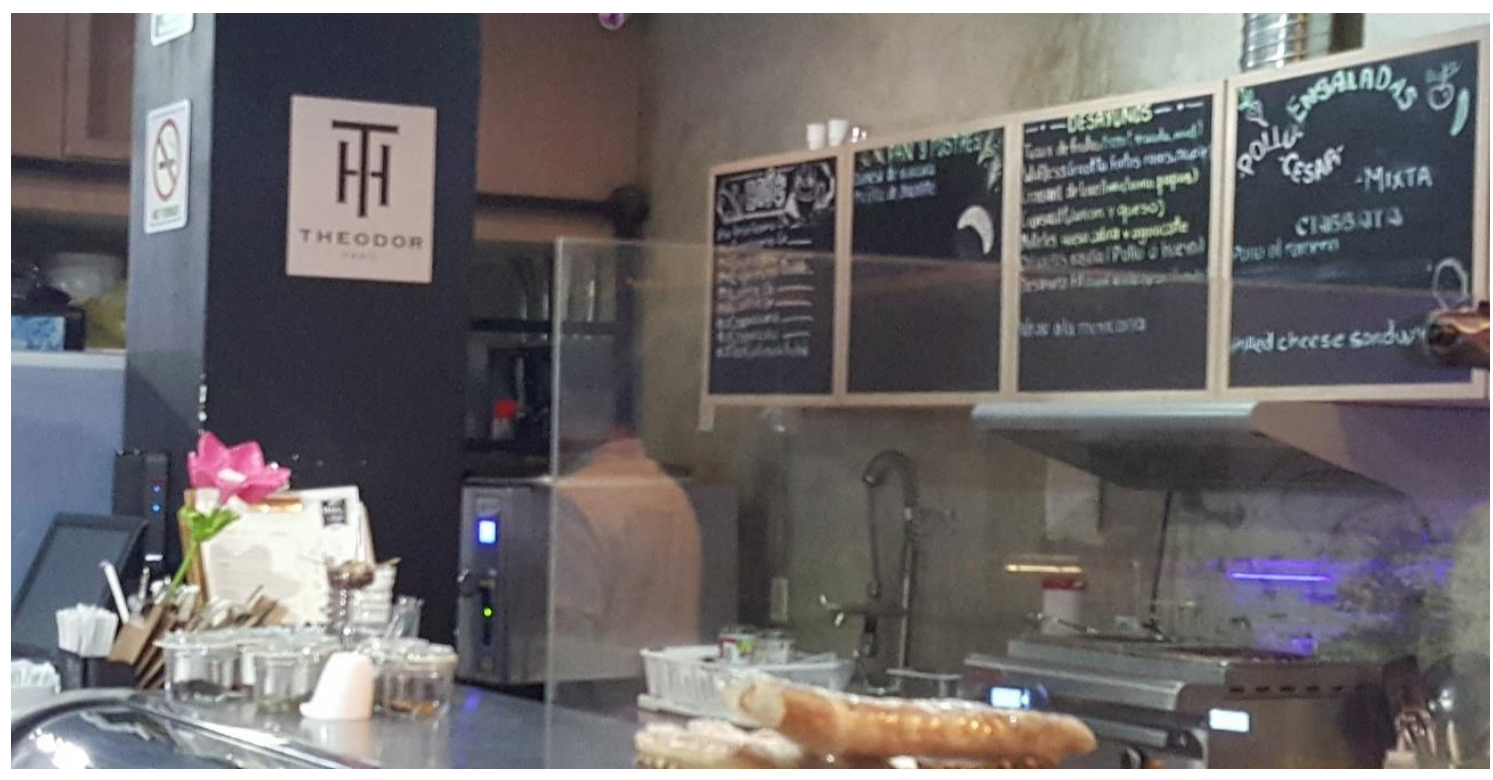

AREA DE CAFETERIA 


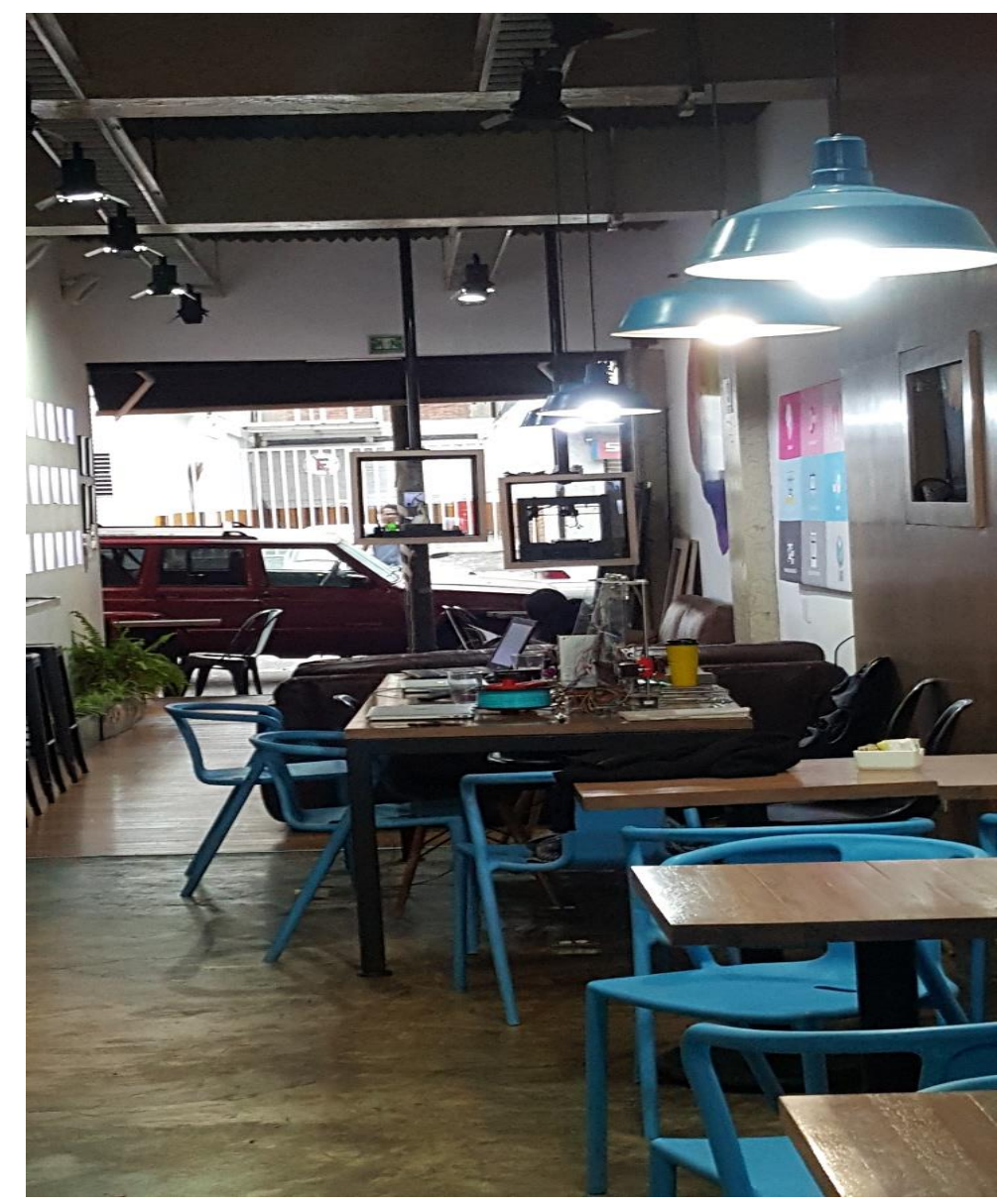

AREA DE MOLDEADO 


\section{Anexo 2: Metodología de investigación}

\begin{tabular}{|c|c|c|c|c|c|}
\hline \multirow[b]{2}{*}{ Objetivos } & \multirow[b]{2}{*}{ Objetivos Específicos } & \multicolumn{4}{|c|}{ Herramientas } \\
\hline & & OI & FS & $\mathbf{E E}$ & EC \\
\hline $\begin{array}{l}\text { Determinar motivadores y expectativas de la } \\
\text { impresión 3D en Lima }\end{array}$ & $\begin{array}{l}\text { Conocer el comportamiento de los usuarios actuales de } \\
\text { impresión 3D }\end{array}$ & $\mathrm{x}$ & & & $\mathrm{x}$ \\
\hline \multirow[t]{2}{*}{ Identificar al público objetivo (Características) } & Conocer los usos y necesidades de la impresión 3D & $\mathrm{x}$ & $\mathrm{x}$ & & $\mathrm{x}$ \\
\hline & Conocer el presupuesto promedio en impresión 3D & $\mathrm{x}$ & $\mathrm{x}$ & & $\mathrm{x}$ \\
\hline Validar la idea de negocio & $\begin{array}{l}\text { Conocer si cumple con las expectativas de los usuarios } \\
\text { actuales de impresión 3D }\end{array}$ & & & $\mathrm{x}$ & $\mathrm{x}$ \\
\hline \multirow[t]{4}{*}{$\begin{array}{l}\text { Determinar el modelo de negocio de acuerdo a la } \\
\text { experiencia actual de los usuarios de impresión 3D }\end{array}$} & Conocer empresas actuales que ofrecen impresiones 3D & $\mathrm{x}$ & $\mathrm{x}$ & & $\mathrm{x}$ \\
\hline & Conocer los servicios actuales que se ofrecen y usos & & $\mathrm{x}$ & & $\mathrm{x}$ \\
\hline & $\begin{array}{l}\text { Determinar las necesidades que complementan la } \\
\text { espectativa del target }\end{array}$ & $\mathrm{x}$ & & & $\mathrm{x}$ \\
\hline & Conocer los riesgos de la puesta en marcha & & $\mathrm{x}$ & & $\mathrm{x}$ \\
\hline \multirow[t]{3}{*}{ Definir el marketing mix de 3D Lab Café } & $\begin{array}{l}\text { Conocer el valor (precio/beneficio) que pagarían los } \\
\text { usuarios }\end{array}$ & & & $\mathrm{x}$ & $\mathrm{x}$ \\
\hline & Definir la promoción & $\mathrm{x}$ & & & $\mathrm{x}$ \\
\hline & Definir lugar del local & $\mathrm{x}$ & & & $\mathrm{x}$ \\
\hline
\end{tabular}

OI: Observación

FS: Fuentes secundarias

EE: Entrevistas

EC: Encuesta 


\section{Anexo 3: Encuestas para público universitario}

Datos

1 demográficos

Centro de estudios

Carrera

Ciclo

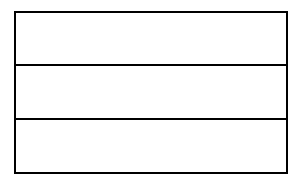

Género

Edad

Distrito/Teléfono

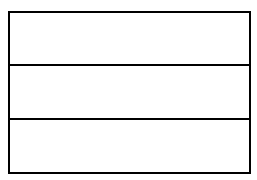

¿Ha escuchado o conoce usted alguno de los servicios que se mencionan a

2 continuación?

Impresión 3D

Escaneo 3D

Modelado 3D

Servicios de Corte (Fresado, láser)

Maquetación 3D

Ninguna de las anteriores, pase a la pregunta 09 en adelante

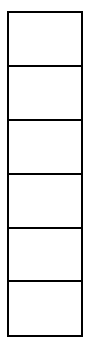

3 ¿De cuál hizo uso?

Impresión 3D

Escaneo 3D

Modelado 3D

Servicios de Corte (Fresado, láser)

Maquetación 3D

Ninguna de las anteriores, pase a la pregunta 09 en adelante

4 ¿Cuál fue la finalidad?

Estudios

Laboral (presentaciones, propuestas, prototipos)

Entretenimiento

Prueba de equipos

Otros:

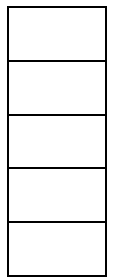

5 ¿Con qué empresas o agencias tomó estos servicios? (mencione al menos uno) 
¿Cuál es el factor más importante para usted a la hora de tomar el 6 servicio?

Calidad de impresión

Rapidez/Precisión impresoras

Cumplimiento de tiempos por parte del Laboratorio

Atención al cliente

El lugar de atención

Recomendación de amigos y/o colegas

Otros:

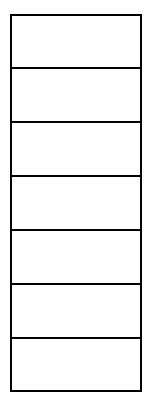

7 ¿Cuál es el tiempo promedio que tarda en completar la impresión 3D de sus diseños?, Indicar un rango de tiempos.

$0-1$ hora

1-2 horas

3-4 horas

4+ horas

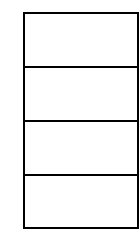

8 ¿Con qué frecuencia toma estos servicios?

Semanal

Mensual

Bimestral

Anual

Otros:

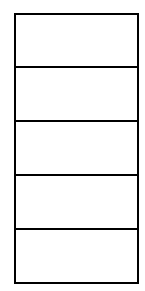

9 ¿Estaría interesado en probar alguno de los servicios mencionados?

SI

NO

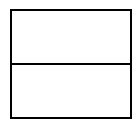

10 ¿Qué debería ocurrir para que usted pruebe esta tecnología?

¿Cuánto es el rango promedio de precios que pagaría por imprimir sus

11 diseños en 3D?

$\mathrm{S} / .50-\mathrm{S} / .100$

$\mathrm{S} / .100-\mathrm{S} / .200$

S/. 200- S/.300

S/. 300- S/.400

$\mathrm{S} / .400+$

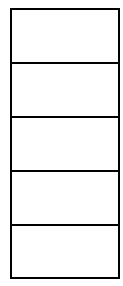


12 ¿Qué considera que falta explotar en el mercado de Diseño e Impresión 3D?

13 Asistiría a una cafetería donde armar su propio diseño, poner a prueba su lado creativo y disfrutar de un ambiente agradable junto con amigos, familia, hijos o colegas

SI

NO

14 ¿A través de qué medio quisiera recibir información sobre estos servicios?

Redes sociales:

Publicidad externa

Charlas informativas en su centro de estudios

Otros: 


\section{Anexo 4: Encuesta para público en general}

1 Datos demográficos

Ocupación:

Género:

Edad:

Distrito de residencia:

2 ¿Con qué frecuencia visita una cafetería?

Todos los días

Semanalmente

Cada 15 días

Una vez al mes

Nunca

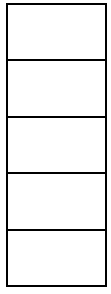

¿Le parece interesante la idea de un espacio con el concepto de cafetería donde 3 usted puede incentivar su creatividad, el intercambio de ideas, el arte y el diseño; que además, combine las nuevas tecnologías de impresión 3D y escáner 3D contando con asesoría especializada y disfrutar de un ambiente agradable junto con amigos, familia, hijos o colegas de trabajo?

Muy interesante

Interesante

Medianamente interesante

Poco interesante

Des interesante

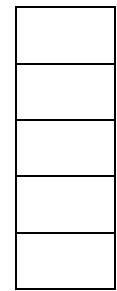

4 ¿Conoces amigos, conocidos o familiares que trabajen o hayan usado impresión 3D, escaneo 3D o se dediquen alguna profesión del diseño en general?

Sí

No

Coméntanos:

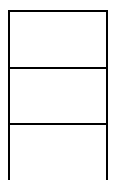

5 ¿Qué tipo de objetos realizados por usted le gustaría poder hacer realidad en una impresora 3D?

Su propia imagen convertida en un muñeco

Su juguete favorito

Retratos de personas

Objetos de recuerdos

Su mascota

Otros:

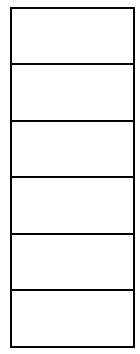


6 ¿En qué distritos te gustaría encontrar este tipo de cafeterías con impresiones en 3D? , coméntanos por qué:

7 Si la cafetería estaría funcionando en este momento, ¿Qué probabilidad hay que la visite durante esta semana?

Muy alta

Alta

Media

Baja

Muy baja

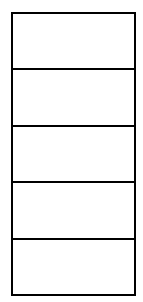

¿Qué tanto estaría dispuesto a pagar por hacer realidad su propio diseño en una 8 impresora 3D?
S/. $50-\mathrm{S} / .100$
S/. $100-\mathrm{S} / .200$
S/. 200- S/.300
S/. 300- S/.400
$\mathrm{S} / .400+$

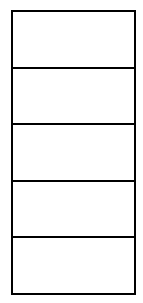

9 ¿Qué tiempo dedicarías a realizar esta actividad?

0-1 hora

1-2 horas

3-4 horas

4+ horas

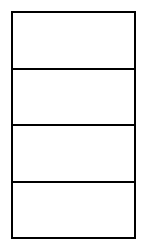

10 ¿Qué días cuenta con mayor tiempo libre?

Lunes

Martes

Miércoles

Jueves

Viernes

Sábado

Domingo

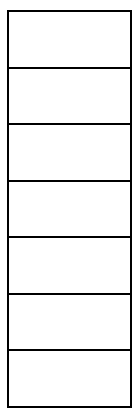

11 ¿Qué otro tipo de servicio o elementos le gustaría encontrar en el local? Video Juegos

Espacios de lectura

Juegos de mesa

Otros:

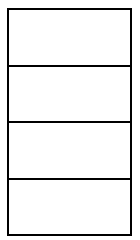


12 ¿Cuál sería el factor más importante para usted a la hora de tomar el servicio?

Calidad de impresión

Facilidad de uso de las impresoras y escáneres

Rapidez/Precisión impresoras

Atención al cliente

El ambiente lugar de atención

Recomendación de amigos

Otros:

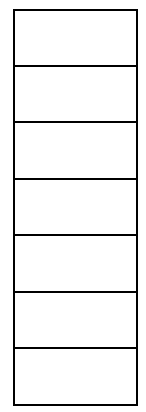

13 ¿A través de qué medio le gustaría recibir información sobre este producto?

Internet - Redes Sociales

Anuncios

Correo

Televisión

Radio

Otros:

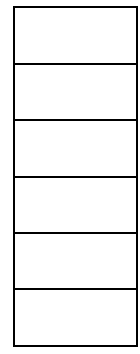

14 ¿Tiene algún comentario o recomendación adicional para este nuevo emprendimiento en la ciudad de Lima? 


\section{Anexo 5: Resultado de encuesta de público universitario}

Referente al distrito que pertenece cada uno de los encuestados se pudo determinar que el $25 \%$ pertenece a la zona 1 , el $23 \%$ a la zona 2 , el $22 \%$ a la zona 3 y el $30 \%$ a la zona 4. Tal como consta en la figura siguiente:

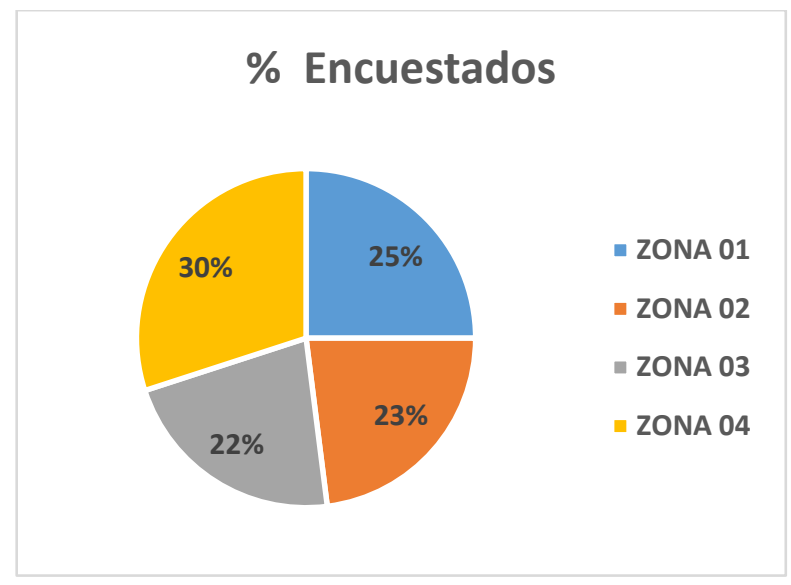

ZONA 01: Jesús María, Lince, Pueblo Libre, Magdalena, San Miguel.

ZONA 02: Miraflores, San Isidro, San Borja, Surco, La Molina.

ZONA 03: Surquillo, Barranco, Chorrillos, San Juan de Miraflores.

Referente al uso de los servicios 3D de cada uno de los encuestados se pudo determinar que el $48 \%$ uso el servicio de impresión 3D, el $41 \%$ no empleo los servicios 3D, el 13\% uso el servicio de corte, el 7\% uso el servicio de maquetación 3D, el 6\% el uso el servicio escaneo y el $5 \%$ uso el servicio de modelado. Tal como consta en la figura siguiente:

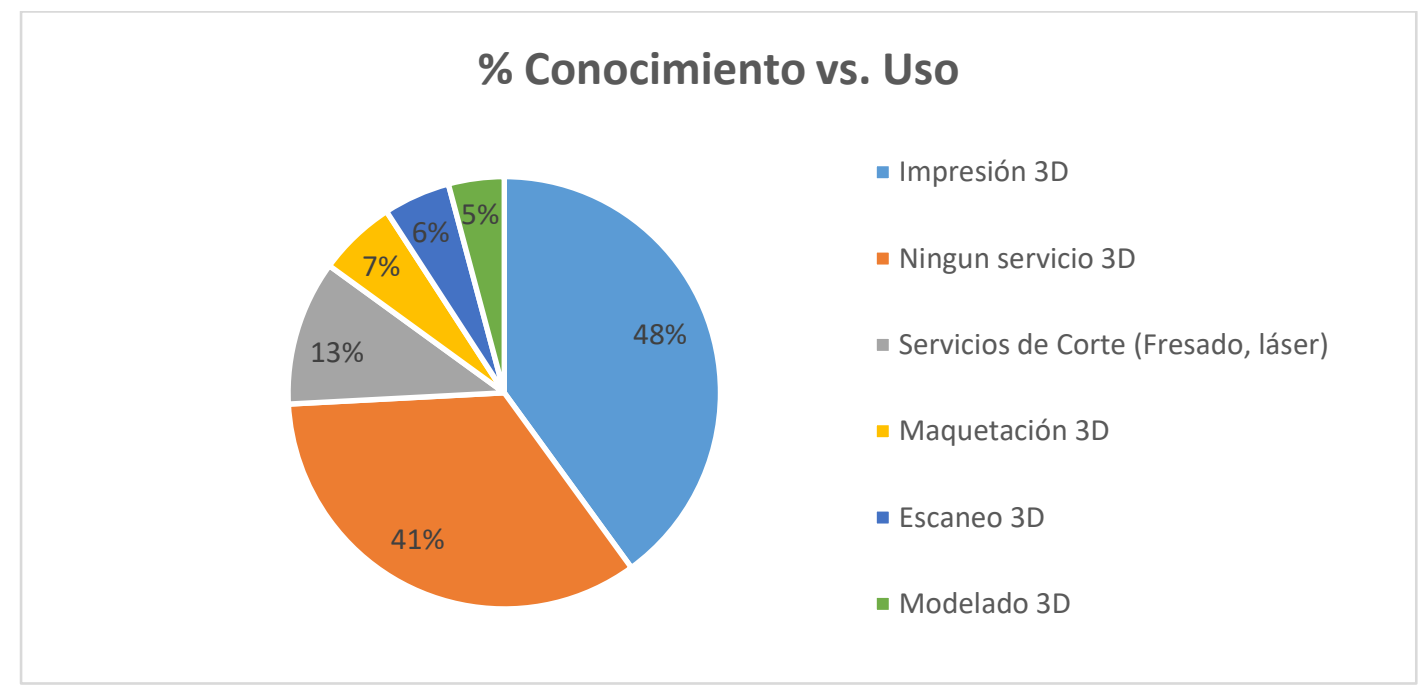


Referente a las carreras profesionales de cada uno de los encuestados se pudo determinar que el $41 \%$ pertenece a la carrera de arquitectura, el $11 \%$ a arte y diseño, el $9 \%$ a comunicaciones, el $8 \%$ a diseño de productos el $10 \%$ a diseño gráfico. Tal como consta en la figura siguiente:

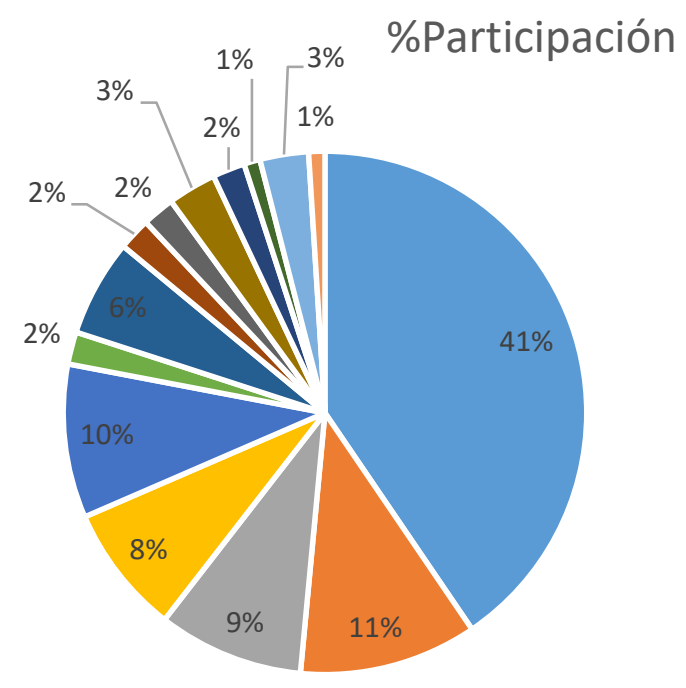

- AQUITECTURA

- ARTE Y DISEÑO

- COMUNICACIONES

- DISEÑO DE PRODUCTOS

- DISEÑO GRÁFICO

- ING CIVIL

Referente a la pregunta si han escuchado o conocen los servicios en 3D el 97\% contesto que si conoce por lo menos un servicio del concepto de 3D y el $3 \%$ desconoce el concepto de 3D, asimismo el 97\% conoce el servicio de impresión, el 86\% conoce el servicio de escaneado, el $77 \%$ el servicio de maquetación y el $71 \%$ el servicio de modelado. Tal como consta en la figura siguiente:

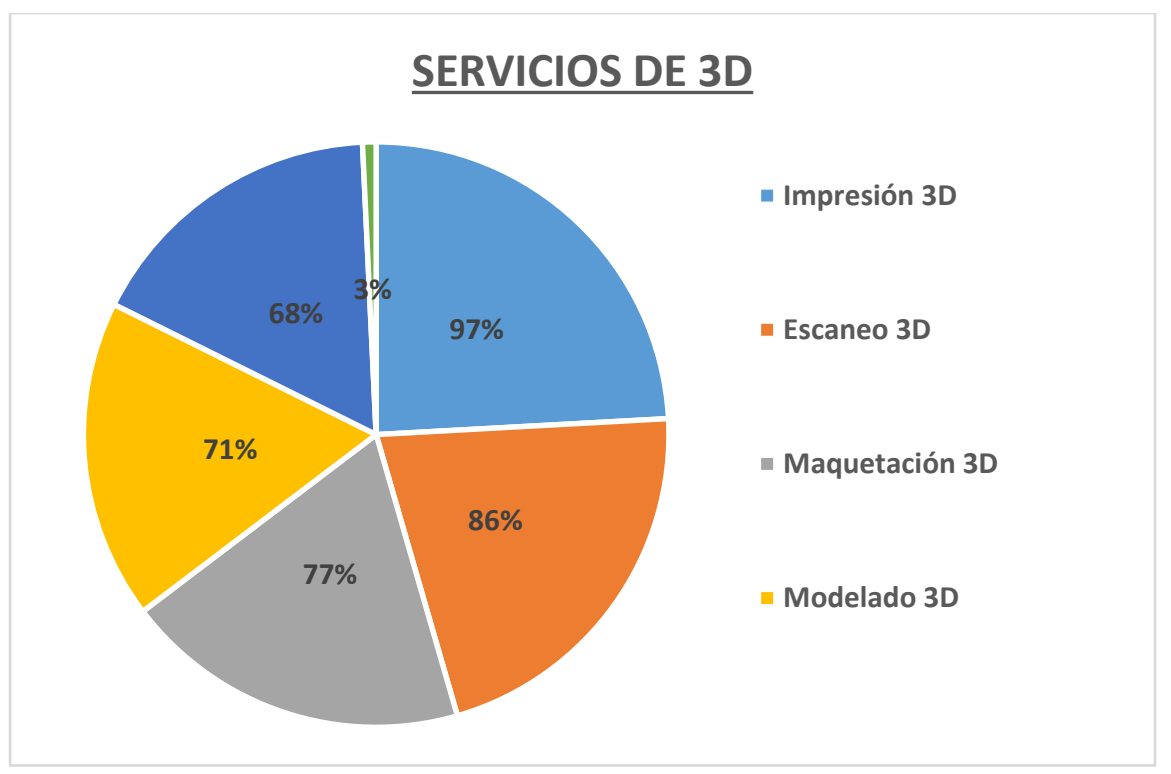


Referente a la pregunta de cuál fue la finalidad del uso de los servicios de 3D, el $86 \%$ de los encuestados respondió que lo realizo por estudios y el $7 \%$ por entretenimiento tal como consta en la figura siguiente:

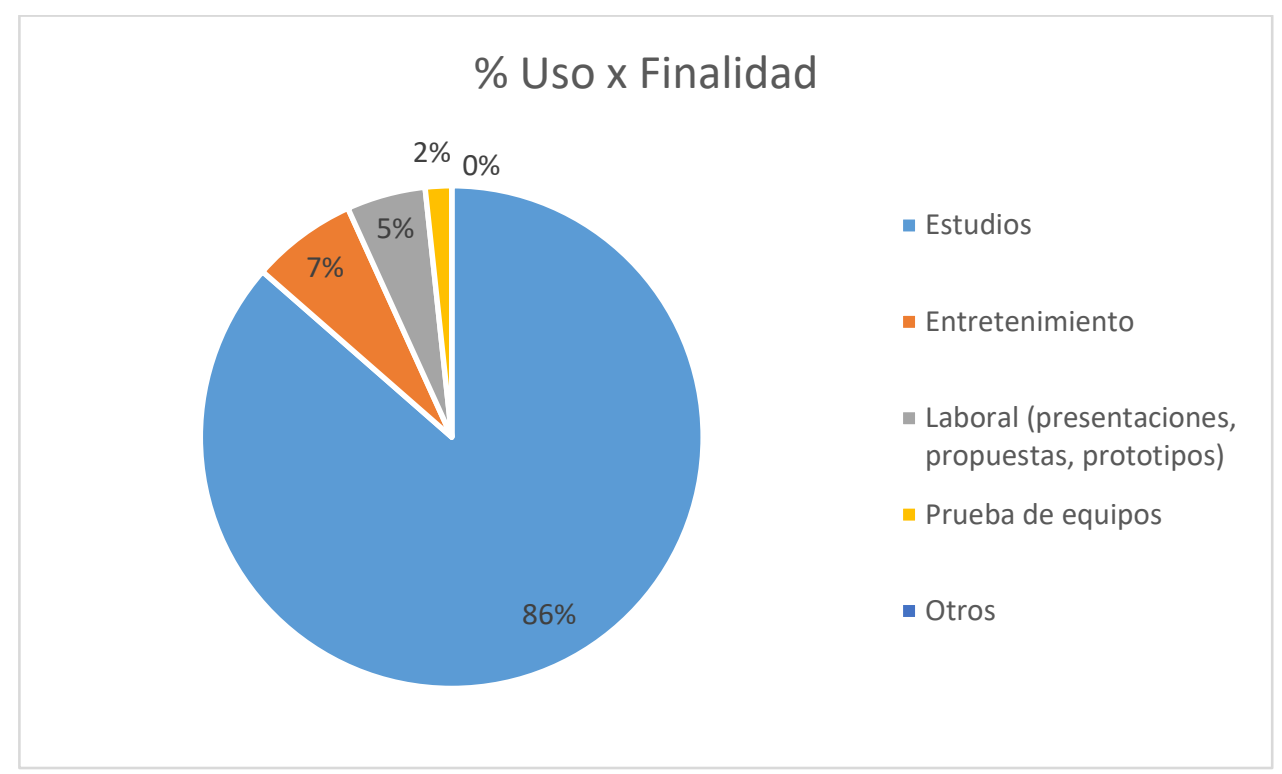

Referente a la pregunta de cuál es el factor más importante considerado a la hora de tomar el servicio de impresión 3D, el 42\% de los encuestados respondió que es la calidad de impresión, el $20 \%$ lo realizo por recomendación de amigos o colegas y el 15\% por la atención al cliente tal como consta en la figura siguiente:

\section{FACTOR MAS IMPORTANTE}

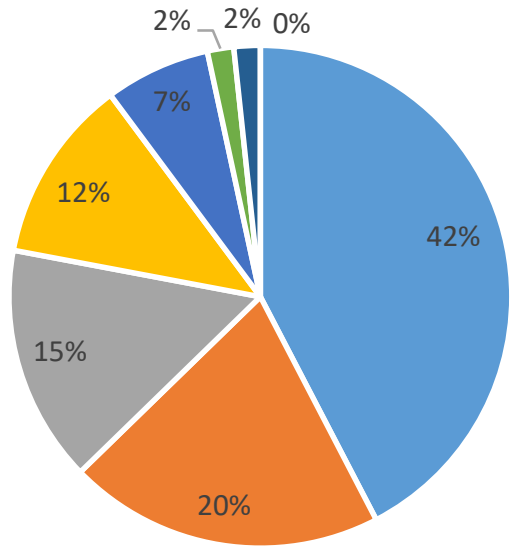

- Calidad de impresión

- Recomendación de amigos y/o colegas

- Atención al cliente

- Rapidez/Presición impresoras

- El lugar de atención

- CALIDAD DE CORTES 
Cuando se preguntó a los encuestados el tiempo promedio que tardan en completar la impresión 3D de sus diseños, el $56 \%$ respondió entre 3 y 4 horas, el 19\% en menos de 1 hora, el $17 \%$ de 1 a 2 horas y el $8 \%$ más de 4 horas. Por lo cual se tiene que tener en cuenta a la hora de adquisición de las impresoras con la finalidad de que se reduzca el tiempo de impresión.

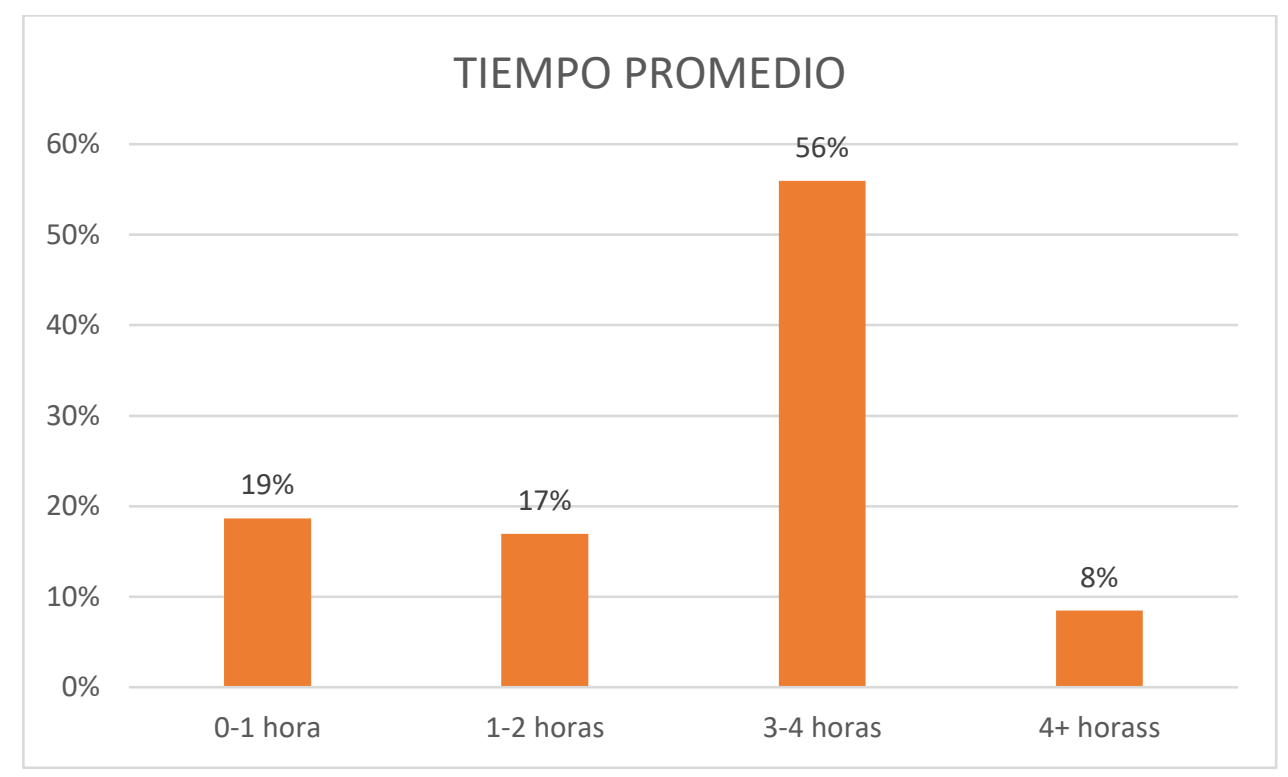

Cuando se preguntó a los estudiantes afines a nuestro modelo de negocio cuantas veces visitarían nuestro negocio al año el $64 \%$ de estos respondieron que lo harían bimestral cuatro (04) veces al año, el 20\% lo haría anualmente y el 10\% lo haría mensualmente de acuerdo a la figura siguiente:

\section{FRECUENCIA DEL USO DE IMPRESION 3D}

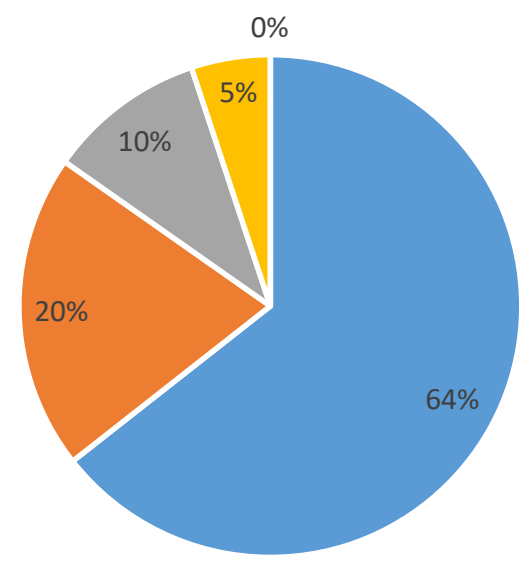

- Bimestral

- Anual

- Mensual

- Frecuencia muy variable

- Semanal 
Cuando se preguntó a los estudiantes afines a nuestro modelo de negocio referente a cuánto estaría dispuesto a pagar en una impresión en 3D el 56 \% respondió entre S/ 100 a S/ 200 y el $31 \%$ respondió entre S/ 200 a S/ 300. El incremento porcentual también puede estar sujeto a los trabajos que se demanden durante los finales de los ciclos de estudios.

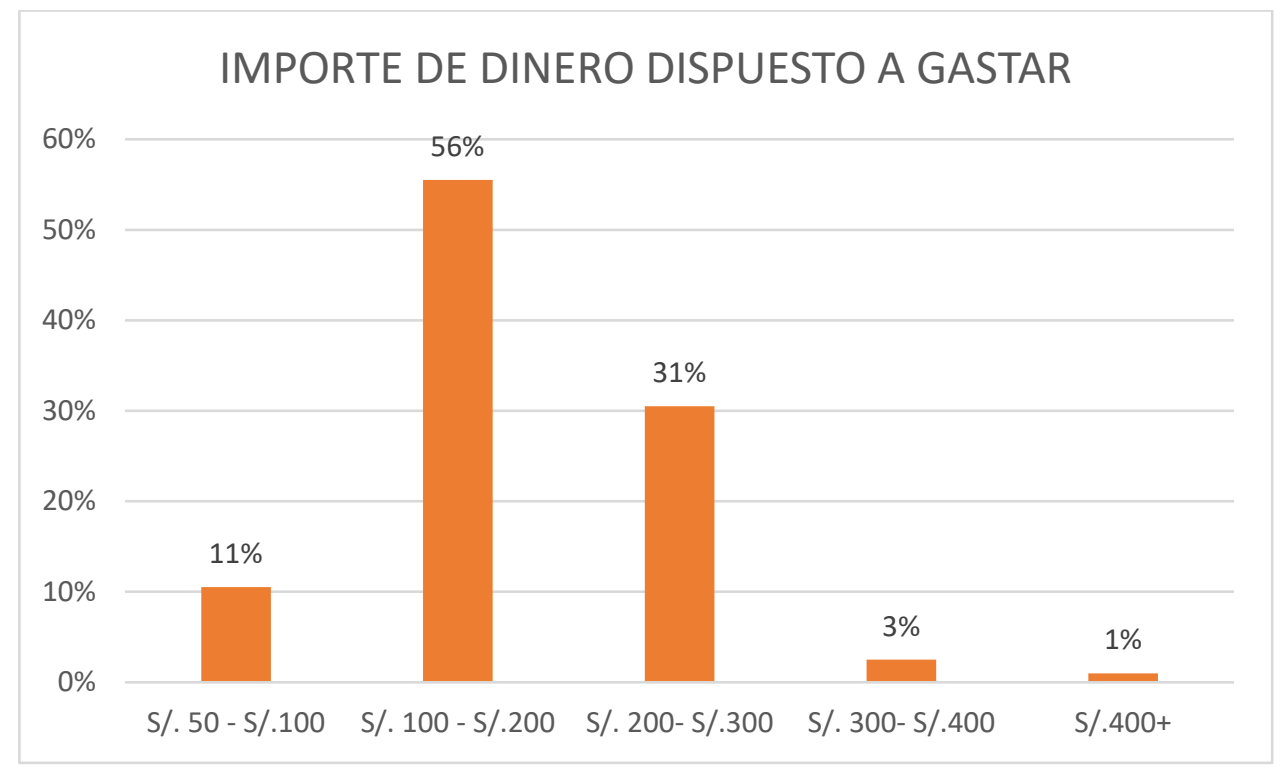




\section{Anexo 6: Resultado de encuesta de público en general}

Referente al rango de edades de cada uno de los encuestados se pudo determinar que el $36 \%$ tiene entre 22 y 25 años, el 32\% entre 26 y 28 años, el $20 \%$ más de 35 años, el $8 \%$ entre 28 y 38 años y el $4 \%$ entre 33 y 35 años. Tal como consta en la figura siguiente:

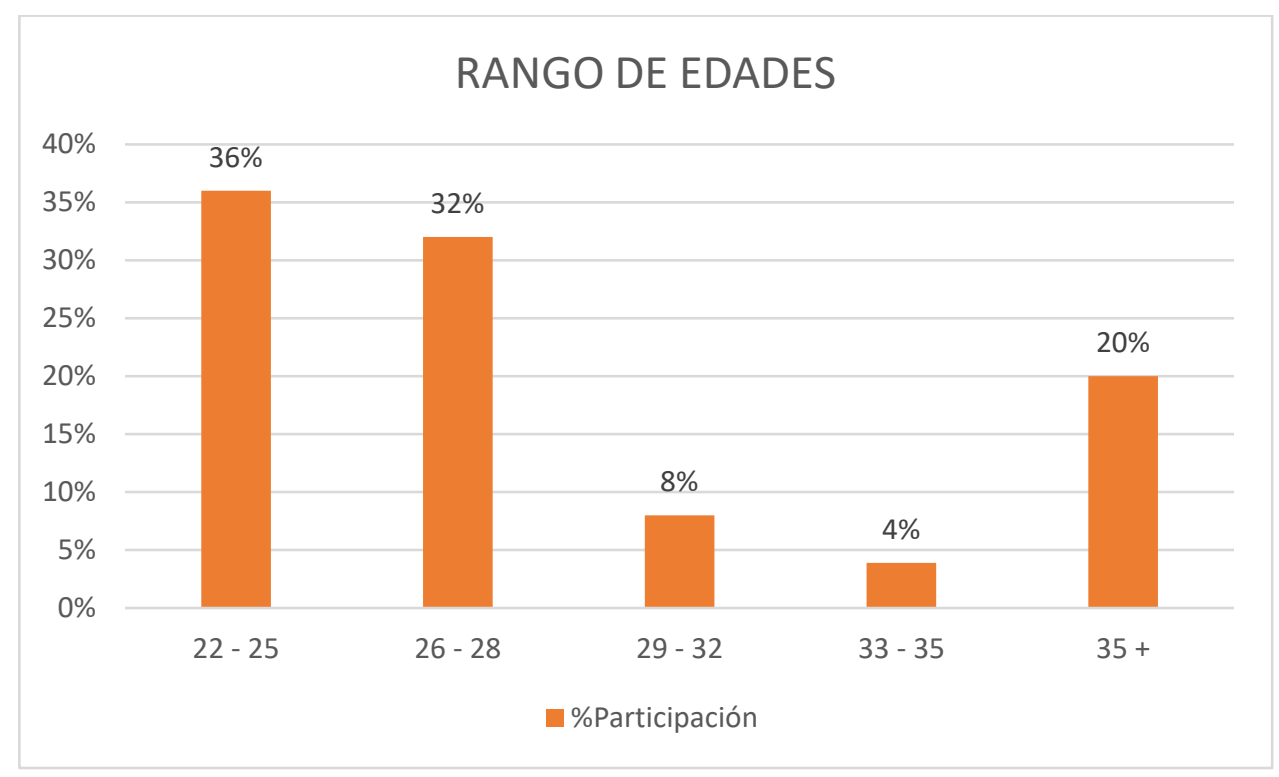

Referente a la frecuencia con que visitaría a una cafetería se pudo determinar que el $40 \%$ lo puede hacer cada 15 días, el $28 \%$ lo puede hacer semanalmente y el $32 \%$ lo puede hacer una vez al mes. Tal como consta en la figura siguiente:

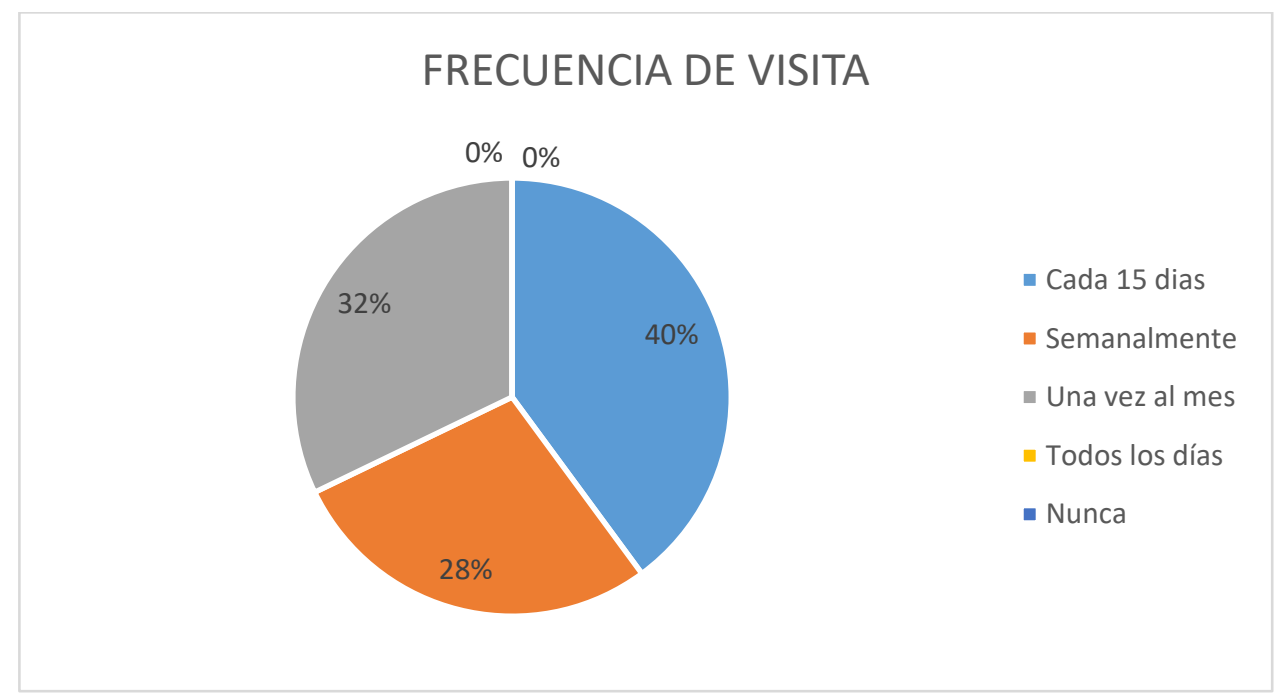


Referente a la pregunta si les parece interesante la idea de un espacio con el concepto de cafetería donde podrían incentivar la creatividad, el intercambio de ideas, el arte y el diseño, el $46 \%$ contesto que le parece muy interesante y el $29 \%$ le parece interesante y al $11 \%$ le parece poco interesante. Tal como consta en la figura siguiente:

\section{COMBINACION DE CAFE CON IMPRESION 3D}

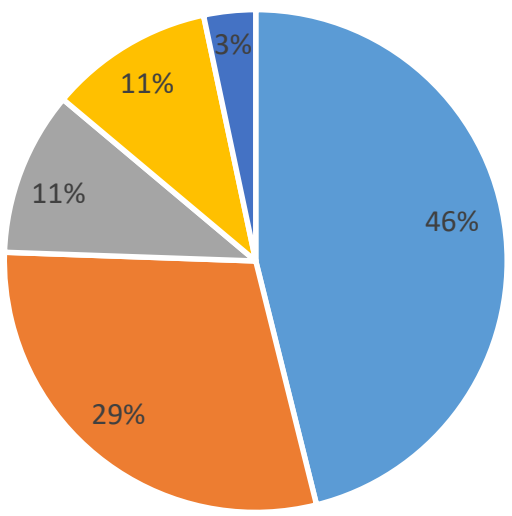

- Muy interesante

- Interesante

- Poco interesante

- Medianamente interesante

- Desinteresante

Referente a la pregunta de probabilidad de visita al negocio de estar funcionando en esta semana, el $48 \%$ de los encuestados respondió que sería muy alta el 29\% respondió que sería media y el $17 \%$ respondió que sería alta. Tal como consta en la figura siguiente:

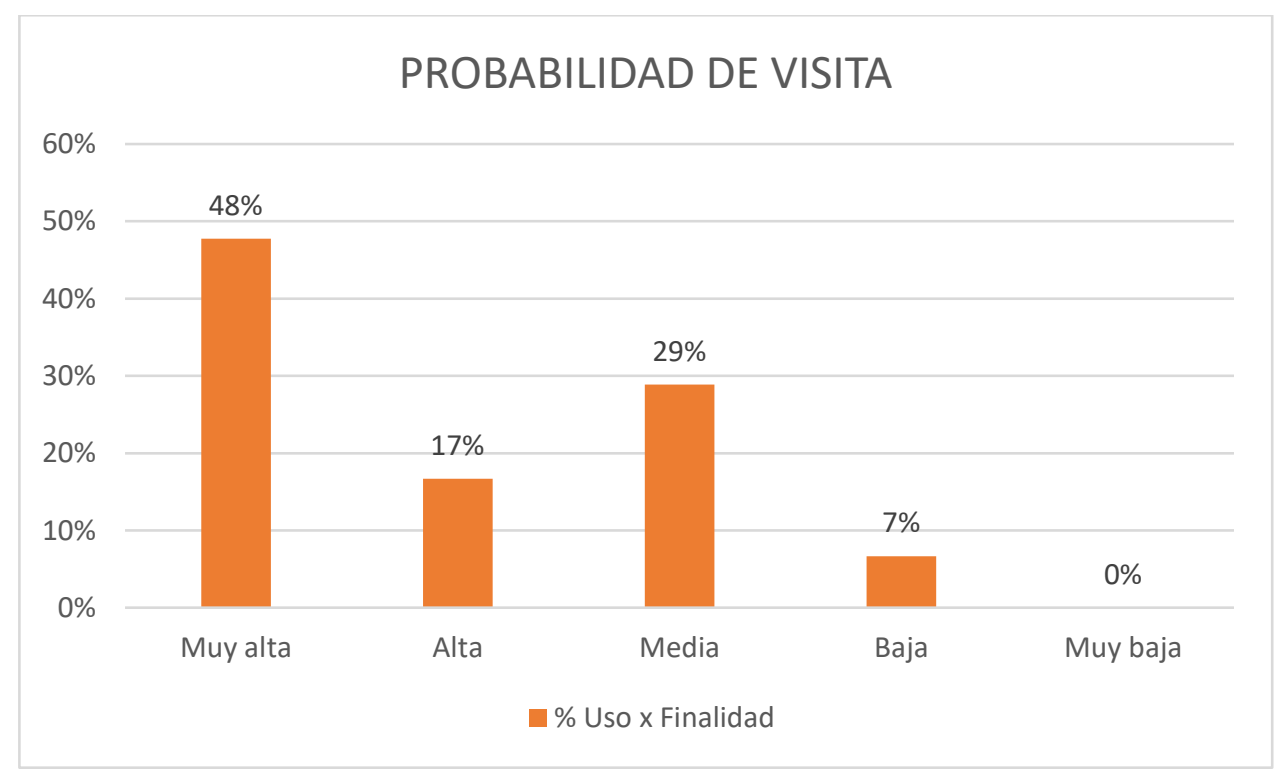


Cuando se preguntó a los encuestados afines a nuestro modelo de negocio referente a cuánto estaría dispuesto a pagar en una impresión en 3D el 47 \% respondió entre S/ 50 a 100 y el $29 \%$ respondió entre S/ 100 a S/ 200.

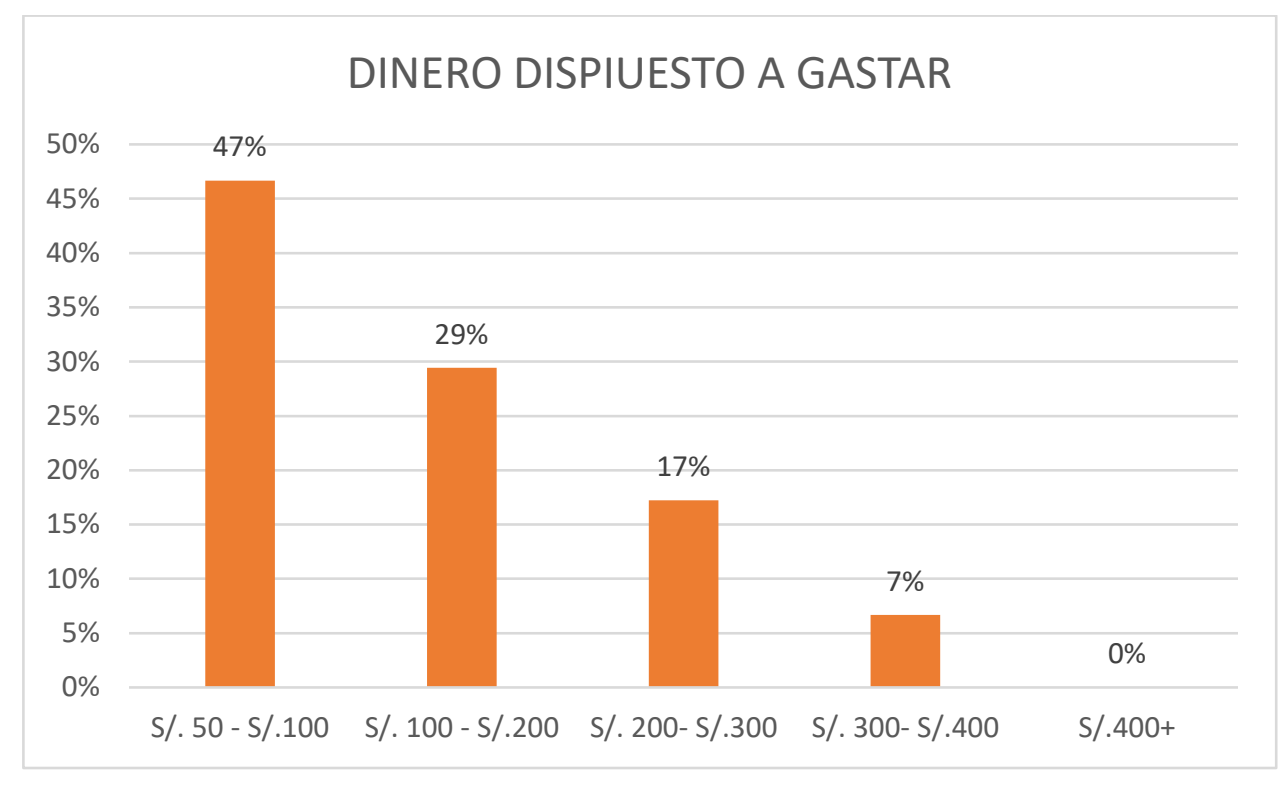

Referente a la pregunta del tiempo que dedicarían a la actividad de los servicio 3D, el $54 \%$ de los encuestados respondió que menos de 1 hora, el 34\% respondió que dedicaría hasta 2 horas y el $11 \%$ respondió que dedicaría hasta 4 horas. Tal como consta en la figura siguiente:

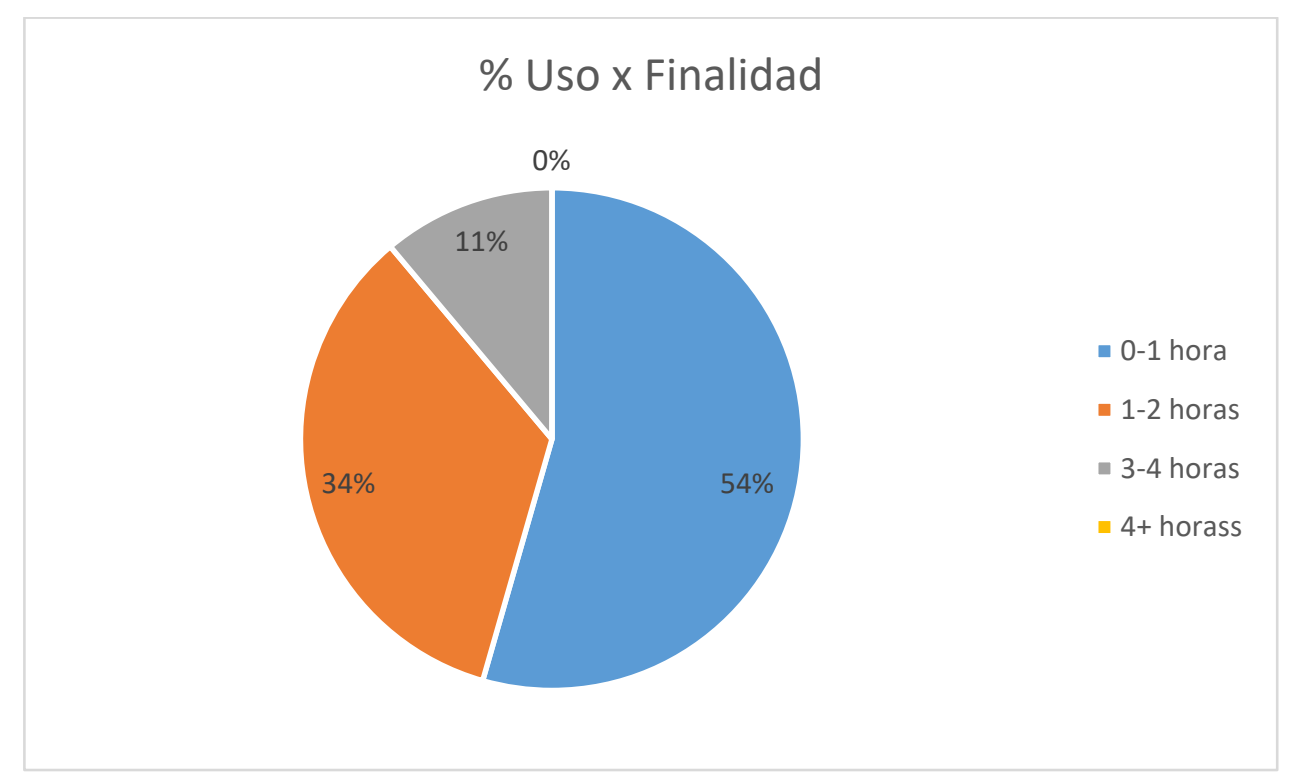


Referente a la pregunta de cuál sería el factor más importante a la hora de tomar el servicio 3D, el 28\% de los encuestados respondió que es la calidad de impresión, el 25\% respondió que es la atención al público, el 17\% que le importa la facilidad de uso de impresoras y escáner y el 13\% respondió que le importa la rapidez del servicio. Tal como consta en la figura siguiente:

\section{\% Uso x Finalidad}

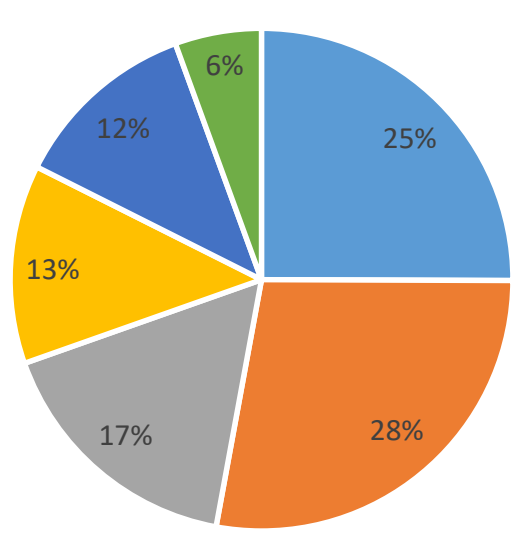

- Atención al cliente

- Calidad de impresión

- Facilidad de uso de las impresoras y escáners

- Rapidez

- El ambiente lugar de atención

- Recomendación de amigos 


\section{Anexo 7: Estudiantes de prepago matriculados en el 2014}

\begin{tabular}{|c|c|c|}
\hline UNIVERSIDAD & $\begin{array}{l}\text { PROGRAMAS DE } \\
\text { ESTUDIO }\end{array}$ & TOTAL \\
\hline & INGENIERIA & \\
\hline PONTIFICIA UNIVERSIDAD CATÓLICA DEL PERÚ & ELECTRONICA & 533 \\
\hline PONTIFICIA UNIVERSIDAD CATÓLICA DEL PERÚ & INGENIERIA INDUSTRIAL & 2,818 \\
\hline PONTIFICIA UNIVERSIDAD CATÓLICA DEL PERÚ & $\begin{array}{l}\text { INGENIERIA MECANICA } \\
\text { INGENIERIA }\end{array}$ & 753 \\
\hline PONTIFICIA UNIVERSIDAD CATÓLICA DEL PERÚ & MECATRONICA & 803 \\
\hline PONTIFICIA UNIVERSIDAD CATÓLICA DEL PERÚ & ARQUITECTURA & 911 \\
\hline PONTIFICIA UNIVERSIDAD CATÓLICA DEL PERÚ & INGENIERIA CIVIL & 2,187 \\
\hline PONTIFICIA UNIVERSIDAD CATÓLICA DEL PERÚ & DISEÑO GRAFICO & 260 \\
\hline PONTIFICIA UNIVERSIDAD CATÓLICA DEL PERÚ & DISEÑO INDUSTRIAL & 204 \\
\hline UNIVERSIDAD ALAS PERUANAS S.A. & $\begin{array}{l}\text { INGENIERIA MECANICA } \\
\text { INGENIERIA }\end{array}$ & 772 \\
\hline UNIVERSIDAD ALAS PERUANAS S.A. & MECATRONICA & 5 \\
\hline UNIVERSIDAD ALAS PERUANAS S.A. & INGENIERIA INDUSTRIAL & 4,167 \\
\hline UNIVERSIDAD ALAS PERUANAS S.A. & ARQUITECTURA & 3,489 \\
\hline UNIVERSIDAD ALAS PERUANAS S.A. & $\begin{array}{l}\text { INGENIERIA CIVIL } \\
\text { INGENIERIA }\end{array}$ & 14,485 \\
\hline UNIVERSIDAD CONTINENTAL S.A.C. & ELECTRONICA & 81 \\
\hline UNIVERSIDAD CONTINENTAL S.A.C. & $\begin{array}{l}\text { INGENIERIA MECANICA } \\
\text { INGENIERIA }\end{array}$ & 334 \\
\hline UNIVERSIDAD CONTIN & MECATRONICA & 227 \\
\hline UNIVERSIDAD CONTINEN & INGENIERIA INDUSTRIAL & 1,583 \\
\hline UNIVERSIDAD CONTINENTAL S.A.C. & ARQUITECTURA & 909 \\
\hline UNIVERSIDAD CONTINENTAL S.A.C. & INGENIERIA CIVIL & 2,482 \\
\hline UNIVERSIDAD CÉSAR VALLEJO S.A.C. & INGENIERIA MECANICA & 213 \\
\hline UNIVERSIDAD CÉSAR VALLEJO S.A.C. & INGENIERIA INDUSTRIAL & 10,620 \\
\hline UNIVERSIDAD CÉSAR VALLEJO S.A.C. & ARQUITECTURA & 4,406 \\
\hline UNIVERSIDAD CÉSAR VALLEJO S.A.C. & $\begin{array}{l}\text { INGENIERIA CIVIL } \\
\text { INGENIERIA }\end{array}$ & 9,955 \\
\hline UNIVERSIDAD DE INGENIERÍA Y TECNOLOGÍA & ELECTRONICA & 106 \\
\hline UNIVERSIDAD DE INGENIERÍA Y TECNOLOGÍA & INGENIERIA MECANICA & 150 \\
\hline UNIVERSIDAD DE INGENIERÍA Y TECNOLOGÍA & INGENIERIA INDUSTRIAL & 183 \\
\hline UNIVERSIDAD DE LIMA & INGENIERÍA INDUSTRIAL & 5,343 \\
\hline UNIVERSIDAD DE LIMA & ARQUITECTURA & 597 \\
\hline UNIVERSIDAD DE SAN MARTÍN DE PORRES & INGENIERIA INDUSTRIAL & 417 \\
\hline UNIVERSIDAD DE SAN MARTÍN DE PORRES & ARQUITECTURA & 380 \\
\hline UNIVERSIDAD DE SAN MARTÍN DE PORRES & $\begin{array}{l}\text { INGENIERIA CIVIL } \\
\text { INGENIERIA }\end{array}$ & 370 \\
\hline UNIVEF & ELECTRONICA & 667 \\
\hline UNIVERSIDAD NACIONAL MAYOR I & INGENIERIA INDUSTRIAL & 1,213 \\
\hline UNIVERSIDAD NACIONAL MAYOR DE SAN MARCOS & INGENIERIA CIVIL & 187 \\
\hline UNIVERSIDAD PERUANA DE CIENCIAS APLICADAS & INGENIERIA & \\
\hline 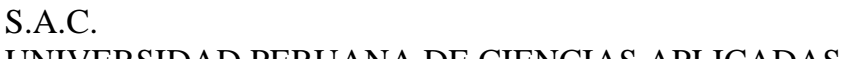 & ELECTRONICA & 403 \\
\hline $\begin{array}{l}\text { UNIVERSIDAD PERUANA DE CIENCIAS APLICADAS } \\
\text { S.A.C. }\end{array}$ & INGENIERIA INDI & 5941 \\
\hline UNIVERSIDAD PERUANA DE CIENCIAS APLICADAS & $\begin{array}{l}\text { INGENIERIA INDUS IRI } \\
\text { INGENIERIA }\end{array}$ & 5,941 \\
\hline S.A.C. & MECATRONICA & 359 \\
\hline UNIVERSIDAD PERUANA DE CIENCIAS APLICADAS & & \\
\hline S.A.C. & ARQUITECTURA & 2,738 \\
\hline $\begin{array}{l}\text { UNIVERSIDAD PERUANA DE CIENCIAS APLICADAS } \\
\text { S.A.C. }\end{array}$ & & \\
\hline $\begin{array}{l}\text { S.A.C. } \\
\text { UNIVERSIDAD PERUANA DE CIENCIAS E }\end{array}$ & & \\
\hline INFORMÁTICA & INGENIERIA INDUSTRIAL & \\
\hline
\end{tabular}




\begin{tabular}{l|lr}
\hline UNIVERSIDAD & PROGRAMAS DE & TOTAL \\
\hline & ESTUDIO & 4 \\
UNIVERSIDAD PRIVADA DEL NORTE S.A.C. & INGENIERIA & ELECTRONICA \\
UNIVERSIDAD PRIVADA DEL NORTE S.A.C. & INGENIERIA & MECATRONICA \\
UNIVERSIDAD PRIVADA DEL NORTE S.A.C. & INGENIERIA INDUSTRIAL & 8,308 \\
UNIVERSIDAD PRIVADA DEL NORTE S.A.C. & ARQUITECTURA & 477 \\
UNIVERSIDAD PRIVADA DEL NORTE S.A.C. & DISENOO INDUSTRIAL & 40 \\
UNIVERSIDAD PRIVADA DEL NORTE S.A.C. & INGENIERIA CIVIL & 4,205 \\
& INGENIERIA \\
UNIVERSIDAD RICARDO PALMA & ELECTRONICA & 248 \\
UNIVERSIDAD RICARDO PALMA & INGENIERIA INDUSTRIAL & 1,303 \\
UNIVERSIDAD RICARDO PALMA & INGENIERIA & 350 \\
UNIVERSIDAD RICARDO PALMA & MECATRONICA & 2,257 \\
UNIVERSIDAD RICARDO PALMA & ARQUITECTURA \\
UNIVERSIDAD SAN IGNACIO DE LOYOLA S.A. & INGENIERIA CIVIL & 2,256 \\
UNIVERSIDAD SAN IGNACIO DE LOYOLA S.A. & INGENIERIA INDUSTRIAL & 783 \\
TOTAL ESTUDIANTES & INGENIERIA CIVIL & 671 \\
\hline
\end{tabular}




\section{Anexo 8: Estudiantes de prepago matriculados en el 2015}

\begin{tabular}{|c|c|c|}
\hline UNIVERSIDAD & PROGRAMAS DE ESTUDIO & TOTAL \\
\hline PONTIFICIA UNIVERSIDAD CATÓLICA DEL PERÚ & INGENIERIA ELECTRONICA & 482 \\
\hline PONTIFICIA UNIVERSIDAD CATÓLICA DEL PERÚ & INGENIERIA INDUSTRIAL & 2,851 \\
\hline PONTIFICIA UNIVERSIDAD CATÓLICA DEL PERÚ & INGENIERIA MECANICA & 752 \\
\hline PONTIFICIA UNIVERSIDAD CATÓLICA DEL PERÚ & INGENIERIA MECATRONICA & 880 \\
\hline PONTIFICIA UNIVERSIDAD CATÓLICA DEL PERÚ & ARQUITECTURA & 925 \\
\hline PONTIFICIA UNIVERSIDAD CATÓLICA DEL PERÚ & INGENIERIA CIVIL & 2,349 \\
\hline PONTIFICIA UNIVERSIDAD CATÓLICA DEL PERÚ & DISEÑO GRAFICO & 278 \\
\hline PONTIFICIA UNIVERSIDAD CATÓLICA DEL PERÚ & DISEÑO INDUSTRIAL & 220 \\
\hline UNIVERSIDAD ALAS PERUANAS S.A. & INGENIERIA INDUSTRIAL & 4,260 \\
\hline UNIVERSIDAD ALAS PERUANAS S.A. & INGENIERIA MECANICA & 788 \\
\hline UNIVERSIDAD ALAS PERUANAS S.A. & INGENIERIA MECATRONICA & 2 \\
\hline UNIVERSIDAD ALAS PERUANAS S.A. & ARQUITECTURA & 3,698 \\
\hline UNIVERSIDAD ALAS PERUANAS S.A. & INGENIERIA CIVIL & 15,789 \\
\hline UNIVERSIDAD CONTINENTAL S.A.C. & INGENIERIA ELECTRONICA & 110 \\
\hline UNIVERSIDAD CONTINENTAL S.A.C. & INGENIERIA INDUSTRIAL & 2,562 \\
\hline UNIVERSIDAD CONTINENTAL S.A.C. & INGENIERIA MECANICA & 599 \\
\hline UNIVERSIDAD CONTINENTAL S.A.C. & INGENIERIA MECATRONICA & 310 \\
\hline UNIVERSIDAD CONTINENTAL S.A.C. & ARQUITECTURA & 1,107 \\
\hline UNIVERSIDAD CONTINENTAL S.A.C. & INGENIERIA CIVIL & 2,768 \\
\hline UNIVERSIDAD CÉSAR VALLEJO S.A.C. & INGENIERIA INDUSTRIAL & 12,762 \\
\hline UNIVERSIDAD CÉSAR VALLEJO S.A.C. & INGENIERIA MECANICA & 70 \\
\hline UNIVERSIDAD CÉSAR VALLEJO S.A.C. & ARQUITECTURA & 5,588 \\
\hline UNIVERSIDAD CÉSAR VALLEJO S.A.C. & INGENIERIA CIVIL & 12,136 \\
\hline UNIVERSIDAD DE INGENIERÍA Y TECNOLOGÍA & INGENIERIA ELECTRONICA & 157 \\
\hline UNIVERSIDAD DE INGENIERÍA Y TECNOLOGÍA & INGENIERIA INDUSTRIAL & 269 \\
\hline UNIVERSIDAD DE INGENIERÍA Y TECNOLOGÍA & INGENIERIA MECANICA & 248 \\
\hline UNIVERSIDAD DE LIMA & INGENIERIA INDUSTRIAL & 5,604 \\
\hline UNIVERSIDAD DE LIMA & ARQUITECTURA & 689 \\
\hline UNIVERSIDAD DE SAN MARTÍN DE PORRES & INGENIERIA ELECTRONICA & 118 \\
\hline UNIVERSIDAD DE SAN MARTÍN DE PORRES & INGENIERIA INDUSTRIAL & 1,229 \\
\hline UNIVERSIDAD DE SAN MARTÍN DE PORRES & ARQUITECTURA & 1,179 \\
\hline UNIVERSIDAD DE SAN MARTÍN DE PORRES & INGENIERIA CIVIL & 986 \\
\hline UNIVERSIDAD NACIONAL DE INGENIERÍA & INGENIERIA ELECTRONICA & 502 \\
\hline UNIVERSIDAD NACIONAL DE INGENIERÍA & INGENIERIA INDUSTRIAL & 815 \\
\hline UNIVERSIDAD NACIONAL DE INGENIERÍA & INGENIERIA MECANICA & 545 \\
\hline UNIVERSIDAD NACIONAL DE INGENIERÍA & INGENIERIA MECATRONICA & 468 \\
\hline UNIVERSIDAD NACIONAL DE INGENIERÍA & ARQUITECTURA & 944 \\
\hline UNIVERSIDAD NACIONAL DE INGENIERÍA & INGENIERIA CIVIL & 1,697 \\
\hline $\begin{array}{l}\text { UNIVERSIDAD NACIONAL MAYOR DE SAN } \\
\text { MARCOS }\end{array}$ & INGENIERIA ELECTRONICA & 693 \\
\hline $\begin{array}{l}\text { UNIVERSIDAD NACIONAL MAYOR DE SAN } \\
\text { MARCOS }\end{array}$ & INGENIERIA INDUSTRIAL & 1,197 \\
\hline
\end{tabular}




\begin{tabular}{|l|l|r|}
\hline UNIVERSIDAD NACIONAL MAYOR DE SAN & INGENIERIA CIVIL & 255 \\
\hline UARCOS & & \\
APLICADADAD PERUANA DE CIENCIAS & INGENIERIA ELECTRONICA & 365 \\
\hline $\begin{array}{l}\text { UNIVERSIDAD PERUANA DE CIENCIAS } \\
\text { APLICADAS S.A.C. }\end{array}$ & INGENIERIA INDUSTRIAL & 5,332 \\
\hline $\begin{array}{l}\text { UNIVERSIDAD PERUANA DE CIENCIAS } \\
\text { APLICADAS S.A.C. }\end{array}$ & INGENIERIA MECATRONICA & 412 \\
\hline $\begin{array}{l}\text { UNIVERSIDAD PERUANA DE CIENCIAS } \\
\text { APLICADAS S.A.C. }\end{array}$ & ARQUITECTURA & 2,870 \\
\hline UNIVERSIDAD PERUANA DE CIENCIAS & & 3,180 \\
\hline APLICADAS S.A.C. & INGENIERIA CIVIL & 491 \\
\hline UNIVERSIDAD PERUANA DE CIENCIAS E & INGENIERIA INDUSTRIAL & 104 \\
\hline UNIVERSIDAD PRIVADA DEL NORTE S.A.C. & INGENIERIA ELECTRONICA & 4,430 \\
\hline UNIVERSIDAD PRIVADA DEL NORTE S.A.C. & INGENIERIA INDUSTRIAL & 333 \\
\hline UNIVERSIDAD PRIVADA DEL NORTE S.A.C. & INGENIERIA MECATRONICA & 78 \\
\hline UNIVERSIDAD PRIVADA DEL NORTE S.A.C. & DISEÑO INDUSTRIAL & 3,723 \\
\hline UNIVERSIDAD PRIVADA DEL NORTE S.A.C. & INGENIERIA CIVIL & 242 \\
\hline UNIVERSIDAD RICARDO PALMA & INGENIERIA ELECTRONICA & 1,218 \\
\hline UNIVERSIDAD RICARDO PALMA & INGENIERIA INDUSTRIAL & 336 \\
\hline UNIVERSIDAD RICARDO PALMA & INGENIERIA MECATRONICA & 2,210 \\
\hline UNIVERSIDAD RICARDO PALMA & ARQUITECTURA & 2,130 \\
\hline UNIVERSIDAD RICARDO PALMA & INGENIERIA CIVIL & 1,283 \\
\hline UNIVERSIDAD SAN IGNACIO DE LOYOLA S.A. & INGENIERIA INDUSTRIAL & 1,058 \\
\hline UNIVERSIDAD SAN IGNACIO DE LOYOLA S.A. & INGENIERIA CIVIL & 1,229 \\
\hline UNIVERSIDAD TECNOLÓGICA DEL PERÚ S.A.C. & INGENIERIA ELECTRONICA & 547 \\
\hline UNIVERSIDAD TECNOLÓGICA DEL PERÚ S.A.C. & INGENIERIA CIVIL & 3,121 \\
\hline UNIVERSIDAD TECNOLÓGICA DEL PERÚ S.A.C. & INGENIERIA INDUSTRIAL & 1,331 \\
\hline UNIVERSIDAD TECNOLÓGICA DEL PERÚ S.A.C. & INGENIERIA MECANICA & 1,551 \\
\hline UNIVERSIDAD TECNOLÓGICA DEL PERÚ S.A.C. & INGENIERIA MECATRONICA & 425 \\
\hline UNIVERSIDAD TECNOLÓGICA DEL PERÚ S.A.C. & INGENIERIA DE DISEÑO & GRAFICO \\
\hline & & 126,880 \\
\hline
\end{tabular}




\section{Anexo 9: Estudiantes de prepago matriculados en el 2016}

\begin{tabular}{|c|c|c|}
\hline UNIVERSIDAD & $\begin{array}{l}\text { PROGRAMAS DE } \\
\text { ESTUDIO }\end{array}$ & TOTAL \\
\hline $\begin{array}{l}\text { PONTIFICIA UNIVERSIDAD CATÓLICA DEL } \\
\text { PERÚ }\end{array}$ & $\begin{array}{l}\text { INGENIERIA } \\
\text { ELECTRONICA }\end{array}$ & 453 \\
\hline $\begin{array}{l}\text { PONTIFICIA UNIVERSIDAD CATÓLICA DEL } \\
\text { PERÚ }\end{array}$ & INGENIERIA INDUSTRIAL & 3,007 \\
\hline $\begin{array}{l}\text { PONTIFICIA UNIVERSIDAD CATÓLICA DEL } \\
\text { PERÚ }\end{array}$ & INGENIERIA MECANICA & 753 \\
\hline $\begin{array}{l}\text { PONTIFICIA UNIVERSIDAD CATÓLICA DEL } \\
\text { PERÚ }\end{array}$ & $\begin{array}{l}\text { INGENIERIA } \\
\text { MECATRONICA }\end{array}$ & 980 \\
\hline $\begin{array}{l}\text { PONTIFICIA UNIVERSIDAD CATÓLICA DEL } \\
\text { PERÚ }\end{array}$ & ARQUITECTURA & 918 \\
\hline $\begin{array}{l}\text { PONTIFICIA UNIVERSIDAD CATÓLICA DEL } \\
\text { PERÚ }\end{array}$ & INGENIERIA CIVIL & 2,598 \\
\hline $\begin{array}{l}\text { PONTIFICIA UNIVERSIDAD CATÓLICA DEL } \\
\text { PERÚ }\end{array}$ & DISEÑO GRAFICO & 280 \\
\hline $\begin{array}{l}\text { PONTIFICIA UNIVERSIDAD CATÓLICA DEL } \\
\text { PERÚ }\end{array}$ & DISEÑO INDUSTRIAL & 259 \\
\hline UNIVERSIDAD ALAS PERUANAS S.A. & INGENIERIA INDUSTRIAL & 3,755 \\
\hline UNIVERSIDAD ALAS PERUANAS S.A. & INGENIERIA MECANICA & 706 \\
\hline UNIVERSIDAD ALAS PERUANAS S.A. & \begin{tabular}{|l} 
INGENIERIA \\
MECATRONICA
\end{tabular} & 1 \\
\hline UNIVERSIDAD ALAS PERUANAS S.A. & ARQUITECTURA & 3,648 \\
\hline UNIVERSIDAD ALAS PERUANAS S.A. & INGENIERIA CIVIL & 14,970 \\
\hline UNIVERSIDAD CONTINENTAL S.A.C. & \begin{tabular}{|l} 
INGENIERIA \\
ELECTRONICA
\end{tabular} & 108 \\
\hline UNIVERSIDAD CONTINENTAL S.A.C. & INGENIERIA INDUSTRIAL & 3,243 \\
\hline UNIVERSIDAD CONTINENTAL S.A.C. & INGENIERIA MECANICA & 1,040 \\
\hline UNIVERSIDAD CONTINENTAL S.A.C. & \begin{tabular}{|l} 
INGENIERIA \\
MECATRONICA
\end{tabular} & 376 \\
\hline UNIVERSIDAD CONTINENTAL S.A.C. & ARQUITECTURA & 1,269 \\
\hline UNIVERSIDAD CONTINENTAL S.A.C. & INGENIERIA CIVIL & 3,219 \\
\hline UNIVERSIDAD CÉSAR VALLEJO S.A.C. & INGENIERIA INDUSTRIAL & 11,013 \\
\hline UNIVERSIDAD CÉSAR VALLEJO S.A.C. & INGENIERIA MECANICA & 38 \\
\hline UNIVERSIDAD CÉSAR VALLEJO S.A.C. & ARQUITECTURA & 4,942 \\
\hline UNIVERSIDAD CÉSAR VALLEJO S.A.C. & INGENIERIA CIVIL & 10,856 \\
\hline UNIVERSIDAD DE INGENIERÍA Y TECNOLOGÍA & \begin{tabular}{|l} 
INGENIERIA \\
ELECTRONICA
\end{tabular} & 224 \\
\hline UNIVERSIDAD DE INGENIERÍA Y TECNOLOGÍA & INGENIERIA INDUSTRIAL & 363 \\
\hline UNIVERSIDAD DE INGENIERÍA Y TECNOLOGÍA & INGENIERIA MECANICA & 367 \\
\hline UNIVERSIDAD DE LIMA & INGENIERIA INDUSTRIAL & 6,002 \\
\hline UNIVERSIDAD DE LIMA & ARQUITECTURA & 811 \\
\hline UNIVERSIDAD DE SAN MARTÍN DE PORRES & INGENIERIA INDUSTRIAL & 1,330 \\
\hline UNIVERSIDAD DE SAN MARTÍN DE PORRES & \begin{tabular}{|l} 
INGENIERIA \\
ELECTRONICA
\end{tabular} & 89 \\
\hline UNIVERSIDAD DE SAN MARTÍN DE PORRES & ARQUITECTURA & 1,212 \\
\hline UNIVERSIDAD DE SAN MARTIIN DE PORRES & INGENIERIA CIVIL & 1,095 \\
\hline UNIVERSIDAD NACIONAL DE INGENIERÍA & \begin{tabular}{|l} 
INGENIERIA \\
ELECTRONICA
\end{tabular} & 533 \\
\hline
\end{tabular}




\begin{tabular}{|c|c|c|}
\hline UNIVERSIDAD & $\begin{array}{l}\text { PROGRAMAS DE } \\
\text { ESTUDIO }\end{array}$ & TOTAL \\
\hline UNIVERSIDAD NACIONAL DE INGENIERÍA & INGENIERIA INDUSTRIAL & 804 \\
\hline UNIVERSIDAD NACIONAL DE INGENIERÍA & INGENIERIA MECANICA & 522 \\
\hline UNIVERSIDAD NACIONAL DE INGENIERÍA & $\begin{array}{l}\text { INGENIERIA } \\
\text { MECATRONICA }\end{array}$ & 441 \\
\hline UNIVERSIDAD NACIONAL DE INGENIERÍA & ARQUITECTURA & 943 \\
\hline UNIVERSIDAD NACIONAL DE INGENIERÍA & INGENIERIA CIVIL & 1,719 \\
\hline $\begin{array}{l}\text { UNIVERSIDAD NACIONAL MAYOR DE SAN } \\
\text { MARCOS }\end{array}$ & $\begin{array}{l}\text { INGENIERIA } \\
\text { ELECTRONICA }\end{array}$ & 692 \\
\hline $\begin{array}{l}\text { UNIVERSIDAD NACIONAL MAYOR DE SAN } \\
\text { MARCOS }\end{array}$ & INGENIERIA INDUSTRIAL & 1,203 \\
\hline $\begin{array}{l}\text { UNIVERSIDAD NACIONAL MAYOR DE SAN } \\
\text { MARCOS }\end{array}$ & INGENIERIA CIVIL & 293 \\
\hline $\begin{array}{l}\text { UNIVERSIDAD PERUANA DE CIENCIAS } \\
\text { APLICADAS S.A.C. }\end{array}$ & \begin{tabular}{|l} 
INGENIERIA \\
ELECTRONICA
\end{tabular} & 397 \\
\hline $\begin{array}{l}\text { UNIVERSIDAD PERUANA DE CIENCIAS } \\
\text { APLICADAS S.A.C. }\end{array}$ & INGENIERIA INDUSTRIAL & 7,492 \\
\hline $\begin{array}{l}\text { UNIVERSIDAD PERUANA DE CIENCIAS } \\
\text { APLICADAS S.A.C. }\end{array}$ & $\begin{array}{l}\text { INGENIERIA } \\
\text { MECATRONICA }\end{array}$ & 691 \\
\hline $\begin{array}{l}\text { UNIVERSIDAD PERUANA DE CIENCIAS } \\
\text { APLICADAS S.A.C. }\end{array}$ & ARQUITECTURA & 3,824 \\
\hline $\begin{array}{l}\text { UNIVERSIDAD PERUANA DE CIENCIAS } \\
\text { APLICADAS S.A.C. }\end{array}$ & INGENIERIA CIVIL & 4,773 \\
\hline $\begin{array}{l}\text { UNIVERSIDAD PERUANA DE CIENCIAS E } \\
\text { INFORMÁTICA }\end{array}$ & INGENIERIA INDUSTRIAL & 468 \\
\hline UNIVERSIDAD PRIVADA DEL NORTE S.A.C. & $\begin{array}{l}\text { INGENIERIA } \\
\text { ELECTRONICA }\end{array}$ & 142 \\
\hline UNIVERSIDAD PRIVADA DEL NORTE S.A.C. & $\begin{array}{l}\text { INGENIERIA } \\
\text { MECATRONICA }\end{array}$ & 329 \\
\hline UNIVERSIDAD PRIVADA DEL NORTE S.A.C. & INGENIERIA INDUSTRIAL & 11,321 \\
\hline UNIVERSIDAD PRIVADA DEL NORTE S.A.C. & ARQUITECTURA & 398 \\
\hline UNIVERSIDAD PRIVADA DEL NORTE S.A.C. & DISEÑO INDUSTRIAL & 86 \\
\hline UNIVERSIDAD PRIVADA DEL NORTE S.A.C. & INGENIERIA CIVIL & 6,420 \\
\hline UNIVERSIDAD RICARDO PALMA & \begin{tabular}{|l} 
INGENIERIA \\
ELECTRONICA
\end{tabular} & 220 \\
\hline UNIVERSIDAD RICARDO PALMA & INGENIERIA INDUSTRIAL & 1,242 \\
\hline UNIVERSIDAD RICARDO PALMA & \begin{tabular}{|l} 
INGENIERIA \\
MECATRONICA
\end{tabular} & 327 \\
\hline UNIVERSIDAD RICARDO PALMA & ARQUITECTURA & 2,256 \\
\hline UNIVERSIDAD RICARDO PALMA & INGENIERIA CIVIL & 2,166 \\
\hline UNIVERSIDAD SAN IGNACIO DE LOYOLA S.A. & INGENIERIA INDUSTRIAL & 1,742 \\
\hline UNIVERSIDAD SAN IGNACIO DE LOYOLA S.A. & INGENIERIA CIVIL & 1,008 \\
\hline UNIVERSIDAD TECNOLÓGICA DEL PERÚ S.A.C. & \begin{tabular}{|l} 
INGENIERIA \\
ELECTRONICA
\end{tabular} & 1,192 \\
\hline UNIVERSIDAD TECNOLÓGICA DEL PERÚ S.A.C. & INGENIERIA INDUSTRIAL & 5,903 \\
\hline UNIVERSIDAD TECNOLÓGICA DEL PERÚ S.A.C. & INGENIERIA MECANICA & 1,428 \\
\hline UNIVERSIDAD TECNOLÓGICA DEL PERÚ S.A.C. & \begin{tabular}{|l} 
INGENIERIA \\
MECATRONICA
\end{tabular} & 1,819 \\
\hline UNIVERSIDAD TECNOLÓGICA DEL PERÚ S.A.C. & ARQUITECTURA & 594 \\
\hline \multirow[t]{2}{*}{ UNIVERSIDAD TECNOLÓGICA DEL PERÚ S.A.C. } & INGENIERIA CIVIL & 2,186 \\
\hline & & 145,499 \\
\hline
\end{tabular}




\section{Anexo 10: Inversión}

\begin{tabular}{|c|c|c|c|c|c|}
\hline Inversión instalaciones & Cantidad & \multicolumn{2}{|c|}{ Tamaño M2 } & Costo USD/ M2 & Total S/. \\
\hline $\begin{array}{l}\text { Remodelación ( incluye diseño, mano de obra, gastos } \\
\text { de decorado, pintado, luminarias, pisos, vitrales, barra } \\
\text { del café) }\end{array}$ & 1 & \multicolumn{2}{|c|}{100} & 250 & 82,500 \\
\hline \multicolumn{5}{|l|}{ Importe Total } & 82,500 \\
\hline Inversión en muebles y enseres & \multicolumn{2}{|c|}{ Cantidad } & \multicolumn{2}{|c|}{ Precio unitario } & Total S/. \\
\hline Mesas y sillas ( 4 sillas por mesa) & & 15 & & 500 & 7,500 \\
\hline Set de menaje y utensilios de cocina & & 1 & & 5,000 & 5,000 \\
\hline Muebles tipo sofa lounge & & 4 & & 500 & 2,000 \\
\hline Escritorios para oficina & & 2 & & 350 & 700 \\
\hline Otros & & & & & 5,000 \\
\hline \multicolumn{5}{|l|}{ Importe Total } & 20,200 \\
\hline
\end{tabular}

\begin{tabular}{|l|r|r|r|}
\hline \multicolumn{1}{|c|}{ Inversión en equipos } & Cantidad & Precio unitario & \multicolumn{1}{c|}{ Total S/. } \\
\hline Equipos de Computo Administrativo e Impresoras & 2 & 1,500 & 3,000 \\
\hline Monitor de diseño 40" & 2 & 4,000 & 8,000 \\
\hline Televisores 50" & 2 & 2,500 & 5,000 \\
\hline Desktops & 15 & 1,200 & 18,000 \\
\hline Laptops & 2 & 1,800 & 3,600 \\
\hline Maquina de Café & 1 & 13,200 & 13,200 \\
\hline Refrigeradora & 1 & 5,000 & 5,000 \\
\hline Congeladora/exhibidora & 1 & 1,500 & 1,500 \\
\hline Microondas & 1 & 700 & 700 \\
\hline Liquadora Industrial & 1 & 700 & 700 \\
\hline Aire Acondicionado & 2 & 4,500 & 9,000 \\
\hline Extinguidores & 4 & 150 & 600 \\
\hline Parrila Eléctrica & 1 & 1,500 & 1,500 \\
\hline Software de diseño & 1 & 8,250 & 8,250 \\
\hline Equipo de sonido alta definición & 1 & 5,000 & 5,000 \\
\hline Equipos de Seguridad & 1 & 2,000 & 2,000 \\
\hline Impresoras 3D & 12 & 114,510 & 114,510 \\
\hline Diseño página Web & 1 & 6,600 & 6,600 \\
\hline Caja Registradora & 1 & 2,500 & 2,500 \\
\hline Scanner & 4 & 6,600 & 26,400 \\
\hline Imprevistos & & & 12,000 \\
\hline & & & $\mathbf{2 4 7 , 0 6 0}$ \\
\hline
\end{tabular}

\begin{tabular}{|l|r|r|r|}
\hline Marketing & Cantidad & Mes & Anual \\
\hline Publicidad y Promoción & $\mathbf{1}$ & 3000 & 36,000 \\
\hline Camisetas para empleados con logo empresa & $\mathbf{1 0}$ & 200 & 2,400 \\
\hline Community Manager & $\mathbf{1}$ & 2500 & 30,000 \\
\hline Merchandising (tripticos, llaveros, tazas, etc) & 1 & 1,000 & 12,000 \\
\hline \multicolumn{1}{|c|}{ Importe Total } & & & $\mathbf{8 0 , 4 0 0}$ \\
\hline
\end{tabular}




\begin{tabular}{|l|r|r|r|}
\hline Costos Fijos de Administración & N $^{\circ}$ personas & Sueldo & Total Anual S/. \\
\hline Gerente & 1 & 3,500 & 73,500 \\
\hline Supervisor & 1 & 2,300 & 48,300 \\
\hline \multicolumn{2}{|c|}{ Importe Total } & & $\mathbf{1 2 1 , 8 0 0}$ \\
\hline
\end{tabular}

\begin{tabular}{|l|r|r|r|}
\hline Costos Fijos de Operación & $\mathbf{N}^{\circ}$ personas & Sueldo & \multicolumn{1}{c|}{ Total Anual S/. } \\
\hline Asesores de Diseño (3 Turnos) & 3 & 700 & 113,400 \\
\hline Barista & 1 & 1,200 & 43,200 \\
\hline Mantenimiento y repuestos de impresoras 3D & & 1,000 & 12,000 \\
\hline Bono empleado del mes & 500 & 6,000 \\
\hline \multicolumn{2}{|c|}{ Importe Total } & & $\mathbf{1 7 4 , 6 0 0}$ \\
\hline
\end{tabular}

\begin{tabular}{|c|c|c|}
\hline Gastos Fijos & Mensual & Anual \\
\hline Alquiler & 9,900 & 118,800 \\
\hline Servicio de Contabilidad & 500 & 6,000 \\
\hline POS uso servicio pago con tarjetas & 1 & 500 \\
\hline Telefono, Internet, cable & 300 & 3,600 \\
\hline Luz & 600 & 7,200 \\
\hline Servicio de Seguridad & 200 & 2,400 \\
\hline Agua & 150 & 1,800 \\
\hline Material Limpieza & 100 & 1,200 \\
\hline \multicolumn{2}{|l|}{ Importe Total } & 141,500 \\
\hline
\end{tabular}

\begin{tabular}{|l|r|}
\hline Permisos otros & \\
\hline Licencias & 400 \\
\hline Constitución de la empresa & 1,100 \\
\hline Registro de marca & 800 \\
\hline Permisos otros & 1200 \\
\hline \multicolumn{1}{|c|}{ Importe Total } & $\mathbf{3 , 5 0 0}$ \\
\hline
\end{tabular}

\begin{tabular}{|l|r|}
\hline \multicolumn{1}{|c|}{ Resumen de Inversión Inicial } & \multicolumn{1}{c|}{ Soles } \\
\hline Inversión en Instalaciones & 82,500 \\
\hline Inversión en muebles y enseres & 20,200 \\
\hline Estudio de mercado & 4,000 \\
\hline Inversión en equipos & 247,060 \\
\hline Alquiler (2 meses adelantado y 1 mes garantía) & 29,700 \\
\hline Gastos Fijos (3 meses antes de apertura) & 35,375 \\
\hline Permisos & 3,500 \\
\hline Inversión inicial & $\mathbf{4 2 2 , 3 3 5}$ \\
\hline
\end{tabular}




\section{Anexo 11: Cronograma de pagos}

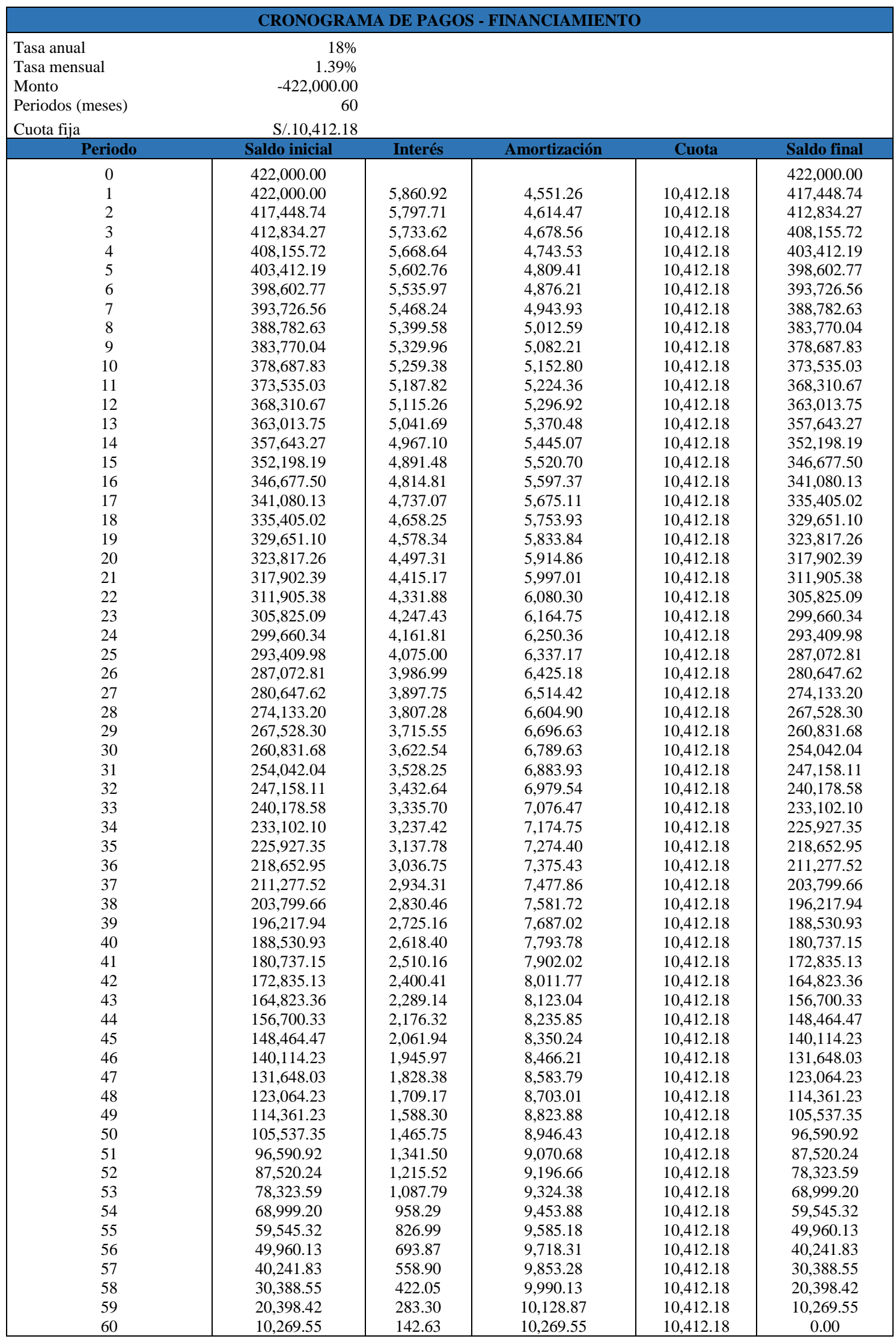




\section{Anexo 12: Análisis del capital de trabajo}

\begin{tabular}{|c|c|c|c|c|c|c|c|c|c|c|c|c|}
\hline & Enero & Febrero & Marzo & Abril & Mayo & Junio & Julio & Agosto & Setiembre & Octubre & Noviembre & Diciembre \\
\hline Estacionalidad (\%) & $2 \%$ & $3 \%$ & $3 \%$ & $4 \%$ & $10 \%$ & $5 \%$ & $12 \%$ & $6 \%$ & $14 \%$ & $18 \%$ & $13 \%$ & $10 \%$ \\
\hline Ingresos por Impresión & 14,766 & 22,149 & 22,149 & 29,532 & 73,831 & 36,916 & 88,597 & 44,299 & 103,364 & 132,896 & 95,980 & 73,831 \\
\hline Ingresos por Diseño & 1,022 & 1,532 & 1,532 & 2,043 & 5,108 & 2,554 & 6,129 & 3,065 & 7,151 & 9,194 & 6,640 & 5,108 \\
\hline Ingresos Cafetería & 1,517 & 2,276 & 2,276 & 3,034 & 7,585 & 3,793 & 9,102 & 4,551 & 10,619 & 13,653 & 9,861 & 7,585 \\
\hline Ingreso neto & 17,305 & 25,957 & 25,957 & 34,610 & 86,524 & 43,262 & 103,829 & 51,914 & 121,134 & 155,743 & 112,481 & 86,524 \\
\hline \multicolumn{13}{|l|}{ Costos directos } \\
\hline Insumos de Impresión & 820 & 1,231 & 1,231 & 1,641 & 4,102 & 2,051 & 4,922 & 2,461 & 5,742 & 7,383 & 5,332 & 4,102 \\
\hline Cafetería & 759 & 1,138 & 1,138 & 1,517 & 3,793 & 1,896 & 4,551 & 2,276 & 5,310 & 6,827 & 4,930 & 3,793 \\
\hline Gastos operativos & 14,550 & 14,550 & 14,550 & 14,550 & 14,550 & 14,550 & 14,550 & 14,550 & 14,550 & 14,550 & 14,550 & 14,550 \\
\hline Total costo directo & 16,129 & 16,918 & 16,918 & 17,708 & 22,444 & 18,497 & 24,023 & 19,287 & 25,602 & 28,760 & 24,813 & 22,444 \\
\hline Utilidad Bruta & 1,176 & 9,039 & 9,039 & 16,902 & 64,080 & 24,765 & 79,806 & 32,628 & 95,532 & 126,984 & 87,669 & 64,080 \\
\hline Gastos administrativos & 10,150 & 10,150 & 10,150 & 10,150 & 10,150 & 10,150 & 10,150 & 10,150 & 10,150 & 10,150 & 10,150 & 10,150 \\
\hline Gastos de Marketing & 6,700 & 6,700 & 6,700 & 6,700 & 6,700 & 6,700 & 6,700 & 6,700 & 6,700 & 6,700 & 6,700 & 6,700 \\
\hline Gastos Financieros & 5,861 & 5,798 & 5,734 & 5,669 & 5,603 & 5,536 & 5,468 & 5,400 & 5,330 & 5,259 & 5,188 & 5,115 \\
\hline $\begin{array}{l}\text { Gastos de alquiler y } \\
\text { servicios }\end{array}$ & 11,792 & 11,792 & 11,792 & 11,792 & 11,792 & 11,792 & 11,792 & 11,792 & 11,792 & 11,792 & 11,792 & 11,792 \\
\hline Total gastos & 34,503 & 34,439 & 34,375 & 34,310 & 34,244 & 34,178 & 34,110 & 34,041 & 33,972 & 33,901 & 33,829 & 33,757 \\
\hline Utilidad Neta & $-33,327$ & $-25,400$ & $-25,336$ & $-17,408$ & 29,835 & $-9,413$ & 45,696 & $-1,413$ & 61,560 & 93,083 & 53,839 & 30,323 \\
\hline Capital de Trabajo & $-33,327$ & $-25,400$ & $-25,336$ & $-17,408$ & & $-9,413$ & & $-1,413$ & & & & \\
\hline Total Capital Trabajo & $-112,298$ & & & & & & & & & & & \\
\hline
\end{tabular}




\section{Anexo 13: Mapa estratégico}

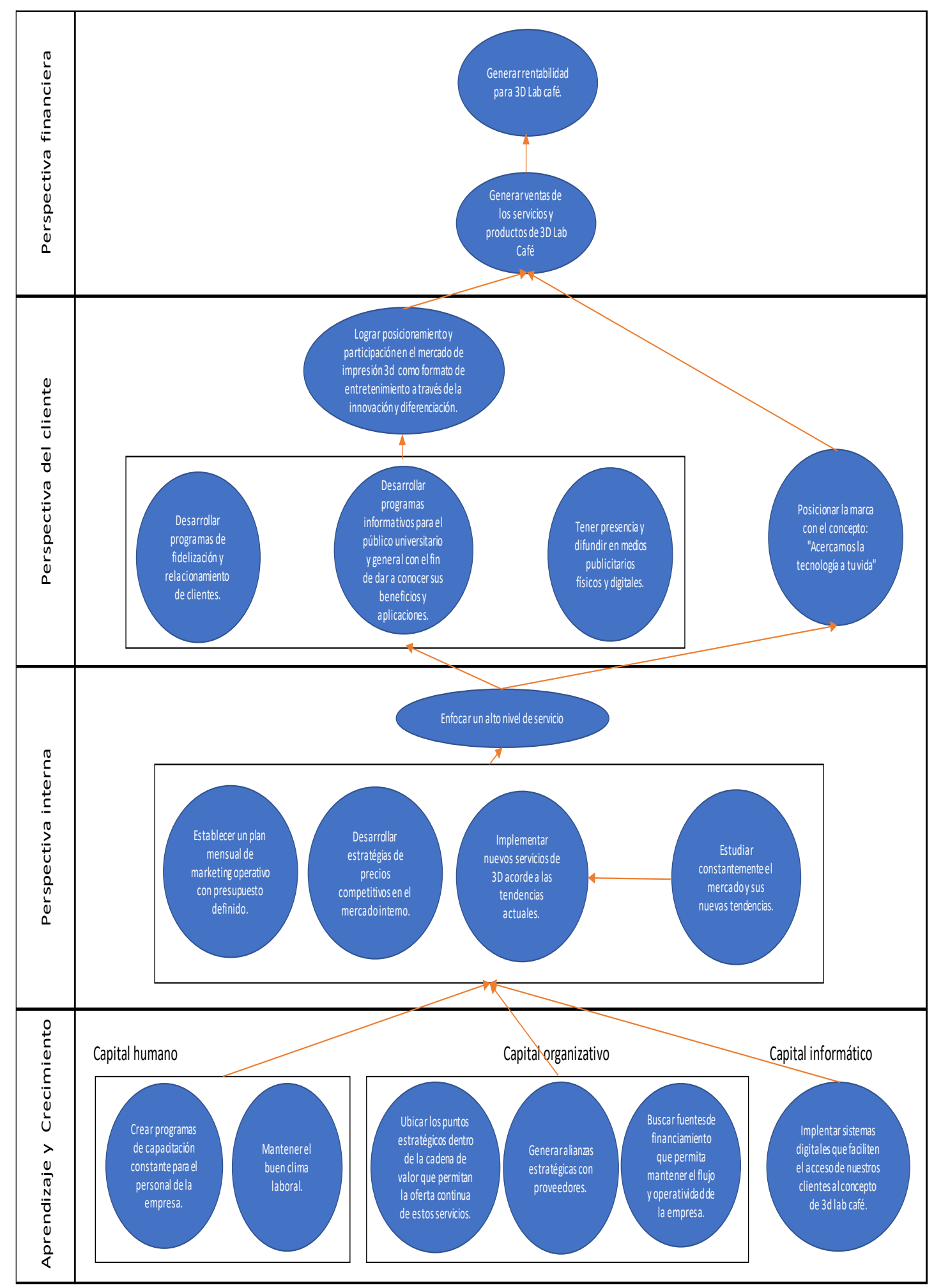




\section{Anexo 14: Distribución de la instalación}

\section{Plano del Proyecto de Negocio}

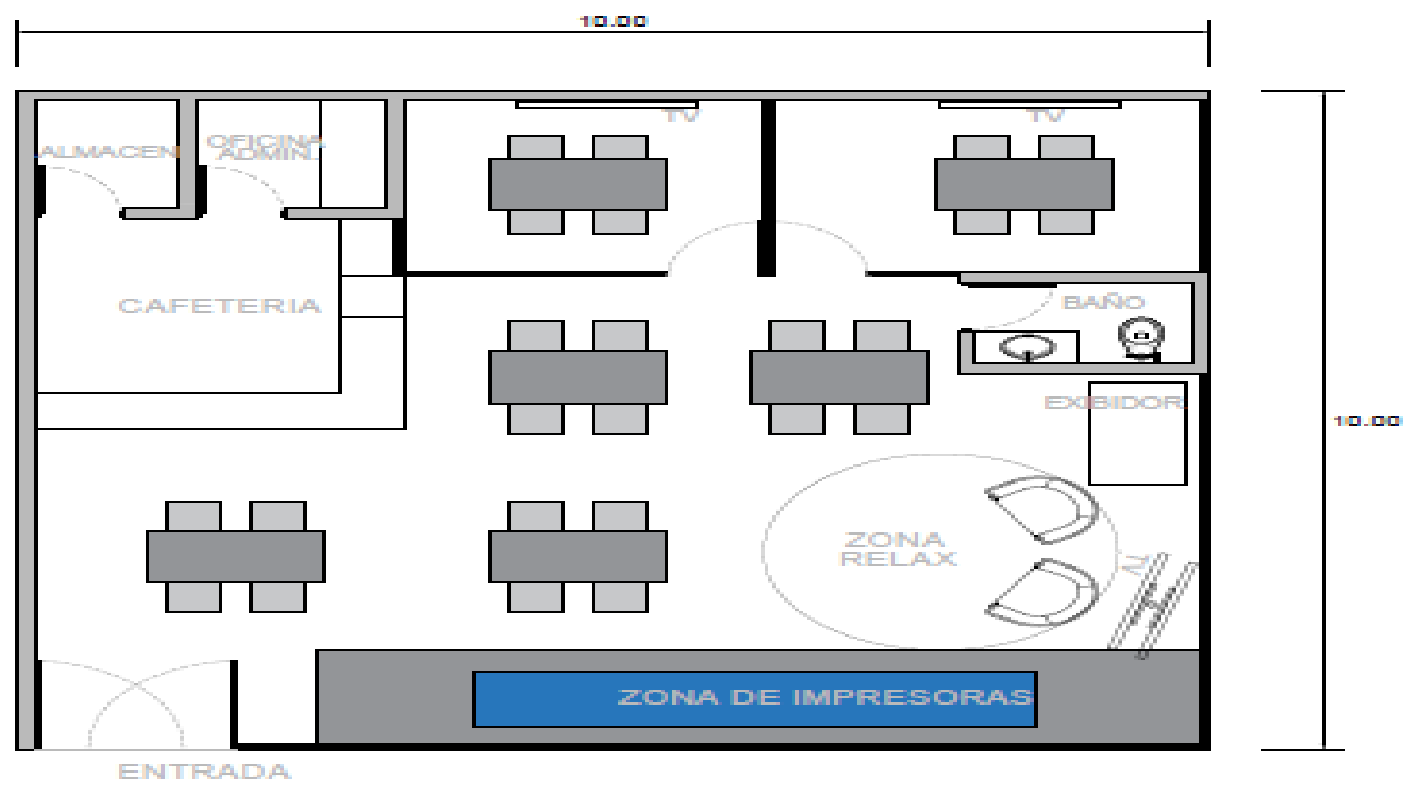

Vista exterior del Proyecto de Negocio

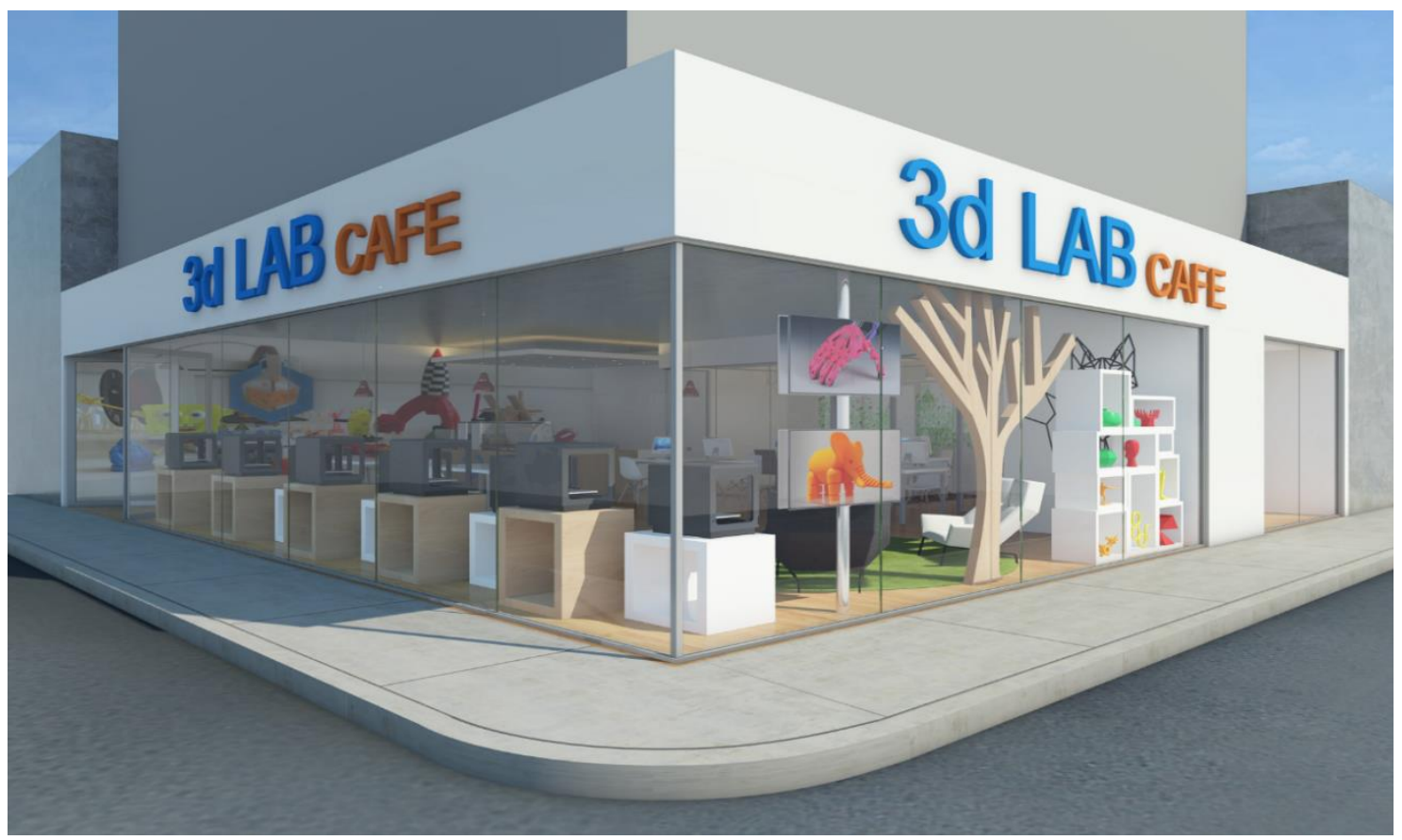




\section{Vista interior del Proyecto de Negocio}
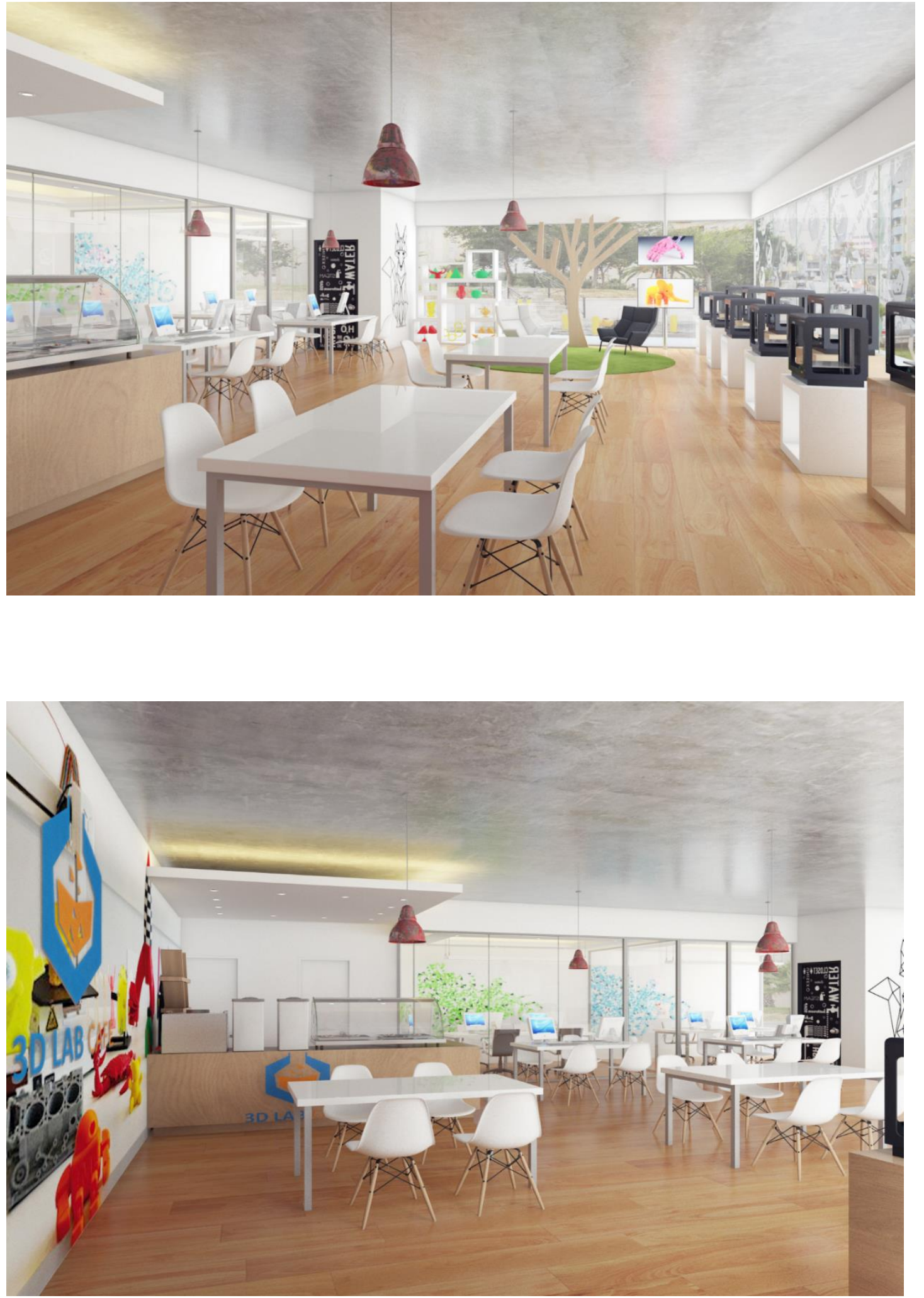


\section{Anexo 15: Proceso general de impresión}

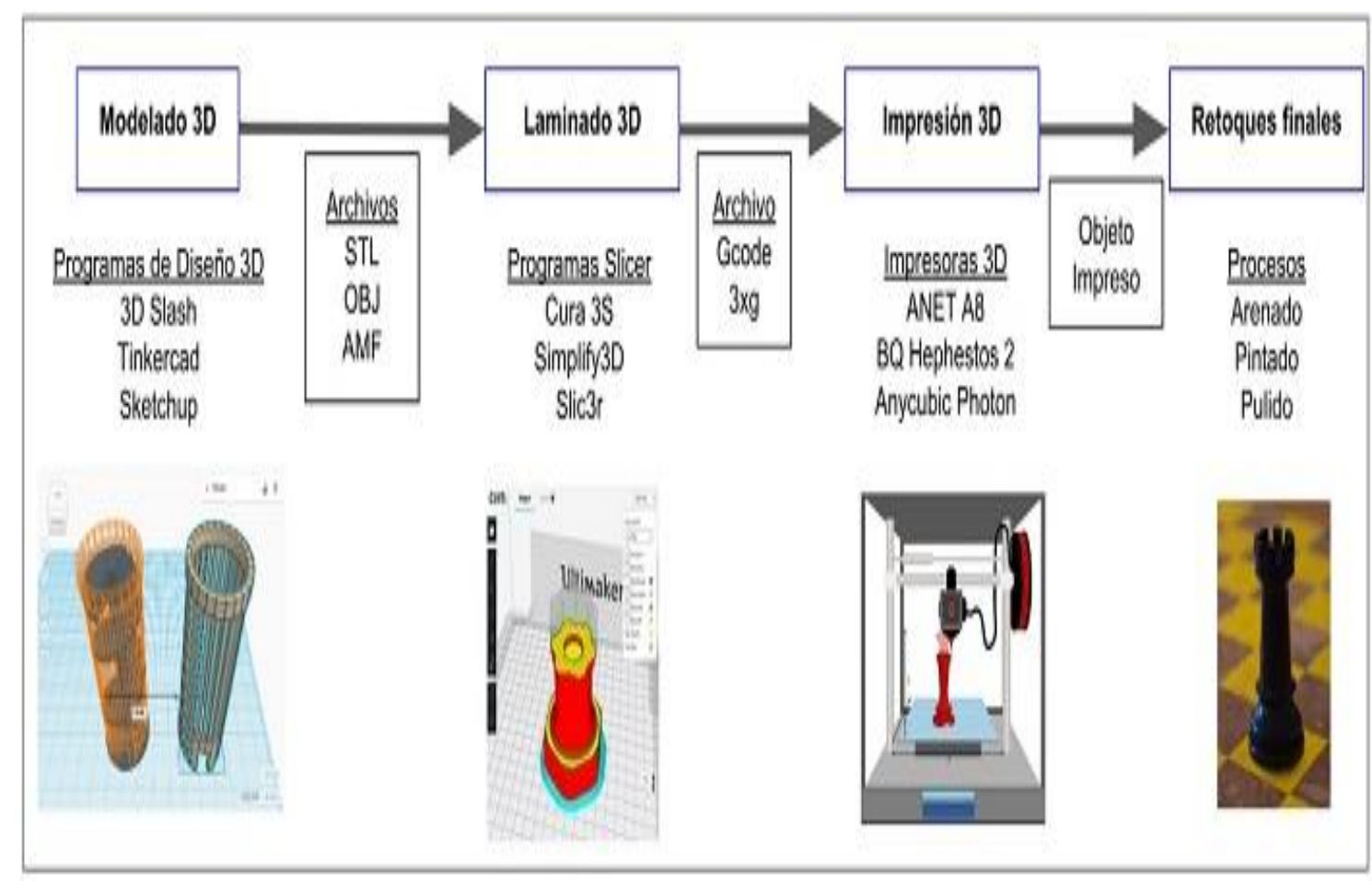


Anexo 16: Equipos de impresión 3D

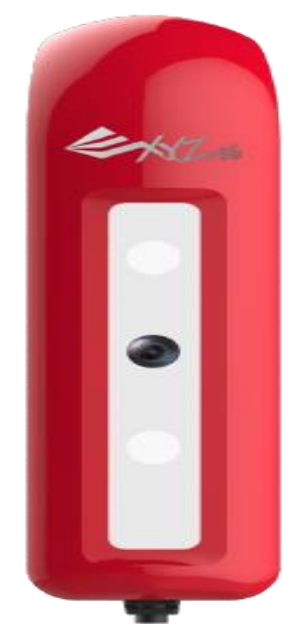

ESCANER XYZ

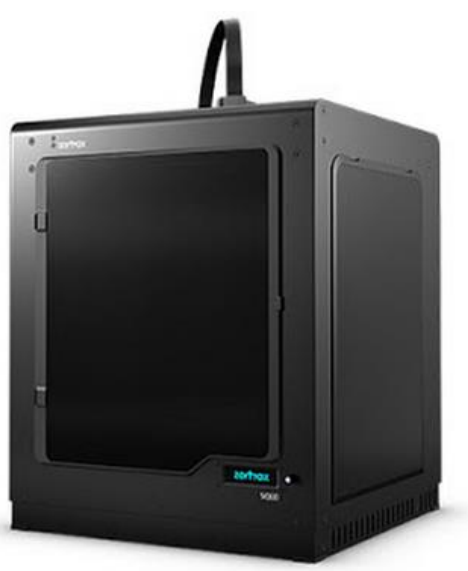

IMPRESORA 3D ZORTRAX M300

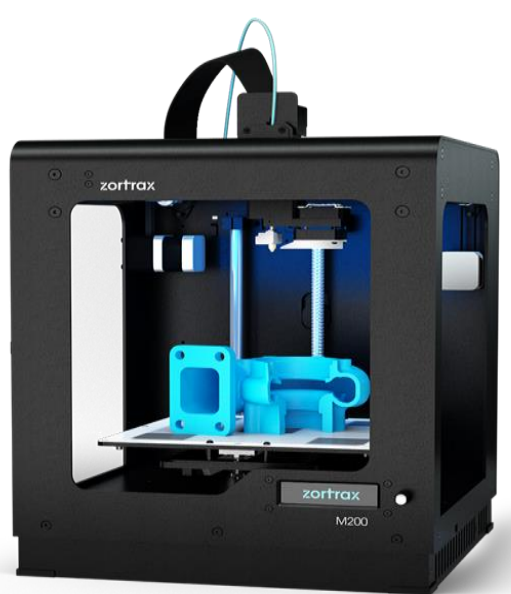

IMPRESORA 3D ZORTRAX M200 